University of Nebraska - Lincoln

DigitalCommons@University of Nebraska - Lincoln

2009

\title{
The Elasticity of Taxable Income with Respect to Marginal Tax Rates: A Critical Review
}

\author{
Emmanuel Saez \\ University of California - Berkeley, saez@econ.berkeley.edu \\ Joel B. Slemrod \\ University of Michigan Business School, jslemrod@umich.edu \\ Seth H. Giertz \\ University of Nebraska-Lincoln, sgiertz2@unl.edu
}

Follow this and additional works at: https://digitalcommons.unl.edu/econfacpub

Part of the Economics Commons

Saez, Emmanuel; Slemrod, Joel B.; and Giertz, Seth H., "The Elasticity of Taxable Income with Respect to Marginal Tax Rates: A Critical Review" (2009). Economics Department Faculty Publications. 54.

https://digitalcommons.unl.edu/econfacpub/54

This Article is brought to you for free and open access by the Economics Department at DigitalCommons@University of Nebraska - Lincoln. It has been accepted for inclusion in Economics Department Faculty Publications by an authorized administrator of DigitalCommons@University of Nebraska - Lincoln. 
NBER WORKING PAPER SERIES

THE ELASTICITY OF TAXABLE INCOME WITH RESPECT TO MARGINAL TAX RATES: A CRITICAL REVIEW

Emmanuel Saez

Joel B. Slemrod

Seth H. Giertz

Working Paper 15012

http://www.nber.org/papers/w15012

NATIONAL BUREAU OF ECONOMIC RESEARCH

1050 Massachusetts Avenue

Cambridge, MA 02138

May 2009

This paper was written for submission to the Journal of Economics Literature. We thank Soren Blomquist, Raj Chetty, Henrik Kleven, Wojciech Kopczuk, Hakan Selin, Jonathan Shaw, editor Roger Gordon, and anonymous referees for helpful comments and discussions, and Jonathan Adams and Caroline Weber for invaluable research assistance. Financial support from NSF Grant SES-0134946 is gratefully acknowledged. The views expressed herein are those of the author(s) and do not necessarily reflect the views of the National Bureau of Economic Research.

(C) 2009 by Emmanuel Saez, Joel B. Slemrod, and Seth H. Giertz. All rights reserved. Short sections of text, not to exceed two paragraphs, may be quoted without explicit permission provided that full credit, including $\odot$ notice, is given to the source. 
The Elasticity of Taxable Income with Respect to Marginal Tax Rates: A Critical Review Emmanuel Saez, Joel B. Slemrod, and Seth H. Giertz

NBER Working Paper No. 15012

May 2009

JEL No. H24,H31

\begin{abstract}
$\underline{\text { ABSTRACT }}$
This paper critically surveys the large and growing literature estimating the elasticity of taxable income with respect to marginal tax rates (ETI) using tax return data. First, we provide a theoretical framework showing under what assumptions this elasticity can be used as a sufficient statistic for efficiency and optimal tax analysis. We discuss what other parameters should be estimated when the elasticity is not a sufficient statistic. Second, we discuss conceptually the key issues that arise in the empirical estimation of the elasticity of taxable income using the example of the 1993 top individual income tax rate increase in the United States to illustrate those issues. Third, we provide a critical discussion of most of the taxable income elasticities studies to date, both in the United States and abroad, in light of the theoretical and empirical framework we laid out. Finally, we discuss avenues for future research.
\end{abstract}

Emmanuel Saez

Department of Economics

University of California, Berkeley

549 Evans Hall \#3880

Berkeley, CA 94720

and NBER

saez@econ.berkeley.edu

Joel B. Slemrod

University of Michigan Business School

Room R5396

Ann Arbor, MI 48109-1234

and NBER

jslemrod@umich.edu
Seth H. Giertz

University of Nebraska

Dept. of Economics, CBA 368

P.O. Box 880489

Lincoln, NE 68588-0489

sgiertz2@unl.edu 


\section{Introduction}

The notion of a behavioral elasticity occupies a critical place in the economic analysis of taxation. Graduate textbooks teach that the two central aspects of the public sector, optimal progressivity of the tax-and-transfer system, as well as the optimal size of the public sector, depend (inversely) on the compensated elasticity of labor supply with respect to the marginal tax rate. Indeed, until recently, the closest thing we have had to a central parameter was the labor supply elasticity. In a static model where people value only two commodities leisure and a composite consumption good - the real wage in terms of the consumption good is the only relative price at issue. This real wage is equal to the amount of goods that can be consumed per hour of leisure foregone (or, equivalently, per hour of labor supplied). At the margin, substitution possibilities, and therefore the excess burden of taxation, can be captured by a compensated labor supply elasticity.

With some exceptions, the profession has settled on a value for this elasticity close to zero for prime-age males, although for married women the responsiveness of labor force participation appears to be significant. Overall, though, the compensated elasticity of labor appears to be fairly small. In models with only a labor-leisure choice, this implies that the efficiency cost of taxing labor income - to redistribute revenue to others or to provide public goods - is bound to be low, as well.

Although evidence of a substantial compensated labor supply elasticity has been hard to find, evidence that taxpayers respond to tax system changes more generally has decidedly not been hard to find. For example, there is compelling evidence in the U.S. the timing of capital gains realizations reacts strongly to changes in capital gains tax rates. There was a surge in capital gains realizations in 1986, after the U.S. government passed the Tax Reform Act of 1986 which increased tax rates on realizations in 1987 and after (Auerbach, 1988). Dropping the top individual rax rate to below the corporate tax rate in the same Act led to a significant increase in business activity carried out in pass-through, non-corporate form (Auerbach and Slemrod, 1997).

Addressing these other margins of behavioral response is crucial because under some assumptions all responses to taxation are symptomatic of deadweight loss. Taxes trigger a host of behavioral responses designed to minimize the burden on the individual. In the absence of externalities or other market failures, and putting aside income effects, all such responses are sources of inefficiency, whether they take the form of reduced labor supply, increased charitable contributions, increased expenditures for tax professionals, or a different form of business organization, and thus they add to the burden of taxes from society's perspective. Because in principle the elasticity of taxable income (which we abbreviate from now on using the stan- 
dard acronym ETI) can capture all of these responses, it holds the promise of more accurately summarizing the marginal efficiency cost of taxation than a narrower measure of taxpayer response such as the labor supply elasticity, and therefore is a worthy topic of investigation.

The new focus raises the possibility that the efficiency cost of taxation is significantly higher than is implied if labor supply is the sole, or principal, margin of behavioral response. Indeed, some of the first empirical estimates of the elasticity of taxable income implied very sizeable responses and therefore a very high marginal efficiency cost of funds. The subsequent literature has found somewhat smaller elasticities, and raised questions about both our ability to identify this key parameter and about the claim that it is a sufficient statistic for doing welfare analysis. Whether the taxable income elasticity is an accurate indicator of the revenue leakage due to behavioral response, the ultimate indicator of efficiency cost absent classical externalities, depends on the situation. For example, if revenue leakage in current year tax revenue is substantially offset by revenue gain in other years or in other tax bases, it is misleading. Secondly, if some of the response involves changes in activities with externalities, then the elasticity is not a sufficient statistic for welfare analysis.

The remainder of the paper is organized as follows. Section 2 presents the theoretical framework underlying the taxable income elasticity concept. Section 3 presents the key identification issues that arise in the empirical estimation of the taxable income elasticity, using the example of the 1993 top tax rate increase in the United States to illustrate those issues. Section 4 reviews empirical studies in light of our conceptual and empirical identification frameworks. Section 5 concludes and discusses the most promising avenues for future research. In appendix A we present a summary of the key U.S. legislated tax changes that have been used in the U.S. literature and in appendix B a brief description of existing U.S. tax return data.

\section{Conceptual Framework}

\subsection{Basic Model}

In the standard labor supply model, individuals maximize a utility function $u(c, l)$ where $c$ is disposable income, equal to consumption in a one-period model, and $l$ is labor supply measured by hours of work. Earnings are given by $z=w l$, where $w$ is the exogenous wage rate. The (linearized) budget constraint is $c=w l(1-\tau)+E$ where $\tau$ is the marginal tax rate and $E$ is virtual income.

The taxable income elasticity literature generalizes this model by noting that hours of work are only one component of the behavioral response to income taxation. Individuals can respond to taxation through other margins such as intensity of work, career choices, form and timing of compensation, tax avoidance, or tax evasion. As a result, the individual's wage rate $w$ might 
depend on effort and respond to tax rates, and reported taxable income might also differ from $w l$ as individuals might split their gross earnings between taxable cash compensation and nontaxable compensation such as fringe benefits, or even fail to report their full taxable income because of tax evasion.

As shown by Feldstein (1999), a simple, reduced-form way to model all those behavioral responses is to posit that utility depends positively on disposable income (equal to consumption) $c$ and negatively on reported income $z$ (because activities generating income are costly, for example they may require foregoing leisure). Hence, individuals choose $(c, z)$ to maximize a utility function $u(c, z)$ subject to a budget constraint of the form $c=(1-\tau) z+E$. Such maximization generates an individual "reported income" supply function $z(1-\tau, E)$ where $z$ depends on the net-of-tax rate $1-\tau$ and virtual income $E$ generated by the tax/transfer system. ${ }^{1}$ Each individual has a particular reported income supply function reflecting his/her skills, taste for labor, opportunities for avoidance, etc. ${ }^{2}$

In most of what follows, we assume away income effects so that the income function $z$ does not depend on $E$ and depends only on the net-of-tax rate. ${ }^{3}$ In the absence of compelling evidence about significant income effects in the case of overall reported income, it seems reasonable to consider the case with no income effects, which simplifies considerably the presentation of efficiency effects. It might seem unintuitive to assume away the effect of changes in exogenous income on (reported taxable) income. However, in the reported income context, $E$ is defined exclusively as virtual income created by the tax/transfer budget constraint and hence is not part of taxable income $z$. Another difference is that the labor component of $z$ is labor income $(w l)$ rather than labor hours $(l)$; this difference requires us to address the incidence of tax rate changes (i.e., their effect on $w$ ), which we do in briefly in Section 2.2.5.

The literature on behavioral responses to taxation has attempted to estimate the elasticity of reported incomes with respect to the net-of-tax rate, defined as

$$
e=\frac{1-\tau}{z} \frac{\partial z}{\partial(1-\tau)}
$$

the percent change in reported income when the net-of-tax rate increases by $1 \%$. With no

\footnotetext{
${ }^{1}$ This reported income supply function remains valid in the case of non-linear tax schedules as $c=(1-\tau) z+E$ is the linearized budget constraint at the utility-maximizing point, just as in the basic labor supply model.

${ }^{2}$ We could have posited a more general model in which $c=y-\tau z+E$, where $y$ is real income while $z$ is reported income that may differ from real income because of tax evasion and avoidance. Utility would be $u(c, y, y-z)$ increasing in $c$, decreasing in $y$ (earnings effort), and decreasing in $y-z$ (costs of avoiding or evading taxes). Such a utility function would still generate a reported income supply function of the form $z(1-\tau, E)$ and our analysis would go through. We come back to such a more general model in Section 2.3.2.

${ }^{3}$ In general, labor supply studies estimate modest income effects (see Blundell and MaCurdy, 1999 for a survey). There is much less empirical evidence on the magnitude of income effects in the reported income literature. Gruber and Saez (2002) estimate both income and substitution effects in the case of reported incomes, and find small and insignificant income effects.
} 
income effects, this elasticity is equal to both the compensated and uncompensated elasticity. Critically and as shown in Feldstein (1999), this elasticity captures not only the hours of work response but also all other margins of behavioral response to marginal tax rates.

As we discuss later, a number of empirical studies have found that the behavioral response to changes in marginal tax rates is concentrated in the top of the income distribution, with less evidence of any response for the middle and upper-middle income class (see Sections 3 and 4 below). ${ }^{4}$ In the United States, because of exemptions and tax credits, individual income tax liabilities are very skewed: the top quintile (top percentile) tax filers remitted $86.3 \%(39.1 \%)$ of all individual income taxes in 2006 (Congressional Budget Office, 2009). Therefore, it is useful to focus on the analysis of the effects of increasing the marginal tax rate on the upper end of the income distribution. Let us therefore assume that incomes in the top bracket, above a given reported income threshold $\bar{z}$, face a constant marginal tax rate $\tau .{ }^{5}$ We denote by $N$ the number of taxpayers in the top bracket.

As in the conceptual framework just described, we assume that individual incomes reported in the top bracket depend on the net-of-tax rate $1-\tau$, and we denote by $z^{m}(1-\tau)$ the average income reported by taxpayers in the top bracket, as a function of the net-of-tax rate. The aggregate elasticity of income in the top bracket with respect to the net-of-tax rate is therefore defined as $e=\left[(1-\tau) / z^{m}\right] \partial z^{m} / \partial(1-\tau)$. This aggregate elasticity is equal to the average of the individual elasticities weighted by individual income, so that individuals contribute to the aggregate elasticity in proportion to their incomes. ${ }^{6}$ Thus, in order to estimate $e$, most empirical analyses (as we will see below) weight individuals by their income.

Suppose that the government increases the top tax rate $\tau$ by a small amount $d \tau$ (with no change in the tax schedule for incomes below $\bar{z}$ ). This small tax reform has two effects on tax revenue. First, there is a "mechanical" increase in tax revenue due to the fact that taxpayers face a higher tax rate on their incomes above $\bar{z}$. The total mechanical effect is

$$
d M \equiv N\left[z^{m}-\bar{z}\right] d \tau>0
$$

This mechanical effect is the projected increase in tax revenue, absent any behavioral response.

Second, the increase in the tax rate triggers a behavioral response that reduces the average reported income in the top bracket by $d z=-e \cdot z^{m} \cdot d \tau /(1-\tau)$. A change $d z$ changes tax

\footnotetext{
${ }^{4}$ The behavioral response at the low end of the income distribution is for the most part out of the scope of the present paper. The large literature on responses to welfare and income transfer programs targeted toward low incomes has, however, displayed evidence of significant labor supply responses (see, e.g., Meyer and Rosenbaum, 2001 , for a recent analysis).

${ }^{5}$ For example, in the case of tax year 2008 federal income tax law in the United States, taxable incomes of married couples filing jointly that are above $\bar{z}=\$ 357,700$ are taxed at the top marginal tax rate of $\tau=0.35$.

${ }^{6}$ Formally, $z^{m}=\left[z_{1}+. .+z_{N}\right] / N$ and hence $e=\left[(1-\tau) / z^{m}\right] \partial z^{m} / \partial(1-\tau)=(1-\tau)\left[\partial z_{1} / \partial(1-\tau)+. .+\right.$ $\left.\partial z_{N} / \partial(1-\tau)\right] /\left[N z^{m}\right]=\left[e_{1} \cdot z_{1}+. .+e_{N} \cdot z_{N}\right] /\left[z_{1}+. .+z_{N}\right]$ where $e_{i}$ is the elasticity of individual $i$.
} 
revenue by $\tau d z$. Hence, the aggregate change in tax revenue due to the behavioral response is equal to

$$
d B \equiv-N \cdot e \cdot z^{m} \cdot \frac{\tau}{1-\tau} d \tau<0 .
$$

Summing the mechanical and the behavioral effect, we obtain the total change in tax revenue due to the tax change:

$$
d R=d M+d B=N d \tau\left(z^{m}-\bar{z}\right) \cdot\left[1-e \cdot \frac{z^{m}}{z^{m}-\bar{z}} \cdot \frac{\tau}{1-\tau}\right] .
$$

Let us denote by $a$ the ratio $z^{m} /\left(z^{m}-\bar{z}\right)$. Note that in general $a \geq 1$, and that $a=1$ when a single flat tax rate applies to all incomes, so that the top bracket starts at zero, that is, when $\bar{z}=0$. If the top tail of the distribution is Pareto distributed, ${ }^{7}$ then the parameter $a$ does not vary with $\bar{z}$ and is exactly equal to the Pareto parameter. As the tails of actual income distributions are very well approximated by Pareto distributions, the coefficient $a$ is extremely stable in the United States for $\bar{z}$ above $\$ 300,000$ and equals approximately 1.6 in recent years. ${ }^{8}$ The parameter $a$ measures the thinness of the top tail of the income the distribution: the thicker the tail of the distribution, the larger is $z^{m}$ relative to $\bar{z}$, and hence the smaller is $a$.

Using the definition of $a$, we can rewrite the effect of the small reform on tax revenue $d R$ simply as:

$$
d R=d M\left[1-\frac{\tau}{1-\tau} \cdot e \cdot a\right]
$$

Formula (5) shows that the fraction of tax revenue lost through behavioral responses-the second term in the square bracket expression-is a simple function increasing in the tax rate $\tau$, the elasticity $e$, and the Pareto parameter $a$. This expression is of primary importance to the welfare analysis of taxation because it is exactly equal to the marginal deadweight burden created by the increase in the tax rate, under the assumptions we have made and that we discuss below. This can be seen as follows: Because of the envelope theorem, the behavioral response to a small tax change $d \tau$ creates no additional welfare loss and thus the utility loss (measured in dollar terms) created by the tax increase is exactly equal to the mechanical effect $d M .^{9}$ However, tax revenue collected is only $d R=d M+d B<d M$ because $d B<0$. Thus

\footnotetext{
${ }^{7}$ A Pareto distribution has a density function of the form $f(z)=C / z^{1+\alpha}$, where $C$ and $\alpha$ are constant parameters. The parameter $\alpha$ is called the Pareto parameter. In that case $z^{m}=\int_{\bar{z}}^{\infty} z f(z) d z / \int_{\bar{z}}^{\infty} f(z) d z=$ $\bar{z} \cdot \alpha /(\alpha-1)$ and hence $z^{m} /\left(z^{m}-\bar{z}\right)=\alpha$.

${ }^{8}$ Saez (2001) provides such an empirical analysis for 1992 and 1993 reported incomes using U.S. tax return data. Piketty and Saez (2003) provide estimates of thresholds $\bar{z}$ and average incomes $z^{m}$ corresponding to various fractiles within the top decile of the U.S. income distribution from 1913 to 2006, allowing a straightforward estimation of the parameter $a$ for any year and income threshold.

${ }^{9}$ Formally, $V(1-\tau, E)=\max _{z} u(z(1-\tau)+E, z)$ so that $d V=u_{c} \cdot(-z d \tau+d E)=-u_{c} \cdot(z-\bar{z}) d \tau$. Therefore, the (money-metric) utility cost of the reform is indeed equal to the mechanical tax increase, individual by individual.
} 
$-d B$ represents the extra amount lost in utility over and above the tax revenue collected $d R$. From (5) and $d R=d M+d B$, the marginal excess burden expressed in terms of extra taxes collected is defined as

$$
-\frac{d B}{d R}=\frac{e \cdot a \cdot \tau}{1-\tau-e \cdot a \cdot \tau} .
$$

In other words, for each extra dollar of taxes raised, the government imposes an extra cost equal to $-d B / d R>0$ on taxpayers. We can also define the "marginal efficiency cost of funds" $(\mathrm{MECF})$ as $1-d B / d R=(1-\tau) /(1-\tau-e \cdot a \cdot \tau)$. Those formulas are valid for any tax rate $\tau$ and income distribution as long as income effects are assumed away, even if individuals have heterogeneous utility functions and behavioral elasticities. ${ }^{10}$ The parameters $\tau$ and $a$ are relatively straightforward to measure, so that the elasticity parameter $e$ is the central parameter necessary to calculate formulas (5) and (6).

To illustrate these formulas consider the following example. In 2006 , for the top $1 \%$ income cut-off (corresponding approximately to the top 35\% federal income tax bracket in that year), Piketty and Saez (2003) estimate that $a=1.60$. For an elasticity estimate of $e=0.5$ (corresponding, as we discuss later, to the mid to upper range of the estimates from the literature), the fraction of tax revenue lost through behavioral responses $(-d B / d M)$, should the top tax rate be slightly increased, would be $43.1 \%$, slightly below half of the mechanical (i.e., ignoring behavioral responses) projected increase in tax revenue. ${ }^{11}$ In terms of marginal excess burden, increasing tax revenue by $d R=\$ 1$ causes a utility loss (equal to the MECF) of $1 /(1-.431)=\$ 1.76$ for taxpayers, and hence a marginal excess burden of $-d B / d R=\$ 0.76$, or $76 \%$ of the extra $\$ 1$ tax collected.

Following the supply-side debates of the early 1980s, much attention has been focused on the revenue-maximizing tax rate. The revenue maximizing tax rate $\tau^{*}$ is such that the bracketed expression in equation (5) is exactly zero when $\tau=\tau^{*}$. Rearranging this equation, we obtain the following simple formula for the tax revenue maximizing rate $\tau^{*}$ for the top bracket:

$$
\tau^{*}=\frac{1}{1+a \cdot e}
$$

A top tax rate above $\tau^{*}$ is inefficient because decreasing the tax rate would both increase the utility of the affected taxpayers with income above $\bar{z}$ and increase government revenue, which can in principle be used to benefit other taxpayers. ${ }^{12}$ At the tax rate $\tau^{*}$, the marginal excess

\footnotetext{
${ }^{10}$ In contrast, the Harberger triangle (Harberger, 1964) approximations are only valid for small tax rates. This expression also abstracts from any marginal compliance costs caused by raising rates, and from any marginal administrative costs unless $d R$ is interpreted as revenue net of administrative costs. See Slemrod and Yitzhaki (2002).

${ }^{11}$ The fraction would be around $50 \%$ if we included average state income tax rates and health insurance payroll taxes in the estimate of $\tau$.

${ }^{12}$ Formally, this a second-best Pareto-inefficient outcome as there is a feasible government policy which can
} 
burden becomes infinite as raising more tax revenue becomes impossible. Using our previous example with $e=0.5$ and $a=1.6$, the revenue-maximizing tax rate $\tau^{*}$ would be $55.6 \%$, not much higher than the combined maximum federal, state, Medicare, and typical sales tax rate in the United States of 2008.

Note that when the tax system has a single tax rate (i.e., when $\bar{z}=0$ ), the tax revenue maximizing rate becomes the well-known expression $\tau^{*}=1 /(1+e)$. As $a \geq 1$, the flat-rate revenue-maximizing rate is always larger than the revenue-maximizing rate for high incomes only. This is because increasing just the top tax rate collects extra taxes only on the portion of incomes above the bracket threshold $\bar{z}$, but produces a behavioral response for high-income taxpayers as large as an across-the-board increase in marginal tax rates.

Giertz (2009) applies the formulas presented in this section to tax return data from published Statistics of Income (SOI) tables produced by the Internal Revenue Service (IRS) in order to analyze the impact of the potential expiration of the Bush tax cuts. Giertz shows that exactly where the ETI falls within the range found in the literature has significant effects on the efficiency and revenue implications for tax policy. For example, Giertz reports that for ETIs of 0.2, 0.5 and 1.0, behavioral responses would respectively erase 12, 31 and $62 \%$ of the mechanical revenue gain. When offsets to payroll and state income taxes are taken into account, these numbers increase by $28 \%$. Likewise, estimates for the marginal cost of public funds $(\mathrm{MCF})$ and the revenue-maximizing rates are quite sensitive to this range of ETIs.

In the basic model we have considered, the ETI $e$ is a sufficient statistic to estimate the efficiency costs of taxation as it is not necessary to estimate the structure parameters of the underlying individual preferences. Using such sufficient statistics for welfare and normative analysis has been used various contexts in the field of public economics in recent years (see Chetty, 2008b for a recent survey). However, it is important to understand the limitations of this approach and the strong assumptions required to apply it, as we show in the next sub-sections.

\subsection{Fiscal Externalities and Income Shifting}

The analysis has assumed so far that the reduction in incomes due to the tax rate increase has no other effect on tax revenue. This is a reasonable assumption if the reduction in incomes is due to reduced labor supply (and hence an increase in untaxed leisure time), or due to a shift from taxable cash compensation toward untaxed fringe benefits or perquisites (more generous

produce a Pareto improvement, ignoring the possibility that the utility of some individuals enters negatively in the utility functions of others. The optimal income taxation literature following Mirrlees (1971) shows that formula (7) is the optimal top tax rate if the social marginal utility of consumption decreases to zero when income is large (see Saez, 2001). 
health insurance, better offices, company cars, etc.) or tax evasion. However, in many instances the reduction in reported incomes is due in part to a shift away from individual income toward other forms of taxable income such as corporate income, or deferred compensation that will be taxable to the individual at a later date (see Slemrod, 1998). For example, as discussed in more detail later, Slemrod (1996) and Gordon and Slemrod (2000) show convincingly that part of the surge in top individual incomes after the Tax Reform Act of 1986 in the United States, which reduced individual income tax rates relative to corporate tax rates (see appendix A), was due to a shift of taxable income from the corporate sector toward the individual sector.

For a tax change in a given base $z$, we define a fiscal externality as a change in tax revenue that occurs in any tax base $z^{\prime}$ other than $z$ due to the behavioral response of private agents to the tax change in the initial base $z$. The alternative tax base $z^{\prime}$ can be a different tax base in the same time period or the same tax base in a different time period. The notion of fiscal externality is therefore dependent on the scope of the analysis both along the base dimension and the time dimension. In the limit where the analysis encompasses all tax bases and all time periods (and hence focuses on the total present discounted value of tax revenue), there can be by definition no fiscal externalities.

To see the implication of income shifting, assume that a fraction $s<1$ of the incomes that disappear from the individual income tax base following the tax rate increase $d \tau$ are shifted to other bases and are taxed on average at rate $t(<\tau)$. For example, if two-thirds of the reduction in individual reported incomes is due to increased (untaxed) leisure and one-third is due to a shift toward the corporate sector, then $s=1 / 3$ and $t$ would be equal to the effective tax rate on corporate income. Therefore, a behavioral response $d z$ generates a tax revenue change equal to $(\tau-t \cdot s) d z$. As a result, the change in tax revenue due to the behavioral response becomes:

$$
d B=-N \cdot e \cdot z^{m} \cdot \frac{\tau}{1-\tau} d \tau+N \cdot e \cdot z^{m} \cdot \frac{t \cdot s}{1-\tau} d \tau
$$

Therefore, formula (5) for the effect of the small reform on total tax revenue becomes:

$$
d R=d M+d B=d M\left[1-\frac{\tau-s \cdot t}{1-\tau} \cdot e \cdot a\right] .
$$

The same envelope theorem logic applies for welfare analysis: the income that is shifted to another tax base at the margin does not generate any direct change in welfare because the tax filer is indifferent between reporting marginal income in the individual income tax base vs. the alternative tax base. Therefore, as above, $-d B$ represents the marginal deadweight burden of the individual income tax, and the marginal excess burden expressed in terms of extra taxes 
collected can be written as

$$
-\frac{d B}{d R}=\frac{e \cdot a \cdot(\tau-s \cdot t)}{1-\tau-e \cdot a \cdot(\tau-s \cdot t)}
$$

The revenue-maximizing tax rate (7) becomes:

$$
\tau_{s}^{*}=\frac{1+s \cdot t \cdot a \cdot e}{1+a \cdot e}>\tau^{*} .
$$

If we assume again that $a=1.6, e=.5, \tau=0.35$ but that half $(s=0.5)$ of marginal income disappearing from the individual base is taxed on average at $t=0.3,{ }^{13}$ the fraction of revenue lost due to behavioral responses drops from $43 \%$ to $25 \%$, and the marginal excess burden (expressed as a percentage of extra taxes raised) decreases from $76 \%$ to $32 \%$. The revenue-maximizing tax rate increases from $55.6 \%$ to $62.2 \%$.

This simple theoretical analysis shows therefore that, in addition to estimating the elasticity $e$, it is critical to analyze whether the source or destination of changes in reported individual incomes is another tax base. Such an alternative tax base can be a concurrent one or in another time period, as we discuss below. Therefore, two additional parameters, in addition to the taxable income elasticity $e$, are crucial in the estimation of the tax revenue effects and marginal deadweight burden: (1) The extent to which individual income changes in the first tax base $z$ shift to another form of income that is taxable, characterized by parameter $s$, and (2) The tax rate $t$ at which the income shifted is taxed. In practice, there are many possibilities for such shifting and measuring empirically all the shifting effects is challenging, especially in the case of shifting across time. The recent literature has addressed several channels for such fiscal externalities.

\subsubsection{Individual vs. Corporate Income Tax Base}

Most countries tax corporate profits with a separate corporate income tax. ${ }^{14}$ Unincorporated business profits (such as sole proprietorships or partnerships) are in general taxed directly at the individual level. In the United States, closely held corporations with few shareholders (less than 100 currently) can elect to become Subchapter S corporations and be taxed solely at

\footnotetext{
${ }^{13}$ We show below that $s=0.5$ and $t=0.3$ are realistic numbers to capture the shift from corporate to individual taxable income following the Tax Reform Act of 1986.

${ }^{14}$ Net-of-tax corporate profits are taxed again at the individual level when paid out as dividends to individual shareholders. Many OECD countries alleviate such double taxation of corporate profits by providing tax credits or preferential tax treatment for dividends. If profits are retained in the corporation, they increase the value of the company stock and those profits may, as in the United States, be taxed as realized capital gains when the individual owners eventually sell the stock. In general, the individual level of taxation of corporate profits is lower than the ordinary individual tax on unincorporated businesses so that the combined tax on corporate profits and distributed profits may be lower than the direct individual tax for individuals subject to high marginal individual tax rates.
} 
the individual level. Therefore, the choice of business organization (regular corporation taxed by the corporate income tax vs. business entity taxed solely at the individual level) might respond to the relative tax rates on corporate vs. individual income.

For example, if the individual income tax rate increases, some businesses taxed at the individual level may choose to incorporate where they would be subjected to the corporate income tax instead. ${ }^{15}$ In that case, the standard taxable income elasticity might be large and the individual income tax revenue consequences significant. However, corporate income tax revenue will increase and partially offset the loss in revenue on the individual side. It is possible to provide a micro-founded model capturing those effects. ${ }^{16}$ Because there are heterogeneous fixed costs of switching business form organization, in the aggregate the shifting response to tax rates is smooth, and marginal welfare analysis is still applicable. As a result, the reduced form formula (9) is a sufficient statistic to derive the welfare costs of taxation in that case. Estimating $s$ and $t$ empirically would require knowing the imputed corporate profits of individual shareholders.

This issue was quite significant for analyses of TRA 86 because of the sharp decline (and change in sign!) in the difference between the top personal and corporate tax rates, which created an incentive to shift business income from the corporation tax base to pass-through entities such as partnerships or Subchapter S corporations, so that the business income shows up in the individual income tax base (see appendix A for a description of the TRA 86 changes). This phenomenon was indeed widespread immediately after TRA 86 (documented by Slemrod, 1996, Carroll and Joulfaian, 1997, and Saez, 2004 among others).

\subsubsection{Short-term vs. Long-term Responses}

If individuals anticipate that a tax increase will happen soon, ${ }^{17}$ they have incentives to accelerate taxable income realizations before the tax change takes place. ${ }^{18}$ As a result, reported taxable income just after the reform will be temporarily depressed. In that case, the tax increase has a positive fiscal externality on the pre-reform period which ought to be taken into account in a welfare analysis.

As we will see below, this issue of re-timing is particularly important in the case of realized

\footnotetext{
${ }^{15}$ Again, to the extent that dividends and capital gains are taxed, shareholders would not entirely escape the individual income tax.

${ }^{16}$ Alvaredo and Saez (2008) develop such a model in the case of the Spanish wealth tax, under which stock in closely held companies is excluded from the wealth tax for individuals who own at least $15 \%$ of the business and are substantially involved in management.

${ }^{17}$ For example, President Clinton was elected in late 1992 on a program to raise top individual tax rates, which was indeed implemented in 1993.

${ }^{18}$ Anticipated tax decreases would have the opposite effect.
} 
capital gains ${ }^{19}$ and stock-option exercises (Goolsbee 2000a). Parcell (1995), Feldstein and Feenberg (1996), as well as Sammartino and Weiner (2007) document the large shift of taxable income into 1992 from 1993 in response to the tax increase on high-income earners promised by President-elect Bill Clinton, and enacted in early 1993.

Conversely, adjusting to a tax change might take time (as individuals might decide to change their career or educational choices or businesses might change their long-term investment decisions), creating a negative fiscal externality in future years. In that case, the shortterm response elasticity would underestimate the welfare cost of taxation. Therefore, in both cases, it is preferable to estimate the long-term response of tax changes although, as we discuss below, the long-term response is more difficult to identify empirically. The empirical literature has primarily focused on short-term (1 year) and medium-term (up to 5 year) responses, and is not able to convincingly identify very long-term responses.

The labor supply literature started with a static framework and then developed a dynamic framework to distinguish between responses to temporary changes versus permanent changes in wage rates (MaCurdy, 1981). Although the ETI literature has not explicitly developed such a framework, the same theoretical issues of responses to temporary versus permanent tax changes arise. Because of inter-temporal substitution, and barring adjustment costs, responses to temporary changes will be larger than responses to permanent changes. ${ }^{20}$ This is an important issue to keep in mind when discussing empirical studies.

The issue of long-term responses is particularly important in the case of capital income, as capital income is the consequence of past savings and investment decisions. For example, a higher top income tax rate might discourage wealth accumulation or dissipate existing fortunes faster. The new long-term wealth distribution equilibrium might not be reached for decades or even generations, which makes it particularly difficult to estimate the long-run elasticity. Estimating the effects on capital would require developing a dynamic model of tax responses, which has not yet been developed in the context of the ETI literature.

\subsubsection{Current vs. Deferred Income}

If current income tax rates increase but long-term future expected income tax rates do not, individuals might decide to defer some of their incomes, for example, in the form of future

\footnotetext{
${ }^{19}$ The most famous example is the U.S. Tax Reform Act of 1986, which increased the top tax rate on realized capital gains from $20 \%$ to $28 \%$, and generated a surge in capital gains realizations at the end of 1986 (Auerbach, 1988; Burman, Clausing, and O'Hare, 1994).

${ }^{20}$ In the labor supply literature, responses to temporary changes are captured by the Frisch elasticity which higher than the compensated elasticity to permanent changes.
} 
pension payments ${ }^{21}$ (deferred compensation) or future realized capital gains. ${ }^{22}$ In that case, a current tax increase might have a positive fiscal externality in future years; such a fiscal externality affects the welfare cost of taxation as we described above. A similar issue applies whenever a change in tax rates affects business investment decisions undertaken by individuals. If, for example, a lower tax rate induces sole proprietors or principals in pass-through entities to expand investment, the short-term effect on taxable income may be negative, reflecting the deductible net expenses in the early years of an investment project.

\subsubsection{Tax Evasion}

Suppose that a tax increase leads to a higher level of tax evasion. In that case, there might be increases in taxes collected on evading taxpayers following audits. This increased auditgenerated tax revenue is another form of a positive fiscal externality. In practice, most empirical studies are carried out using tax return data before audits take place, and therefore do not fully capture the revenue consequences. Chetty (2008) makes this point formally and shows that, under risk neutrality assumptions, at the margin an individual is indifferent between evading one dollar more and facing a marginally higher audit rate, and therefore the tax revenue lost due to increased tax evasion is exactly recouped (in expectation) by increased fines collected by the government. As a result, in that case, the elasticity that matters for deadweight burden is not the elasticity of reported income but instead the elasticity of real income.

\subsubsection{Other Fiscal Externalities}

Changes in reported incomes might also have consequences for bases other than federal income taxes. An obvious example is the case of state income taxes in the United States. If formula (6) is applied to the federal income tax only, it will not capture the (negative) externality on state income tax revenue (as states use virtually the same tax base as the federal government). In that case (ignoring the deductibility of state income taxes for federal tax purposes), we have $s=-1$ and $t$ is the state income tax rate. Put another way, our original analysis should be based on the total federal plus state income tax rate $\tau+t$.

Changes in reported individual income due to real changes in economic behavior (such as reduced labor supply) can also have consequences for consumption taxes (if, for example, less

\footnotetext{
${ }^{21}$ In the United States, individual workers can electively set aside a fraction of their earnings into pension plans (traditional IRAs and 401(k)s) or employers can provide increased retirement contributions at the expense of current compensation. In both cases, those pension contributions are taxed when the money is withdrawn as pension income.

${ }^{22}$ For example, companies, on behalf of their shareholders, may decide to reduce dividend payments which are taxed now and retain earnings in order to generate capital gains that are taxed later when the stock is sold.
} 
labor income is accompanied by less consumption). In particular, a broad-based value added tax is economically equivalent to an income tax (with expensing) and therefore should also be included in the tax rate used for welfare computations.

Finally, fiscal externalities may also arise due to classical general equilibrium incidence effects. For example, a reduced tax rate on high incomes might stimulate labor supply of workers in highly paid occupations, and hence could decrease their pre-tax wage rate while increasing the pre-tax wage rates of lower-paid occupations through general equilibrium effects. ${ }^{23}$ Such incidence effects are effectively transfers from some factors of production (high-skilled labor in our example) to other factors of production (low-skilled labor). If different factors are taxed at different rates (due for example of a progressive income tax), then those incidence effects will have fiscal consequences. Conceptually, however, as those incidence effects are transfers, the government can always readjust tax rates on each factor in order to undo those incidence effects at no fiscal cost. Therefore, in a standard competitive model, incidence effects do not matter for the efficiency analysis nor for optimal tax design. ${ }^{24}$

\subsection{Other Issues}

\subsubsection{Classical Externalities}

There are situations where individual responses to taxation may involve classical externalities. Two prominent examples are charitable giving and mortgage interest payments for residential housing, which in the United States and some other countries are deductible from taxable income, a tax treatment which is often justified on the grounds of classical externalities. Contributions to charitable causes create positive externalities when the contributions increase the utility of the beneficiaries of the nonprofit organizations. To the extent that mortgage interest deductions increase home ownership, they arguably create positive externalities in neighborhoods (although the level or even the existence of such a net home ownership externality is debated, see e.g., Glaeser and Shapiro, 2003). Expenditures on such deductible items may rise following a tax increase because their net price is equal to the net-of-tax rate $1-\tau$ when deductions are itemized. ${ }^{25}$ Increased expenditures on these items will decrease taxable income.

Suppose a fraction $s$ of the taxable income response to a tax rate increase $d \tau$ is due to

\footnotetext{
${ }^{23}$ Such effects are extremely difficult to convincingly estimate empirically. Kubik (2004) attempts such an analysis and finds that, controlling for occupation-specific time trends in wage rates, individuals in occupations that experienced large decreases in their median marginal tax rates due to TRA86 received lower pre-tax wages after 1986 as the number of workers and the hours worked in these professions increased.

${ }^{24}$ Indeed, Diamond and Mirrlees (1971) showed that optimal tax formulas are the same in a model with fixed prices of factors (with no incidence effects) and in a model with variable prices (with incidence effects).

${ }^{25}$ There is a large empirical literature finding significant responses of charitable giving to individual marginal income tax rates. See, for example, Auten, Sieg and Clotfelter (2002), Clotfelter and Schmalbeck (1996), Randolph (1995) and Karlan and List (2007).
} 
higher expenditures on activities such as charitable giving that create an externality with a social marginal value of $t$ dollars, per dollar of additional expenditure. In that case, formula (9) applies by just substituting the alternative tax base rate $t$ by the social marginal value of the externality. For example, in the extreme case where all the taxable income response comes from tax expenditures $(s=1)$ with income before tax expenditures being unresponsive to tax rates, and if $t=\tau$ (the social marginal value of tax expenditures externalities is equal to the income tax rate $\tau$ ) then there is zero marginal excess burden from taxation. (It is a Pigouvian tax.) ${ }^{26}$ More generally, to the extent that the behavioral response to higher tax rates generates positive externalities, formula (4) will overstate the marginal efficiency cost of taxation.

Because the bulk of items that are deductible from taxable income in the United States - state and local income taxes, mortgage interest deductions, and charitable giving - may generate fiscal or classical externalities, the elasticity of a broader, pre-deduction, concept of income (such as adjusted gross income in the United States) is of interest in addition to a taxable income elasticity. That is why much conceptual and empirical analyses focus on adjusted gross income - which is not net of such deductible items - rather than taxable income.

Classical externalities might also arise in agency models where executives set their own pay by expending efforts to influence the board of directors. ${ }^{27}$ It is conceivable that such pay-setting efforts depend on the level of the top income tax rate and would increase following a top tax rate cut. In such a case, top executive compensation increases come at the expense of shareholders returns which produces a negative externality. ${ }^{28}$ Such an externality would reduce the efficiency costs of taxation (as correcting the externality precisely requires a positive tax in that case).

\subsubsection{Changes in the Tax Base Definition and Tax Erosion}

As pointed out by Slemrod (1995) and Slemrod and Kopczuk (2002), how broadly the tax base is defined affects the taxable income elasticity. For example, in general the more tax deductions that are allowed, the higher will be the taxable income elasticity. This implies that the final taxable income elasticity depends not only on individual preferences (as we posited

\footnotetext{
${ }^{26}$ Saez (2004b) develops a simple optimal tax model to capture those effects.

${ }^{27}$ Under perfect information and competition, executives would not be able to set their pay at a different level from their marginal product. In reality, the marginal product of top executives cannot be perfectly observed, which creates scope for influencing pay, as discussed extensively in Bebchuk and Fried (2004).

${ }^{28}$ Such externalities would fit into the framework developed by Chetty (2008). Following the analysis of Chetty and Saez (2007), such agency models produce an externality only if the pay contract is not second-best Pareto efficient, e.g., it is set by executives and large shareholders on the board without taking into account the best interests of small shareholders outside the board.
} 
in our basic model in Section 2.1) but also on the tax structure. Therefore, the tax base choice determines in part the taxable income elasticity, and hence the latter can be thought of as a policy choice. The same logic applies to the enforcement of a given tax base, which can particularly affect the behavioral response of avoidance schemes and evasion.

This point is paramount for policy analysis. Suppose that we estimate a large taxable income elasticity because the tax base is set such that there are loopholes making it easy to shelter income from tax (we discuss in detail such examples using U.S. tax reforms below). In the narrow model of Section 2.1, the policy prescription is to have a lower tax rate. However, in a broader context, a much better policy may be to eliminate loopholes in order to reduce the taxable income elasticity and the deadweight burden of taxation. ${ }^{29}$

Let us consider a simple example to illustrate this point. As in our basic model, individuals supply effort to earn income $z$. Suppose individuals can, at some cost, shelter part of their income $z$ into another form that might receive preferable tax treatment. Let us denote $w+y=$ $z$, where $y$ is sheltered income and $w$ is unsheltered income. Formally, individuals maximize a utility function of the form $u(c, z, y)$ that is decreasing in $z$ (earning income requires effort) and $y$ (sheltering income is costly). Suppose we start from a comprehensive tax base where $z$ is taxed at rate $\tau$ so that $c=(1-\tau) z+E$ ( $E$ denotes a lump-sum transfer). In that case, sheltering income is costly and provides no tax benefit so that individuals choose $y=0$ and the analysis is the same as in Section 3.1 where the relevant elasticity is the elasticity of total income $z$ with respect to $1-\tau$.

Suppose now that the tax base is eroded by excluding $y$ from taxation. In that case $c=(1-\tau) w+y+E=(1-\tau) z+\tau y+E$. Therefore, individuals will find it profitable to shelter some of their income up to point where $\tau \cdot u_{c}=u_{y}$. We can define the indirect utility $v\left(c^{\prime}, w\right)=\max _{y} u\left(c^{\prime}+y, w+y, y\right)$ and the analysis of Section 3.1 applies using the elasticity of taxable income $w$ with respect to $1-\tau$. Because $w=z-y$ and sheltered income $y$ responds (positively) to the tax rate $\tau$, the elasticity of $w$ is larger than the elasticity of $z$ and hence the deadweight burden of taxation is higher with the narrower case. Intuitively, giving preferential treatment to $y$ induces taxpayers to waste resources to shelter income $y$, which is pure deadweight burden. As a result, starting from the eroded tax base and introducing a small tax $d t>0$ on $y$ actually reduces the deadweight burden from taxation, showing that the eroded tax base is a suboptimal policy choice. ${ }^{30}$

Therefore, comprehensive tax bases with low elasticities are preferable to narrow bases with

\footnotetext{
${ }^{29}$ This possibility is developed in the context of an optimal linear income tax in Slemrod (1994), which draws on the metaphor of Okun (1975) in which revenue leakage is the leak in a bucket that transfers income from the top of the income distribution to the bottom.

${ }^{30}$ This can be proved easily in a separable model with no income effects where $u(c, z, y)=c-h^{1}(z)-h^{2}(y)$.
} 
large elasticities. Possible legitimate reasons for narrowing the tax base are (1) administrative simplicity (as in the model of Slemrod and Kopczuk, 2002), ${ }^{31}$ (2) redistributive concerns ${ }^{32}$ and (3) externalities such as charitable contributions, as discussed above. ${ }^{33}$

\section{Empirical Estimation and Identification Issues}

\subsection{A Framework to Analyze the Identification Issues}

In order to assess the validity of various empirical methods and the key identification issues, it is useful to consider a very basic model of income reporting behavior. Individual $i$ reports income $z_{i t}$ and faces a marginal tax rate $\tau_{i t}=T^{\prime}\left(z_{i t}\right)$ in year $t$. We assume that reported income $z_{i t}$ responds to marginal tax rates with elasticity $e$ so that $z_{i t}=z_{i t}^{0} \cdot\left(1-\tau_{i t}\right)^{e}$, where $z_{i t}^{0}$ is income reported when the marginal tax rate is zero, which we call potential income. ${ }^{34}$ Therefore, using logs, we have:

$$
\log z_{i t}=e \cdot \log \left(1-\tau_{i t}\right)+\log z_{i t}^{0}
$$

Note, in light of our previous theoretical discussion, the assumptions that are embedded in this simple model: (1) No income effects (as virtual income $E$ is excluded from specification (12), (2) The response to tax rates is immediate and permanent (so that short-term and longterm elasticities are identical), (3) The elasticity $e$ is constant over time and uniform across individuals at all levels of income, ${ }^{35}$ (4) Individuals have perfect knowledge of the tax structure and choose $z_{i t}$ after they know the exact realization of potential income $z_{i t}^{0}$. We will come back to these assumptions below.

Even within the context of this simple model, an OLS regression of $\log z_{i t}$ on $\log \left(1-\tau_{i t}\right)$ would not identify the elasticity $e$ in the presence of a graduated income tax schedule because $\tau_{i t}$ is positively correlated with potential $\log$-income $\log z_{i t}^{0}$; this occurs because the marginal tax rate may increase with realized income $z$. Therefore, it is necessary to find instruments correlated with $\tau_{i t}$ but uncorrelated with potential log-income, $\log z_{i t}^{0}$, to identify the elasticity $e$. The recent taxable income elasticity literature has used changes in the tax rate structure created by tax reforms in order to obtain such instruments. Intuitively, in order to isolate the

\footnotetext{
${ }^{31}$ In many practical cases, however, a comprehensive tax base such as a VAT is actually administratively simpler than a complex income tax with many exemptions and a narrower base.

${ }^{32}$ Excluding large out-of-pocket health expenditures, as done in the U.S. individual income tax code, could be such an example.

${ }^{33}$ The public choice argument that narrow bases constrain Leviathan governments would fall in that category, as a Leviathan government produces a negative externality.

${ }^{34} \mathrm{~A}$ quasi-linear utility function of the form $u(c, z)=c-z^{0}\left(z / z^{0}\right)^{1+1 / e} /(1+1 / e)$ generates such income response functions.

${ }^{35}$ This assumption can be relaxed in most cases, but it sometimes has important consequences for identification, as we discuss below.
} 
effects of the net-of-tax rate, one would want to compare observed reported incomes after the tax rate change to the incomes that would have been reported had the tax change not taken place. Obviously, the latter are not observed and must be estimated. We describe in this Section the methods that have been proposed and used to overcome this identification issue.

\subsection{Simple before and after Reform Comparison}

The simplest method uses reported incomes before a tax reform as a proxy for reported incomes after the reform (had the reform not taken place). This simple difference estimation method amounts to comparing reported incomes before and after the reform and attributing the change in reported incomes to the changes in tax rates.

Suppose that tax rates increase at time $t=1$ because of a tax reform. Using repeated cross sections spanning the pre and post-reform periods, we can run the following 2SLS regression:

$$
\log z_{i t}=e \cdot \log \left(1-\tau_{i t}\right)+\varepsilon_{i t}
$$

using the post-reform indicator $1(t \geq 1)$ as an instrument for $\log \left(1-\tau_{i t}\right)$. This regression identifies $e$ if $\varepsilon_{i t}$ is uncorrelated with $1(t \geq 1)$. In the context of our simple model (12), this requires that potential log-incomes are not correlated with time. This assumption is very unlikely to hold in practice, as real economic growth creates a direct correlation between income and time. If more than two years of data are available, one could add a linear trend $\beta \cdot t$ in (13) to control for secular growth. However, as growth rates vary year-to-year due to macroeconomic business cycles, the elasticity estimate will be biased if economic growth happens to be different from year $t=0$ to year $t=1$ for reasons unrelated to the level of tax rates-we will ascribe to the tax change the impact of an unrelated but coincident change in average incomes.

In many contexts, however, tax reforms affect subgroups of the population differentially, and in some cases they leave tax rates essentially unchanged for most of the population. For example, in the United States during the last three decades, the largest absolute changes in tax rates have taken place at the top of the income distribution, with much smaller changes on average in the broad middle. In that context, one can use the group less (or not) affected by the tax change as a control and hence proxy unobserved income changes in the affected group (absent the tax reform) with changes in reported income in the control group. Such methods naturally lead to consideration of difference-in-differences estimation methods discussed in Section 3.4 . 


\subsection{Share analysis}

When the group affected by the tax reform is relatively small, one can simply normalize incomes of the group affected by a tax change by the average income in the population in order to control for macro-economic growth. Indeed, the most dramatic changes in U.S. marginal federal income tax rates have taken place at the top percentile of the income distribution (in appendix A we discuss in more detail the key individual tax changes since 1960). Therefore, and following Feenberg and Poterba (1993) and Slemrod (1996), a natural measure of the evolution of top incomes relative to the average is the change in the share of total income reported by the top percentile. ${ }^{36}$ Figure $1 \mathrm{~A}$ displays the average marginal tax rate (weighted by income) faced by the top percentile income earners (scaled on the left y-axis) along with the share of total personal income reported by the top percentile earners (scaled on the right y-axis) from 1960 to $2006 .{ }^{37}$ The figure shows that indeed the marginal tax rate faced by the top $1 \%$ have declined dramatically since 1980 . It is striking to note that the share received by the top $1 \%$ of income recipients started to increase precisely after 1981 — when marginal tax rates started to decline. The timing of the jump in the share of top incomes from 1986 to 1988 corresponds exactly to the sharp drop in the weighted average marginal tax rate from $45 \%$ to $29 \%$ after the Tax Reform Act of 1986 . These correspondences in timing, first noted by Feenberg and Poterba (1993), provide circumstantial but quite compelling evidence that high incomes are indeed responsive to marginal tax rates.

Figure 1B shows the same income share and marginal tax rate series for the next $9 \%$ highest income tax filers (i.e., the top decile excluding the top $1 \%$ from Panel A). The marginal tax rate follows a different pattern, first increasing from 1960 to 1981 due primarily to bracket creep (as the tax system in this period was not indexed for inflation), followed by a decline until 1988 and relative stability afterwards. In contrast to the top 1\%, however, the share of the next $9 \%$ in total income is very smooth and trends slightly upward during the entire period. Most importantly, it displays no correlation with the level of the marginal tax rate either in the short run or in the long run. Thus, the comparison of Panel A and Panel B suggests that the behavioral responses of the top $1 \%$ are very different from those of the rest of top decile, and hence that the elasticity $e$ is unlikely to be constant across income groups.

Using the series displayed in Figure 1, one can estimate the elasticity of reported income around a tax reform episode taking place between pre-reform year $t_{0}$ and post-reform year $t_{1}$

\footnotetext{
${ }^{36}$ In what follows, we always exclude realized capital gains from our income measure as realized capital gains in general receive a tax-favored treatment and there is a large literature analyzing specifically capital gains realization behavior and taxes (see Auerbach 1988 for a survey). See a further discussion of this issue in Section 4.1 .

${ }^{37}$ This figure is an update of a figure presented in Saez (2004).
} 
as follows:

$$
e=\frac{\log p_{t_{1}}-\log p_{t_{0}}}{\log \left(1-\tau_{p, t_{1}}\right)-\log \left(1-\tau_{p, t_{0}}\right)},
$$

where $p_{t}$ is the share of income accruing to the top 1\% (or the next $9 \%$ ) earners in year $t$ and $\tau_{p, t}$ is the average marginal tax rate (weighted by income) faced by taxpayers in this income group in year $t$. This method identifies the elasticity if, absent the tax change, the top $1 \%$ income share would have remained constant from year $t_{0}$ to year $t_{1}$. As shown in Table 1, Panel A, applying this simple method using the series depicted in Figure 1 around the 1981 tax reform by comparing 1981 and 1984 generates an elasticity of 0.60 for the top 1\%. Comparing 1986 and 1988 around the Tax Reform Act of 1986 yields a very large elasticity of 1.36 for the top 1\%. ${ }^{38}$ In contrast, column (2) in Table 1 shows that the elasticities for the next $9 \%$ are much closer to zero around those two tax episodes. The 1993 tax reform also generates a substantial elasticity of 0.45 for the top 1\% when comparing 1992 and 1993. Strikingly, though, comparing 1991 to 1994 yields a negative elasticity for the top 1\% - probably due to tax rate endogeneity, as there were no legislated changes between 1991 and 1992 or between 1993 and 1994. Hence, Table 1 shows that the elasticity estimates obtained in this way are sensitive to the specific reform, the income group, as well as the choice of years - important issues we will come back to later on.

A natural way to estimate the elasticity $e$ using the full time-series evidence is to run a simple time-series regression of the form:

$$
\log p_{t}=e \cdot \log \left(1-\tau_{p, t}\right)+\varepsilon_{t}
$$

As reported in Table 1, such a regression generates a very high estimate of the elasticity $e$ of 1.71 for the top $1 \% .{ }^{39}$ However, this is an unbiased estimate only if, absent any marginal tax rate changes, the top $1 \%$ income share series would have remained constant or moved in a way that is uncorrelated with the evolution of marginal tax rates. But it is entirely possible that inequality changed over time for reasons unrelated to tax changes: the secular increase in income concentration in the United States since the 1960s was probably not entirely driven by changes in the top tax rates, hence biasing upward the estimate of $e .{ }^{4041}$ For example, Figure 1 shows that there was a sharp increase in the top $1 \%$ income share from 1994 to 2000 in spite of little change in the marginal tax rate faced by the top $1 \%$, which suggests that changes in marginal tax rates are not the sole determinant of the evolution of top incomes (at least in

\footnotetext{
${ }^{38}$ Goolsbee (2000b) also obtained such a large elasticity using TRA 1986 and a similar approach.

${ }^{39}$ The estimated elasticity for the next $9 \%$ is very small $(e=0.01)$, and not significantly different from zero.

${ }^{40}$ See Katz and Autor (1999) for a comprehensive analysis of wage inequality in the United States since 1960.

${ }^{41}$ Reverse causality is also a possibility. If incomes of the already affluent increase, the group might have more political influence and success in lobbying the government to cut top tax rates.
} 
the short run). ${ }^{42}$

It is possible to add controls for various factors affecting income concentration through channels other than tax rates in regression (15), as in Slemrod (1996). Unfortunately, we do not have a precise understanding of what those factors might be. An agnostic solution is to add time trends to (15). As shown in Table 1, such time trends substantially reduce the estimated elasticity, although it remains significant and above 0.5. The key problem is that we do not know exactly what time-trend specifications are necessary to control for non-tax related changes, and adding too many time controls necessarily destroys the time-series identification.

It could be fruitful to extend this framework to a multi-country time-series analysis. In that case, general time trends will not destroy identification, although it is possible that inequality changes differentially across countries (for non-tax related reasons), in which case country-specific time trends would be required and a similar identification problem would arise. Atkinson and Leigh (2004) and Roine, Vlachos, and Waldenstrom (2008) propose first steps in that direction. The macro-economic literature has recently used cross-country timeseries analysis to analyze the effects of tax rates on aggregate labor supply (see e.g., Ohanian, Raffo, and Rogerson, 2008) but has not examined directly effects on reported income, let alone reported income by income groups.

\subsection{Differences-in-difference Methods}

Most of the recent literature has used micro-based regressions using "differences-in-difference" (DD) methods ${ }^{43}$ in which changes in reported income of a treatment group (experiencing a tax change) are compared to changes for a "control" group (which does not experience the same, or any, tax change). ${ }^{44}$ It is useful to point out from the start that the concept of treatment and control groups in the ETI context is substantially different from the ideal randomized experiment where a randomly selected treatment group would be assigned to a specific tax rate. Indeed, in the ETI context, control and treatment groups are almost always defined by income which creates several identification issues.

In order to illustrate the identification issues that arise with those various methods, we will examine the 1993 tax reform in the United States that introduced two new income tax brackets - raising rates for those at the upper-end of the top tax bracket from 31\% (in 1992 and before) to $36 \%$ or $39.6 \%$ (in 1993 and after) and enacted only minor other changes (see

\footnotetext{
${ }^{42}$ Slemrod and Bakija (2001) call the behavior of reported taxable income over this period a "non-event study."

${ }^{43}$ For earlier reviews of this literature, see Slemrod (1998) and Giertz (2004).

${ }^{44}$ Note that share analysis is conceptually related to the DD method as share analysis compares the evolution of incomes is a given quantile (the numerator of the share is the treatment group) relative to the full population (the denominator of the share is implicitly the control group).
} 
appendix A for details). Figure 1 shows that the average marginal tax rate for the top $1 \%$ increased sharply from 1992 to 1993 but that the marginal tax rate for the next 9\% was not affected. Our empirical analysis is based on the Treasury panel of tax returns described in Giertz (2008c). As we discuss in appendix B, those panel data are created by linking the large annual tax return data stratified by income used by U.S. government agencies. Therefore, the data include a very large number of top $1 \%$ taxpayers.

\subsubsection{Repeated Cross-Section Analysis}

Let us denote by $T$ the group affected by the tax change (the top $1 \%$ in our example) and by $C$ a group not affected by the reform (the next $9 \%$ in our example). We denote by $t_{0}$ the pre-reform year and by $t_{1}$ the post-reform year. Generalizing our initial specification (13), we can estimate the 2SLS regression:

$$
\log z_{i t}=e \cdot \log \left(1-\tau_{i t}\right)+\alpha \cdot 1\left(t=t_{1}\right)+\beta \cdot 1(i \in T)+\varepsilon_{i t}
$$

on a repeated cross-section sample including both the treatment and control groups and including the year $t_{0}$ and year $t_{1}$ samples, and using as an instrument for $\log \left(1-\tau_{i t}\right)$ the post-reform and treatment group interaction $1\left(t=t_{1}\right) \cdot 1(i \in T)$.

Although we refer in this section to income tax rate schedule changes as a treatment, they certainly do not represent a classical treatment in which a random selection of taxpayers is presented with a changed tax rate schedule, while a control group of taxpayers is not so subject. In fact, in any given year all taxpayers of the same filing status face the same rate schedule. When the rates applicable at certain income levels change more substantially than the rates at other levels of income, however, some taxpayers are more likely to face large changes in the applicable marginal tax rate than other taxpayers. Two problems arise. The first is that when the likely magnitude of the tax rate change is correlated with income, any non-tax-related changes in taxable income that vary systematically by income group will need to be disentan-

gled from the effect on taxable incomes of the rate changes. Second, non-tax-related changes in income may affect which marginal tax rate is applicable to a taxpayer in a given year. Because the presence of transitory income implies mean reversion, some of this year-to-year change will be systematic; this will be especially problematic in periods when tax rates converge, or diverge, because the mean reversion in taxable income will be correlated (negatively or positively, respectively) with the expected effect of the tax rate changes themselves.

We run regression (16) weighted by income $z_{i t}$ (in order to give proportionally more weight to high-income taxpayers, as their response contributes proportionately more to the aggregate elasticity as discussed in Section 2.1). The 2SLS estimate is a classical difference-in-difference 
estimate equal to:

$$
e=\frac{\left[E\left(\log z_{i t_{1}} \mid T\right)-E\left(\log z_{i t_{0}} \mid T\right)\right]-\left[E\left(\log z_{i t_{1}} \mid C\right)-E\left(\log z_{i t_{0}} \mid C\right)\right]}{\left[E\left(\log \left(1-\tau_{i t_{1}}\right) \mid T\right)-E\left(\log \left(1-\tau_{i t_{0}}\right) \mid T\right)\right]-\left[E\left(\log \left(1-\tau_{i t_{1}}\right) \mid C\right)-E\left(\log \left(1-\tau_{i t_{0}}\right) \mid C\right)\right]} .
$$

Thus, the elasticity estimate is the ratio of the pre- to post-reform change in log incomes in the treatment group minus the same ratio for the control group to the same difference-in-differences in log net-of-tax rates (with all expectations weighted by income).

Using data from 1992 (pre-reform) and 1993 (post-reform), we define the treatment group as the top $1 \%$ and the control group as the next $9 \%$ (90th percentile to 99th percentile). Note that being in the treatment group depends on the taxpayer's behavior. Table 2, Panel A shows that the elasticity estimate is around one, which reflects the fact that the top $1 \%$ incomes decreased sharply from 1992 to 1993 while the next 9\% incomes remained stable as shown in Figure 1. However, comparing 1991 to 1994 generates a negative elasticity, as the top 1\% incomes increased faster than the next 9\% incomes from 1991 to 1994 (Figure 1). The sign switch mirrors the results of Table 1, Column 1.

As is standard in the case of DD estimation, formula (17) will yield an unbiased estimate of the elasticity $e$ if the parallel trend assumption holds: Absent the tax change, the numerator would have been zero, i.e., log-income changes pre- to post-reform would have been the same in the treatment and control groups. In the case of our example, that means that the top $1 \%$ incomes grow at the same rate as the next $9 \%$ incomes (absent the tax change). Such an assumption can be tested using pre-reform years or post-reform years in order to construct placebo differences-in-difference estimates. As is clear from Figure 1, the top 1\% incomes increase sharply from 1994 to 2000 relative to average incomes while the share of the next $9 \%$ income is almost flat. Therefore, the DD identification assumption is clearly violated in the post-reform period.

In cases where the parallel trend assumption does not hold, we can generalize equation (16) by pooling together several pre-reform years and post-reform years and running the following 2SLS regression (assuming the tax change takes place in year $\bar{t}$ ):

$$
\log z_{i t}=e \cdot \log \left(1-\tau_{i t}\right)+\alpha \cdot 1(t \geq \bar{t})+\beta \cdot 1(i \in T)+\gamma_{C} \cdot t+\gamma_{T} \cdot t \cdot 1(i \in T)+\varepsilon_{i t},
$$

where we have added separate time trends for the control and treatment groups and where the instrument is the post-reform and treatment interaction $1(t \geq \bar{t}) \cdot 1(i \in T)$. As shown in Table 2, Panel A, with no time trends the regression produces a negative elasticity of $e=-0.404(0.089)$ because the top $1 \%$ incomes increase faster than next $9 \%$ incomes over the period 1991 to 1997 in spite of the top tax rate increase. Adding time trends generates a very large and positive elasticity of $e=1.329(0.107)$. This large elasticity can be explained using 
the evidence from Figure 1: from 1991 to 1997, the top 1\% incomes increase relative to the next 9\%. However, from 1992 to 1993, top 1\% incomes fall overall and relative to the next 9\% incomes exactly at the time of the tax change. Hence, the pooled regression (18) assumes that this reversal is due to a large immediate and permanent elasticity of reported income with respect to tax rates. We discuss below the issue of short-term vs. long-term responses, which is central to this particular tax episode. Column (2) in Table 2 shows that those repeated cross-section estimates are not sensitive to broadening the control group from the next $9 \%$ to the next $49 \%$ as incomes for both the next $9 \%$ and the next $49 \%$ move together, exhibiting very slow growth over the period.

Finally, note that if the control group faces a tax change, DD estimates will consistently estimate the elasticity only if the elasticities are the same for the two groups. To see this, refer back to equation (17). Suppose that the control group experiences a change in tax rates that is half the size of the tax rate change for the treatment group, so that $E\left(\log \left(1-\tau_{i t_{1}}\right) \mid C\right)-$ $E\left(\log \left(1-\tau_{i t_{0}}\right) \mid C\right)=0.5 \cdot\left[E\left(\log \left(1-\tau_{i t_{1}}\right) \mid T\right)-E\left(\log \left(1-\tau_{i t_{0}}\right) \mid T\right)\right]$. Assume further that the DD identification assumption holds, but that the elasticity in the control group is zero while the elasticity is $e_{T}>0$ in the treatment group. In that case, we have $E\left(\log z_{i t_{1}} \mid T\right)-E\left(\log z_{i t_{0}} \mid T\right)=$ $e_{T} \cdot\left[E\left(\log \left(1-\tau_{i t_{1}}\right) \mid T\right)-E\left(\log \left(1-\tau_{i t_{0}}\right) \mid T\right)\right]$ and $E\left(\log z_{i t_{1}} \mid C\right)-E\left(\log z_{i t_{0}} \mid C\right)=0$ and hence formula (17) leads to $e=2 \cdot e_{T}$ : the estimated elasticity is twice as large as the true elasticity in the treatment group. This example might actually apply around TRA 1986 as we have seen in Table 1 that, based on share elasticities, the elasticity around that episode may be large for the top $1 \%$ but close to zero for the next $9 \%$ (and the next $9 \%$ experiences a tax rate cut that is about half of the tax rate cut for the top $1 \%$ from 1986 to 1988). This source of bias partly explains why Feldstein (1995) obtained such large elasticities around TRA 1986, a point made originally by Navratil (1995b), as we discuss in Section 4.1.2.

\subsubsection{Panel Analysis}

Following the influential analysis of Feldstein (1995), the great majority of empirical studies have used panel data to estimate the elasticity of reported taxable income with respect to netof-tax rates. With panel data, we can define the treatment group $T$ as the top $1 \%$ of income earners and the control group $C$ as the next $9 \%$ of tax filers based on income in pre-reform year $t_{0}$, and follow those tax filers into post-reform year $t_{1}$. We can then run the 2SLS panel regression:

$$
\log \frac{z_{i t_{1}}}{z_{i t_{0}}}=e \cdot \log \left(\frac{1-\tau_{i t_{1}}}{1-\tau_{i t_{0}}}\right)+\varepsilon_{i t}
$$


using $1(i \in T)$ as the instrument. This regression also estimates a difference-in-difference parameter:

$$
e=\frac{E\left(\log \frac{z_{i t_{1}}}{z_{i t_{0}}} \mid T\right)-E\left(\log \frac{z_{i t_{1}}}{z_{i t_{0}}} \mid C\right)}{E\left[\log \left(\frac{1-\tau_{i t_{1}}}{1-\tau_{i t_{0}}}\right) \mid T\right]-E\left[\log \left(\frac{1-\tau_{i t_{1}}}{1-\tau_{i t_{0}}}\right) \mid C\right]} .
$$

As shown in Table 2, Panel B, such a regression generates a very large elasticity of 1.395 (0.107), as the top 1\% income earners in 1992 experience a drop in reported taxable income of about 15\% in 1993 while the next 9\% income earners in 1992 experience a drop of less than $5 \%$.

As above, this elasticity estimate is unbiased if, absent the tax change, the numerator of (20) is zero: log income changes are the same in the treatment and control group. As we described in our discussion of repeated cross-section analyses, this assumption might be violated if there are changes in income inequality: the top $1 \%$ incomes might have increased faster than the next $9 \%$ earners even in the absence of a tax change. In the case of panel analysis, however, another problem arises. Even in the absence of changes in the income distribution, the identification assumption might not hold because of mean reversion: the top $1 \%$ incomes in base year $t_{0}$ are likely to decrease because many individuals were in the top $1 \%$ in year $t_{0}$ due to large positive transitory incomes. ${ }^{45}$ The longitudinal tax data can be used to illustrate the issue. In 1992, tax returns in the top $1 \%$ of incomes average $\$ 460,000$ of income but in 1993 those same tax filers report only $\$ 400,000$ on average. In contrast, the top $1 \%$ income earners in 1993 report $\$ 430,000$. Hence, the drop in the income of those in the top $1 \%$ in 1992 is twice as large as in the repeated cross section. This helps to explain why the panel estimate of the elasticity of taxable income of 1.395 is larger than the repeated cross-section estimate of 0.998 . As shown in column (2), when the control group is broadened to the next $49 \%$, the panel estimate increases further to 1.878 , as mean reversion of the top $1 \%$ is larger relative to the next $49 \%$ than relative to the next $9 \%$.

Mean reversion in panel analysis is more pronounced when lengthening the lag between year $t_{0}$ and $t_{1}$; Table 2 shows that the estimates comparing 1991 to 1994 are much larger than the estimates comparing 1992 to 1993. Indeed, the large positive estimates of the taxable income elasticity using panel data from 1991 and 1994 data are in stark contrast to the negative estimates from using repeated cross-section analysis. This suggests that mean reversion bias swamps the increase in the top 1\% incomes from 1991 to 1994 that is apparent in the repeated cross sections.

Therefore, in the case of panel analysis - and in contrast to the repeated cross-section

\footnotetext{
${ }^{45}$ In the context of our initial model, potential log-earnings may be $\log z_{i t}^{0}=\mu_{i}+\nu_{i t}$, (i.e., having a permanent component $\mu_{i}$ and a transitory component $\nu_{i t}$ ). If the transitory component is iid, the mean reversion phenomenon is likely to occur.
} 
analysis - stability of the income distribution over time absent the tax change is not sufficient to ensure identification, and the natural specification (20) may be biased because of mean reversion due to year-to-year income fluctuations. Mean reversion produces an upward bias in the panel estimates in the case of a tax increase at the top such as the 1993 tax reform, but produces a downward bias in the case of a tax rate decrease at the top such as ERTA 1981 or TRA 1986. Ironically, the conventional wisdom, following Lindsey (1987) and Feldstein (1995), is that repeated cross-section analysis is biased in case of income mobility and that panel analysis can solve the problem. ${ }^{46}$ In reality, income mobility with stability of the income distribution over time does not bias repeated cross-section analysis, but will bias panel analysis unless the econometric specification controls for mean reversion.

In order to alleviate the mean reversion bias as well as potential changes in income inequality, following Auten and Carroll (1999), one can add year $t_{0}$ income controls in regression (20), either in a simple way by including $\log z_{i t_{0}}$, or in a richer way by including either polynomials or splines in $\log z_{i t_{0}} \cdot{ }^{47}$ As shown in Table 2, adding such income controls has a dramatic effect on the estimates: the estimated elasticities become negative with large absolute values and large standard errors. ${ }^{48}$

With only two years of data, adding too many base-year income controls destroys identification by absorbing much of the independent variation in tax rates, as the instrument-a dummy for those with incomes in the top $1 \%$ in the base year-is a also function of base-year income. Therefore, we conclude that no convincing estimates of the ETI can be obtained with a panel analysis using only two years of data when the tax rate changes are concentrated in a single part of the distribution (such as the top percentile in our example). As we will see in Section 4, many empirical panel studies use only two years of data and obtain estimates that are critically sensitive to their base-year income controls.

In order to overcome this issue, one would want to assess whether the numerator of (20) is uniquely large when a tax reform happens (relative to times when no tax reform happens). In order to implement this idea, and following Gruber and Saez (2002), we can add additional years in regression (20) by stacking differences for years 1991 to 1992,1992 to $1993, \ldots, 1996$ to 1997, and adding year dummies as follows:

$$
\log \frac{z_{i t+1}}{z_{i t}}=e \cdot \log \left(\frac{1-\tau_{i t+1}}{1-\tau_{i t}}\right)+f\left(z_{i t}\right)+\alpha_{t}+\varepsilon_{i t}
$$

\footnotetext{
${ }^{46}$ Feldstein 1995, p. 557, "Although the comparisons of separate cross sections provide much useful information, a concern remains about the extent to which the individuals in the same fractile in successive cross sections are comparable."

${ }^{47}$ Decile-based splines are a set of 10 variables. The p-th spline is constant outside decile $p$ (of the distribution of log income) and varies like log income within the p-th decile.

${ }^{48}$ Adding base-year income controls in the 1991 to 1994 comparison also makes the elasticity estimates become negative and very imprecisely estimated.
} 
where $f\left(z_{i t}\right)$ denotes controls in base-year income. In that case, we use as an instrument $1\left(i \in T_{t}\right) \cdot 1(t=1992)$, i.e., the interaction of being in the top $1 \%$ in the base year and the tax reform year 1992. Table 2 shows that, the elasticity estimate with no base-year income controls is very large 1.395 (0.296) and falls to around 0.5 to 0.6 when adding base-year income controls. The key identifying assumption in this case is that, absent the tax change, the extent of year-to-year mean reversion and year-to-year income inequality changes are stable over the period 1991 to 1997. Note that the estimates are no longer highly sensitive to the number of income controls (and as the income controls $f\left(z_{i t}\right)$ are not year-specific, they do not destroy the identification).

\section{- Additional Issues in Panel Analysis}

A troubling weakness of panel analysis (relative to repeated cross-section analysis) is that the identification assumptions lack transparency because they mix assumptions regarding mean reversion and assumptions regarding changes in income inequality. As a result, it is not possible to draw simple graphs (such as Figure 1) to assess the validity of the panel approach, especially when base-year income controls are added. Our empirical analysis also reveals a large sensitivity of panel regressions even in the case where many years are pooled and many base-year income controls are included (as in Table 2, Panel B2).

First, comparing columns (1) and (2) on Table 2, Panel B2, we note that panel estimates are somewhat sensitive to the choice of the control group, probably due to differences in mean reversion across control groups. Therefore, in situations with mean reversion, it is useful to both increases and decreases in tax rates for identification as mean reversion creates biases in opposite directions in the case of tax increases vs. tax decreases.

Second, the panel regressions are very sensitive to the choice of the instrument for the marginal tax rate. We have so far defined the instrument based on membership in the top $1 \%$ group in order to exploit the fact that the 1993 tax change was concentrated among the top 1\%. Many studies have instead used as an instrument a predicted change in log net-of-tax rates assuming that income, often inflation-adjusted income, remains the same as in the base year (allowing the tax schedule to change). ${ }^{49}$ Such an instrument has the advantage of taking account of all changes in the tax rate schedule. In the case of the 1993 reform, the choice of the instrument should not matter much because the tax rate change was concentrated among the top 1\%. However, the elasticity estimates, shown in the fourth row of Panel B2, are much smaller when using the predicted change in the log of the net-of-tax tax rate as an instrument.

\footnotetext{
${ }^{49}$ We estimated the predicted marginal tax rate in year $t+1$ by inflating year $t$ incomes using the inflation adjustment used in the tax code. As a result, only statutory changes in the tax law such as the top rate reduction in 1993 or elements of the tax code that are not indexed can produce a change in predicted net-of-tax rates.
} 
This may be due to the fact that predicted marginal tax rate changes are sometimes non-zero due to minor changes in the tax code or various provisions that are not indexed for inflation. If tax filers are unlikely to respond to such minor changes, this may explain why estimates using the traditional instrument are smaller than those using the top 1\% instrument.

Third, in principle, an "inverted" panel analysis could be carried out by reversing year $t_{0}$ and year $t_{1}$ in regression (19). This would amount to selecting the treatment group as those tax filers who are in the top $1 \%$ in the post-reform year $t_{1}$, in which case the problem of mean reversion is exactly inverted (Auten and Carroll, 1995 or Giertz 2008b). Some authors (Carroll, 1998 and Blomquist and Selin, 2009) have also proposed to construct the instrument based on the average of pre and post-tax income. ${ }^{50}$ In the case of our example, the treatment group is defined as tax filers in the top $1 \%$ of average pre and post income. Using average income brings the panel analysis closer to the repeated cross-section analysis as mean reversion no longer biases the results systematically. Changes in the distribution of income remain a potential issue, however. Practically, empirical attempts at using such alternative instruments have shown that estimates are quite sensitive to the choice of instruments, suggesting that the standard methods do not control fully adequately for mean reversion.

\section{- Advantages of Panel Analysis}

Under some assumptions, panel analysis offers several advantages. First, in principle, panel analysis is useful (relative to repeated cross-section analysis) if individual income in a base year is a good predictor of income after the reform (absent any tax change). This is another way of restating that the presence of income mobility weakens the case for using panel data. $^{51}$ In reality, there is substantial persistence of income from year to year and therefore panel estimates tend to have smaller standard errors than repeated cross-section estimates (keeping sample size the same). In practice, this advantage is counter balanced by the fact that cross-sectional datasets are often much larger than available panel datasets. Furthermore, there is a non-negligible fraction of individuals who experience very substantial mobility and can have a significant influence on panel estimates (based on our computations). This requires some trimming of outliers in order to obtain more stable estimates.

Second, panel analysis is also useful when one wants to analyze a tax change targeted to a specific group and there is a concern that the composition of this group will change significantly over time in the repeated cross sections. Consider again the case of the 1993 reform, which affected the top $1 \%$ income earners. Suppose that the increase in the top $1 \%$

\footnotetext{
${ }^{50}$ Blomquist and Selin actually use income for a year in between $t_{0}$ and $t_{1}$, which is similar in spirit to using average income.

${ }^{51}$ To see this, note that in the extreme case where potential incomes $z_{i t}^{0}$ were iid, there would be no point in using panel data.
} 
income share is due entirely to new tax filers who entered the high-income category in 1993 for reasons unrelated to the tax change and who were not part of the control group either (e.g., a student starting a successful new dot-com company), and that neither the top $1 \%$ income earners nor the next 9\% control group in 1992 experienced any change in income (absent the tax change). In that case, the repeated cross-section analysis is biased because of composition effects (that change the cross-section distribution of income for non-tax reasons), but the panel analysis is unbiased because (1) there is no mean reversion among the 1992 top 1\% income earners relative to the control group and (2) there is no change in inequality from 1992 to 1993 between the top 1\% and the control group defined based on 1992 incomes. Obviously these two assumptions never hold exactly, as there is substantial mobility with respect to the top 1\%. For example, Slemrod (1992) reports that in the 1980s, between 28 and $40 \%$ of the households in the top $1 \%$ were new from one year to the next.

Finally, panel data are required to study some questions other than the overall response of reported incomes. For example, if one wants to study how a tax change affects income mobility (for example, do more middle-income individuals become successful entrepreneurs following a tax rate cut?), panel data is clearly necessary.

In sum, those considerations lead us to conclude that the advantage of longitudinal analysis relative to repeated cross-section analysis has been exaggerated in the empirical literature following Feldstein (1995), especially when one wants to analyze tax changes happening primarily at the top of the income distribution. In that context, we believe that repeated cross-section analysis or share-based time-series analysis may be a more robust and transparent approach. ${ }^{52}$

\subsubsection{Short-term vs. long-term responses}

Figure 1 illustrates the difficulty of obtaining convincing estimates of the elasticity of reported income with respect to the net-of-tax rate. As we discussed above in our repeated cross-section analysis and as can be seen in Figure 1, the tax reform of 1993 seems to have generated a temporary decline in top 1\% incomes in 1993 and a temporary spike in 1992 as tax filers tried to pull reported taxable income from 1993 into 1992 to take advantage of the lower 1992 tax rate. As a result, the elasticity estimated using only the years 1992 and 1993 is large. For executives, Goolsbee (2000a) showed that indeed a significant fraction of the response was due to timing in the realization of stock-options by top executives, and Parcell (1995) and Sammartino and Weiner (1997) document the extent of year-end re-timing of taxable income. In that case, we would expect the long-term response to be much smaller. As Table 2, Panel A1

\footnotetext{
${ }^{52}$ Obviously, access to panel data is never worse than access to repeated cross-sectional data, as it is always possible to ignore the longitudinal aspect of panel data and carry out a repeated cross-section analysis with panel data.
} 
documented, using 1991 to 1994 in the basic repeated cross-section regression (13) generates a negative elasticity.

The central question is whether the clearly visible short-term responses persist over time. In particular, how should we interpret the continuing rise in top incomes after 1994? If one thinks that this surge is evidence of diverging trends between high-income individuals and the rest of the population independent of tax policy, then the long-term response to the tax change is arguably close to zero. Alternatively, one could argue that the surge in top incomes since the mid-1990s was the long-term consequence of the decrease in tax rates in the 1980s and that such a surge would not have occurred had high-income tax rates remained as high as they were in the 1960s and 1970s. It is unfortunately impossible to disentangle those various scenarios with a single time series of top incomes and top tax rates. As mentioned above, cross-country time-series analysis might be a fruitful area to make progress, taking advantage of varying time patterns of tax rate changes.

The literature on capital gains realizations has proposed dynamic micro-econometrics models in order to estimate simultaneously short-term and long-term responses to tax changes (see e.g., Burman and Randolph, 1994). In the case of the ETI, such explicit modelling has only been used in a few studies (Holmlund and Soderstrom, 2008, Giertz, 2008b, and Heim, 2007 and 2009). These papers augment the traditional panel specification (21) by adding a lagged change in marginal tax rate term (and sometimes a prospective rate change term). If some components of taxable income respond with a one-year lag then, in principle, the lagged term will capture this effect. This method could be useful to disentangle short-term from mediumterm responses, although compelling identification is difficult.

\subsubsection{Alternative control groups}

The tax code offers some possibilities to generate alternative control groups that might be more comparable to treatment groups than the lower-income groups used in the analysis above. For example, inflation (before the inflation adjustment of the tax schedule after TRA 1986) or the loss of a personal exemption can also push taxpayers into a higher bracket, and in some cases married and unmarried couples experience different changes in their tax schedules. Those changes have been explored by Saez (2003), Looney and Singhal (2006) and Singleton (2007), respectively. ${ }^{53}$ The advantage of those changes is that one can compare taxpayers who are very similar - but by being on opposite sides of a bracket threshold face different marginal tax rates - and hence potentially obtain a much more convincing identification.

\footnotetext{
${ }^{53}$ In Singleton's case, the focus is on individual earned income and EGTRRA's provision to reduce the marriage penalty. The provision substantially lowered marginal tax rates for some middle-income married couples, while not changing rates for single filers with similar incomes.
} 
The main drawback of this strategy is that taxpayers may not be aware of the minute details of the tax code, and hence might not respond to very localized changes in their marginal tax rate situation. As a result, elasticities obtained from those studies might not be relevant to predict behavioral responses to well-advertised, more salient, and broader tax rate changes. This lack of perfect information might also explain why there does not appear to be significant bunching at the kink points of the tax schedule (Saez 2009) as predicted in the standard model. ${ }^{54}$ Chetty et al. (2009) use Danish tax return data and show that large kinks generate disproportionately stronger bunching responses than small kinks, consistent with the the hypothesis that tax filers are not paying as much attention to small changes than to large changes. As a result, elasticities estimated from large changes may be larger than elasticities estimated from small changes, an important point formally developed in Chetty (2009). Second, from a modelling perspective, as informational considerations are a central aspect of the size of the behavioral response, it is important to develop models of how individuals learn about a budget set and its consequences for the optimal design of tax and transfer policies.

Tax response analysis thus faces this fundamental difficulty: large reforms are the most likely to be noticed and understood by taxpayers, but rarely generate fully convincing control groups for identification. Small reforms or quirks in the tax code can generate better control groups, but might not lead to meaningful, generalizable estimates if most taxpayers are not aware of such tax changes or provisions. ${ }^{55}$

\subsubsection{Tax base changes}

Although estimation of the ETI focuses on changes in the schedule of tax rates, the definition of the tax base subject to the rate schedule also changes periodically, often at the same time the rates change as part of comprehensive tax reform legislation. This raises a number of issues that are especially important when, as in TRA86, multiple tax base changes accompanied the tax rate changes, and are much less important for the 1993 change, when the top marginal tax rate changed with little base definition change. That tax rates changes often coincide with changes in the definition of taxable income is not a coincidence, because the theme of many income tax reforms since the 1980s has been to broaden the tax base and lower the rates applied to the base in a revenue-neutral way.

First, identifying the taxable income elasticity when the tax base changes becomes problematic because the taxable income elasticity is plausibly different in the post-reform era compared

\footnotetext{
${ }^{54}$ Chetty and Saez (2009) show that providing information to EITC recipients does produce changes in subsequent reported incomes, indicating that tax filers do not have perfect information about the tax system.

${ }^{55}$ Chetty (2009) develops an econometric method to set bounds on elasticities when responses are incomplete due to lack of awareness from tax filers.
} 
to the pre-reform era. For example, TRA86 broadened the tax base by both reducing deductions and the attractiveness of tax "shelters." It is likely that, due to these changes, the taxable income elasticity post-TRA86 was lower than pre-TRA86, as documented by Kopczuk (2005). In this situation even an otherwise well-specified estimation strategy will yield an estimate of neither the pre- nor post-reform elasticity, but rather a weighted average of the two, where the weights need not be positive.

Second, when the definition of the tax base changes, using as the dependent variable a concurrent definition of taxable income runs the risk of confounding tax-induced changes in behavior with purely definitional changes. For example, the base broadening of TRA86 would, ceteris paribus, show taxable incomes to have increased, perhaps to different degrees at different income levels. ${ }^{56}$ This problem suggests using either a consistent pre- or post-reform definition. $^{57}$ When the issue is changing deductions or credits, for data availability reasons it is generally easier to use the broader definition (i.e., not net of the deductions), because otherwise the investigator needs, but will not have, measures of deductions or credits that are not reported in the year with the broader base; the argument is reversed when new sources of income are added to the tax base. Because the former type of broadening was more prevalent, those studying TRA 86 have attempted to analyze a post-TRA86 definition of taxable income; this cannot, though, be done in a completely satisfactory manner.

Even if a consistent measure of taxable income could be constructed, the choice of which constant-law definition of taxable income to use is by no means an innocuous one. ${ }^{58}$ If the objective is to estimate the leakage from a given base when the rate of tax is altered, either method has problems. As discussed in Auerbach and Slemrod (1997), the response to a reform that changes both the marginal tax rate and the tax base does not, without further assumptions, reveal the impact of a tax change for a given base. If the broader definition of taxable income is used, the measured response mixes two things: the response of the old base to an increase in the net-of-tax rate, and the response of the newly-included base to a decrease in the net-of-tax rate. The response of tax base to the decline in tax rate probably understates its response when the tax base is constant. On the other hand, the response of the pre-reform base will probably overestimate the partial elasticity of the base with respect to a change in the tax rate. Using a consistent post-reform definition will produce a change in

\footnotetext{
${ }^{56}$ This is why Slemrod (1996) adjusted downward the post-TRA86 Feenberg and Poterba (1993) measures of the high-income shares; otherwise, the change from including $40 \%$ of capital gains in taxable income in the years up to 1986 to $100 \%$ inclusion afterward would increase the measured high-income share even in the absence of any behavioral response.

${ }^{57}$ Alternatively one could, like Kopczuk (2005), employ a model where independent variables account for changes to the tax base.

${ }^{58} \mathrm{An}$ exception would be if the elasticity of substitution between activities whose tax status changes and those whose status does not change equals zero (Heim, 2007).
} 
taxable income that is less than what is obtained using the pre-reform definition.

An excellent example of this issue concerns interest deductions. TRA86 eliminated the deductibility of consumer interest, and Maki (1996) and others have noted that there was a large shift into still-deductible, and highly substitutable, home equity loans. Using the postTRA86 definition will include in the measured taxable income change the decline in consumer interest, and cause a downward bias in the estimate of the change in taxable income with respect to a tax rate change.

\subsection{Multiple tax rates: The special case of capital gains realizations}

Another complicating factor is capital gains. Although real accrued gains are income according to the Haig-Simons definition, those countries that tax capital gains at all do so upon realization (usually sale), and those countries that do tax realizations now generally subject them to a lower rate than applies to other income. In the United States, the extent of preferential tax has varied significantly since 1980. Before TRA86, 40\% of long-term gains were included in taxable income; with a top rate of $50 \%$, the top rate on realizations was $20 \%$. When the TRA 86 lowered the top rate to $28 \%$, the exclusion was eliminated, so that the top rate on long-term capital gains was also $28 \%$. Since TRA86, the top rate on ordinary income has risen and a preferential rate re-introduced; since 2003, the two rates have been $35 \%$ and $15 \%$, respectively. ${ }^{59}$

Almost all studies of the ETI in the U.S. have excluded capital gains realizations from the measure of taxable income or broad income, on the reasonable grounds that they are generally subject to a different marginal tax rate than other income. It is also true that they are especially responsive to anticipated changes in the applicable tax rate. (See Burman, Clausing and O'Hare, 1994).

Ignoring capital gains completely, though, raises some difficult issues. As background, in the United States, they constitute a very large fraction of the taxable income of the top income groups. ${ }^{60}$ Second, they fluctuate year-to-year much more than other income, both in the aggregate and, especially, for given taxpayers. Thus, for example, much of the year-to-year change in which taxpayers are in the top $1 \%$ income group, capital gains included, may be due to changes in capital gains realizations.

Taxpayers often have many opportunities for converting wage and salary income to capital gains income - and these opportunities are exercised when the tax advantages of so doing are

\footnotetext{
${ }^{59}$ Additionally, many gains that accrue as tax-preferred savings are never taxed, as is the case for savings in $401 \mathrm{k}$ plans, IRAs and the various education savings accounts.

${ }^{60}$ In 2005, for example, for taxpayers with AGI exceeding $\$ 500,000$, who represent just less than $1 \%$ of all taxable returns, taxable net capital gain comprised $33.3 \%$ of AGI, compared to $3.8 \%$ of AGI for all other taxable returns.
} 
sufficient. Because the tax advantage depends on the differential between the rate on ordinary income and capital gains, this rate matters and should ideally be controlled for in analyses of how the tax rate on ordinary income affects the reported amount of ordinary income. Furthermore, converting ordinary income to capital gains income often is accompanied by deferral of the realization of the latter for tax purposes, so the offsetting revenue may not come for several years, if ever.

In microeconometric analysis, the standard procedure is to calculate the marginal tax rate on ordinary income assuming no capital gains income. This would be appropriate if decisions that trigger ordinary income were made before decisions regarding capital gains realizations, but this is unrealistic and thus this procedure causes error in measuring the actual MTR.

The same issues arise in share analysis. Slemrod (1996) includes capital gains in his measure of adjusted gross income, and includes as explanatory variables the top rates on both ordinary income and capital gains. He finds no evidence that a higher capital gains tax rate is associated with a higher share of wages and salaries, though. ${ }^{61}$

In a related model with individual-level data, Hall and Liebman (2000) and Eissa and Giertz (2007) examine the relationship between corporate, personal income and capital gains tax rates and the share of compensation that CEOs and other executives receive in the form of stock options. Over the past couple of decades, stock options have been the largest source of growth in compensation for top executives (Murphy, 1999). While Hall and Liebman (2000) show that the advantages of paying executives with stock options are directly related to the capital gains tax rate and inversely related to the corporate and personal income tax rates, neither their paper nor Giertz and Eissa's reports well-identified estimates for the magnitude of the income shifting.

Ideally, one would need a model of joint determination of capital gains and ordinary income as a function of the marginal tax rates on capital gains and ordinary income in the general methodology of the elasticity of taxable income.

\subsection{Income Shifting: The Anatomy of Behavioral Responses}

We have seen in the previous section that estimating taxable income elasticities in a fully convincing way is challenging because of the difficulty of untangling tax-related from nontax-related changes in reported incomes. Furthermore, our conceptual analysis in Section 2 showed that, in addition to measuring the reported income elasticity, to obtain a welfarerelevant elasticity it is important to assess fiscal externalities. A way to make progress on

\footnotetext{
${ }^{61} \mathrm{Saez}(2004)$ excludes capital gains from his measure of adjusted gross income and does not include a measure of the tax rate applying to capital gains in his analysis.
} 
those two issues is to analyze the "anatomy of the behavioral response" (Slemrod, 1996) by examining the components of reported income.

Figure 2 (updated from Saez 2004) displays the share and composition of the top $0.01 \%$ income earners in the U.S. since the 1960s along with the average marginal tax rate they face (in bold line on the right $\mathrm{y}$-axis). We focus on this very top group because tax rate changes and tax responses are the strongest and most salient at the very top. We have divided income into seven income components: (1) wages and salaries (which include bonuses and profits from exercised stock options), (2) dividends, (3) interest income, (4) sole proprietorship profits (profits from small businesses that are fully owned by the taxpayer, this includes most forms of self-employment income), (5) partnership profits (profits from businesses where the taxpayer is a partner such as a law or medical practice partnership), (6) profits from subchapter $\mathrm{S}$ corporations, and (7) other income. Subchapter S corporations (as opposed to subchapter C corporations) are corporations which are not subject to the corporate income tax and whose profits are taxable directly and solely at the individual level (on the individual income tax returns of owners). Hence S-corporations do not face the double tax of regular C-corporations (C-corporations pay the corporate income tax on their profits.)

Four points are worth noting about Figure 2. First, the top $0.01 \%$ income earners faced extremely high marginal tax rates in the early 1960s (around 80\%) which were reduced significantly by the Kennedy tax cuts in 1964-5 (to about 65\%). This implies a $75 \%$ increase in the net-of-tax rate, a much larger increase than the ERTA 1981 and TRA 1986 tax rate reductions. In spite of this large rate cut, the top $0.01 \%$ income share remains flat in the 1960s, and well into the 1970s, suggesting a complete absence of behavioral response in both the short and the long run. This stands in contrast to the sharp response of the top $0.01 \%$ income share to the 1981 and 1986 tax changes, consistent with the view that the elasticity is not an immutable parameter but instead depends on the tax system.

Second, Figure 2 shows clearly that about one-third of the response to the Tax Reform Act of 1986 from 1986 to 1988 is due to a surge in S-corporation income. ${ }^{62}$ Partnership income also rose dramatically immediately after TRA 1986, mostly because of the disappearance of partnership losses. The sudden jump in S-corporation income, exactly at the time of the tax reform, strongly suggests that this was the consequence of a one-time shift of taxable income from the corporate sector, and the one-time closing of the partnership loss tax shelters (Slemrod 1996, Gordon and Slemrod 2000). The surge in business income reported on individual returns in the 1980s thus cannot be interpreted as a "supply-side" success, as most of those individual income gains came either at the expense of taxable corporate income, or were obtained from

\footnotetext{
${ }^{62}$ ERTA 1981 also produced a sudden increase of S-corporation income (which was negligible up to 1981), which explains most of the increase in top incomes from 1981 to 1984, first documented by Lindsey (1987).
} 
the closing of tax shelters by imposing stricter rules on losses from passive businesses.

Third, Figure 2 displays a dramatic shift in the composition of very top incomes away from dividends (which represented more than $60 \%$ of top incomes in the early 1960s) toward wage income and S-corporation and partnership income. In the early $1960 \mathrm{~s}$, the top $0.01 \%$ incomes were facing extremely high marginal tax rates of about $80 \%$ on average, while tax rates on long-term capital gains were around $25 \%$. Thus, dividends were a very disadvantaged form of income for the rich, suggesting that those top income earners had little control over the form of payment, and thus might have been in large part passive investors. The Kennedy tax cuts apparently did not reduce the top individual rate enough (the top rate became $70 \%$ ) to make the S-corporation form attractive relative to the C-corporation form, explaining perhaps the contrast in behavioral responses between the Kennedy tax cuts episodes and the tax changes of the 1980s. Interestingly, Figure 2 also displays an increase in the dividend income component after 2003 , when the tax rate on dividend income was lowered to $15 \%{ }^{63}$

Fourth and related, the wage income component of the top $0.01 \%$ has experienced a dramatic secular growth since the 1970s. The wage component exhibits clear spikes in 1988 and 1992, which are likely to reflect short-term responses to the tax changes due to re-timing of compensation. ${ }^{64}$ The difficult question to resolve is whether the secular growth in top wage incomes is due to the dramatic decline in top marginal tax rates since the 1960s. This question cannot be resolved solely looking at U.S. evidence. Evidence from other countries on the pattern of top incomes and top tax rates (Atkinson and Piketty, 2007, 2010) suggests that reducing top tax rates to levels below $50 \%$ is a necessary - but not sufficient - condition to produce a surge in top incomes. Countries such as the United States or the United Kingdom have experienced both a dramatic reduction in top tax rates and a surge in top incomes (Brewer, Saez and Shephard, 2008), while other countries such as Japan have also experienced significant declines in top tax rates but no comparable surge in top incomes over recent decades (Moriguchi and Saez, 2008).

Overall, the compositional graph displayed on Figure 2 casts significant light on the anatomy of the behavioral response and allows us to distinguish short-term from long-term effects, as well as effects due to income shifting from the corporate base to the individual base or due to tighter regulations regarding business losses. Therefore, we believe that moving away from the "taxable income elasticity" paradigm and (back) to a more granular understanding of the various components of behavioral responses to taxation is fruitful both to predict the

\footnotetext{
${ }^{63}$ This is consistent with the firm-based analysis of Chetty and Saez (2005) who show that dividends paid out by publicly traded US companies rose sharply after the dividend tax cut was enacted.

${ }^{64}$ There is also a very large spike in 2000 that is likely due to the boom and bust in the dot-com sector, where stock-option exercises peaked in 2000 before collapsing in 2001 and 2002.
} 
effects of future tax reforms as well as to analyze the overall welfare and fiscal consequences of actual tax changes.

\section{Empirical Analysis}

Most of the empirical literature on the ETI has focused on individual taxable income in the U.S., although some studies have examined individual taxable income in Canada and Western Europe. ${ }^{65}$ To examine the literature and investigate the challenges associated with attempts to estimate the ETI, we first review those studies that analyze legislated changes in U.S. federal (and to a lesser extent, state) marginal tax rates. In the next subsection, we consider unlegislated variation in U.S. tax rates, which both solves some issues inherent in analyzing legislated tax rate changes and creates new difficulties. Then we examine studies that have estimated the ETI for other countries. We emphasize how, and how well, each study addresses the methodological issues discussed in the previous section.

\subsection{Empirical Analysis based on U.S. Legislated Tax Changes}

\subsubsection{Analysis Using Repeated-Cross-Section Data}

Lindsey (1987) was the first to estimate something akin to an elasticity of taxable income (although his income measure is actually much closer to AGI). ${ }^{66}$ He uses repeated cross-sections of tax return data from 1979 to make post-ERTA projections of the income distribution based on pre-ERTA law and the macroeconomic conditions existing in the intervening years. Lindsey splits the data into income groups and regresses the log deviations of average income (relative to projected average income assuming no tax change) on the log change in the group average net-of-tax rate. His core estimates of the ETI lie between 1.6 and 1.8, and finds evidence suggesting that higher-income groups have higher elasticities. This methodology is essentially a difference-in-difference method based on income shares. Very large elasticities are obtained because top incomes grew faster than lower incomes from 1981 to 1984 (as we showed in Figure 1). The key identification assumption is that absent the tax change, the income distribution

\footnotetext{
${ }^{65}$ See Gruber and Rauh (2007) for an estimate of the elasticity of reported corporate income that uses data from Compustat for 1960 to 2003 and a methodology similar to that of Gruber and Saez (2002). There is little graduation in marginal tax rates for corporate income, so variation is achieved by constructing a marginal effective tax rate for each industry. They regress log income for each industry against the instrumented log of the effective tax rate, year dummies (after first-differencing, consecutive years' data), and a 10-piece lagged-income spline. Their baseline ETI estimate for corporate taxable income is 0.2 .

${ }^{66}$ Although he acknlowledges that a number of others, including Minarik (1984) and Simonson (1984a,b), had noted that the share of taxable income reported by high-income taxpayers rose after ERTA reduced the top marginal tax rate.
} 
would not have changed (except for the macro-economic aggregates Lindsey controls for). ${ }^{67}$

For the most part, repeated-cross-section data have not been used to estimate the ETI since Lindsey (1987). One exception is Goolsbee (1999), who uses it to investigate the ETI for key U.S. tax changes from 1920 to 1966 (excluding those during World War II). Returnlevel data are not available for this time period, so Goolsbee uses aggregated data. ${ }^{68} \mathrm{He}$ employs two different methods to estimate the ETI-tabulated difference-in-differences, and a regression-based strategy.

In the regression-based strategy, he regresses the change in log income against the change in the log average net-of-tax rate by income group. As a benchmark, he first applies this methodology to TRA 86, and obtains an estimate of the ETI of approximately 1 . For the five episodes between 1920 and 1966, he finds ETI estimates ranging from -0.83 to 0.59, and for several episodes the ETI is not significantly different from zero. Goolsbee speculates that the smaller ETI estimates prior to 1980 are due both to increases in the true ETI over time due to "institutional or other factors" as well as the importance of particular upward biases affecting ETI estimates based on the tax changes in the 1980s, discussed later.

\subsubsection{Analysis Using Aggregated Time-Series Data}

Feenberg and Poterba (1993) were the first to use aggregate tax return data to shed light on the high-income share of reported aggregate income in the United States and to what extent this might be influenced by changes in the tax rate structure. They calculate for 1951 to 1990 the share of AGI and several components of AGI that were received by the top $0.5 \%$ of households ranked by AGI. Consistently with Figure 1 reported in Section 3.3, the four-decade time series is sharply U-shaped, beginning with a steady decline from over $8 \%$ in the early 1950s to just below $6 \%$ around 1970. Then, after being approximately flat at about $6.0 \%$ from 1970 to 1981, the high-income share of income begins in 1982 to increase continuously to $7.7 \%$ in 1985, then jumps sharply in 1986 to $9.2 \%$. There is a slight increase in 1987 to $9.5 \%$, then another sharp increase in 1988 to $12.1 \%$. Although they conduct no formal analysis of

\footnotetext{
${ }^{67}$ Interestingly, Navratil (1995a) re-examines the analysis of Lindsey using the Continuous Work History Sample (CWHS) panel (see Appendix B.1) of tax returns for years 1979 to 1981 and 1983 . In one exercise, Navratil treats different years of his panel as repeated cross-sections and estimates an elasticity of 1.99 (similar to Lindsey's estimates). When exploiting the properties of the panel, though, Navratil reports much smaller estimates, ranging from 0.78 to 0.84 , with an estimated ETI of 1.38 for those in the top rate bracket. This illustrates well the issue of mean reversion we discussed in Section 3: top incomes did not increase as much in the panel as in the repeated cross-section.

${ }^{68}$ Goolsbee interpolates portions of the income distribution as necessary by assuming a Pareto distribution. He studies taxable income, but in his interpolation holds the relationship between taxable income and AGI constant, which forces deduction and itemization responses to be constant over time. Thus, his results are effectively for AGI. Note that the literature is not very strict in its income definition when measuring the ETI, and papers focusing on AGI (as opposed to taxable income) often refer to their results as estimated ETIs.
} 
the data they calculate, Feenberg and Poterba (1993) argue that the time-series pattern they find is consistent with a behavioral response to the reductions in the top marginal tax rate, especially during the TRA 86 episode.

Slemrod (1996) uses high-income share data for 1954 to $1990^{69}$ to examine in a regression framework the tax and non-tax causes of inequality. The data up to 1986 are taken directly from Feenberg and Poterba (1993), but the data from 1987 to 1990 are adjusted to correspond to a pre-TRA 86 definition of AGI so as to get closer to a consistent definition over time. Dependent variables studied include the high-income share of AGI and four components of income. Explanatory variables in the regressions include measures of the contemporaneous, one-year-lagged, and one-year-leading top tax rates for both ordinary individual income and long-term capital gains. ${ }^{70}$ To control for exogenous, non-tax-related, income trends, also included are a measure of earnings inequality between the 90 th and 10th percentiles not based on tax return data and some macroeconomic variables that might differentially influence incomes at different percentiles (the real level of stock prices and the average nominal corporate AAA bond rate). He separately performs regressions for the years up to 1985 and for the years up to 1990 to investigate whether or not there was a break in the structure of the model in 1986.

Consistent with the evidence we reported on Figure 1 in Section 3.3, Slemrod (1996) finds that up to 1985 decreases in the top tax rate on individual income play almost no role in explaining the variation in the high-income share of AGI; indeed, more than two-fifths of the increase in high-income share between 1973 and 1985 can be associated with the increase in 90-10 wage inequality. However, when data up to 1990 are included in the regression, the coefficient on the top tax rate term becomes large in absolute value and significant.

After analyzing different pieces of AGI, including wages and salaries, Subchapter S income, and partnerships, Slemrod (1996) concludes that the regression results point to the impact of the new tax base structure instituted by TRA 86 . This new structure provided very different incentives and opportunities for high-income individuals to report income (and losses) via the individual tax system. He cautions that the results do not necessarily imply that taxpayer response to marginal tax rates, holding the structure constant, was higher post-TRA 86. Instead the tax rate variables, which changed dramatically at the same time the structure changed, are picking up some of the effect of this structural change. ${ }^{71}$ Because of the simultaneity of the tax rate changes and scores of tax base changes, the high tax rate elasticity estimated over the sample up to 1990 is not an unbiased estimate of the true elasticity, either before or after

\footnotetext{
${ }^{69}$ Slemrod examines both the top $0.5 \%$ as well as the top $1 \%$ of taxpayers, although all regressions exclusively use the top $0.5 \%$.

${ }^{70}$ For individual income, he uses the AGI-weighted difference between the tax rate for the top $0.5 \%$ and the rate for everyone else. For capital gains, only the maximum rate is used.

${ }^{71}$ Fullerton (1996), in a comment on Slemrod (1996), emphasized this interpretation.
} 
the reform.

Saez (2004) examines IRS data from 1960 to $2000 .{ }^{72}$ He runs regressions of top $1 \% \log$ average income on the log average net-of-tax rate for the top $1 \%$ over the time period. Consistently with our findings from Section 3.3 (Table 1), he finds large elasticities, even when including time trends or instrumenting the log net-of-tax rate using the statutory top marginal tax rate.

Saez (2004) goes on to investigate which categories of his income measure are responsible for its size, primarily in order to ascertain to what extent the estimated ETIs reflect income shifting. He, like Slemrod (1996), finds a break in the series following TRA86. When he examines categories of gross income, he finds that income shifting can explain most of the rise in Subchapter S and partnership income. What remains unclear is whether any portion of the wage and salary growth is attributable to the marginal decline in taxes, or is simply another form of income shifting. Saez concludes that it is very difficult to distinguish the long-term effect of tax cuts from a non-tax related secular widening in the disparity of earnings.

\subsubsection{Analysis using panel data}

The seminal study using panel data was Feldstein (1995), who investigated the response to TRA 86 using the U.S. public-use panel tax data (see Appendix B.1). ${ }^{73}$ Feldstein (1995) groups taxpayers by their 1985 marginal tax rates and uses a tabulated difference-in-differences methodology to estimate the ETI with respect to the net-of-tax rate. Specifically, to compute elasticities the percentage change in taxable income (relative to adjusted 1985 income) in each group is compared to the change in the average net-of-tax-rate in each group. Feldstein obtains large ETI estimates, ranging from 1 to 3 in alternative specifications. Although based on a much smaller sample (Feldstein's top group included only 57 tax returns), the Feldstein (1995) results apparently corroborated the conclusion of Feenberg and Poterba (1993) based on observing the time-series of share-of-income data that something extraordinary had happened to the dispersion of taxable income at the same time as TRA86.

Auten and Carroll (1995) reexamine and build directly on Feldstein's analysis of TRA86 using the much larger panel data available within Treasury (see appendix B.1). They compare

\footnotetext{
${ }^{72}$ To obtain a consistent income definition, he excludes capital gains and government transfers (note that this is an even broader measure than AGI). Slemrod (1996) excludes capital gains but analyzes capital gains separately; Feenberg and Poterba (1993) begin their analysis with an income definition that includes capital gains but, after noting problems with its inclusion, conduct analysis that excludes capital gains from the income definition.

${ }^{73}$ In his sample, Feldstein includes only married taxpayers filing jointly who were under age 65 in 1988 and for whom both 1985 and 1988 tax returns are available. Those with incomes below $\$ 21,020$ in 1985 are not included in the sample. Individuals who filed Subchapter S income only in 1988 are also excluded. Capital gains are excluded. There were also other miscellaneous adjustments. This leaves less than 4000 observations.
} 
tax returns in 1989 and 1985. ${ }^{74}$ Auten and Carroll find that moving from the small publicly available sample Feldstein used to the much larger sample they can use reduces substantially the estimated elasticities from around 2 to around 0.60 for taxable income (even using exactly the same regression based methodology). However, even with the richer dataset, Auten and Carroll note that their ETI estimates are "highly sensitive" to specification decisions regarding whether to weight observations by income or by population. For example, with the full set of controls, the elasticity of taxable income is 1.09 when population-weighted, and 0.60 when income-weighted. For the elasticity of AGI, the estimates are 0.90 and -0.09 , respectively. ${ }^{75}$

In another reexamination of Feldstein (1995), Navratil (1995b) made the point discussed in Section 3.4.2 that Feldstein's difference-in-difference approach is sensitive to the choice of groups and critically assumes that elasticities are constant across groups. In order to relax the assumption of equal elasticities across income groups, Navratil looks at the same group of taxpayers before and after TRA 86, but instead of using another income group for comparison, he uses a similarly defined group over a period where tax rates did not change. Consistently with our description in Section 3.3, Navratil reports estimated ETIs as high as 1 for the top $3 \%$ of the income distribution, but much smaller estimates for the rest of the distribution. The population-weighted average ETI estimate is 0.37. Navratil's estimates are, however, sensitive to the choice of comparison years and to the definition of taxable income.

Subsequent research using panel data focused on addressing issues such as mean reversion, marginal tax rate endogeneity, and secular income trends, which likely plagued some of the earlier studies. Auten and Carroll (1999) address mean reversion and attempt to control for divergence within the income distribution by including control variables for region and occupation. Auten and Carroll adopt a two-stage least-squares regression approach, regressing the change in constant-law (log) AGI ${ }^{76}$ between 1985 and 1989 against the change in the log of the net-of-tax rate and a set of other exogenous variables. They instrument for the change in the net-of-tax rate by inflating adjusted 1985 incomes by the CPI to 1989 levels and then applying 1989 law to these incomes, as discussed in Section 3.4.2. ${ }^{77}$ When adding non-tax factors that may have been correlated with the rise in income inequality over this period (such as age, age-squared, occupation, region, and notably 1985 income), they report an elasticity

\footnotetext{
${ }^{74}$ The sample includes only married taxpayers filing joint returns, ages 25 to 55 , who were at or above the $22 \%$ marginal tax bracket (i.e., at least $\$ 21,020$ joint, $\$ 15,610$ single) in 1985 . Also excluded are AMT filers and those who report Subchapter S income in 1989, but not in 1985.

${ }^{75}$ Interestingly, their population-weighted estimates are higher than the income-weighted estimates. The opposite is found in most other studies that have produced both population- and income-weighted estimates.

${ }^{76}$ The constant-law calculations are based on post-TRA 86. They do a robustness test and find that using pre-TRA 86 laws does not significantly change the results.

${ }^{77}$ They calculate this by inflating 1985 taxable income to 1989 and calculating the corresponding tax rates under 1989 law using the NBER TAXSIM tax calculator. For an overview of TAXSIM, see Feenberg and Coutts (1993).
} 
estimate of 0.55. However, when employing the inverted panel approach (discussed in Section 4), their estimate doubles to 1.13. This result is consistent with mean reversion, as their estimate is much larger when the data ordering simulates a tax increase (or a rising NTR). As discussed in Section 3.4.2, no fully convincing estimate of the ETI can be obtained using only two years of data when tax rate changes are concentrated at the top.

Carroll (1998) applies a similar methodology to the tax increases of the 1990s - OBRA 90 and OBRA 93. He uses the SOI data set for a group of taxpayers from 1989 to $1995{ }^{78}$ Because these tax acts did not include many base changes, examining this time period eliminates issues associated with concurrent tax base definition changes that complicate analysis of TRA 86 . He uses year-to-year (log) income changes as his dependent variable (i.e., he differences over one-year intervals). Although he emphasizes the value of looking at pairs of years both with and without intervening tax rate changes, focusing on one-year changes also likely means that his estimates are capturing transitory responses as opposed to longer-term shifts in behavior.

To control for tax-rate endogeneity, Carroll estimates 2SLS regressions, basing his instrument on the tax rate corresponding to each filer's average income over the seven-year period, meant to proxy for permanent income. Note, however, that this instrument is a function of post-reform income and hence is endogenous, as discussed in Section 3.4.2. To control for non-tax factors, he includes year dummies, age, age-squared, occupation, region, financial wealth, and the number of dependent children. The resulting elasticity estimate is 0.38 for adjusted taxable income and 0.32 for gross income; excluding more returns at the low end of the distribution by raising the exclusion to $\$ 75,000$ increases the estimated elasticity to 0.56 .

Both Auten and Carroll (1999) and Carroll (1998) use dummy variables for occupation as a control for non-tax factors that might have differentially affected income growth over the period spanning the tax change. The idea is that a differing occupational mix may explain a given income group's different percentage change in taxable income. However, to the extent that one's occupation reflects the flexibility to alter work schedules or compensation arrangements in response to tax rate changes (i.e., different elasticities), inclusion of these variables may affect the interpretation of the estimated elasticity. By interacting the occupation dummies with the net-of-tax rate, Auten and Carroll produce estimated elasticities that are allowed to differ by occupation. In fact, the estimated elasticities do vary greatly by occupation, being as high as 2.9 for "investors," 1.65 for the self-employed and farmers, and 1.63 for executives and managers. ${ }^{79}$

\footnotetext{
${ }^{78}$ Prior to Carroll, Sammartino and Weiner (1997) analyze a panel of tax returns from 1989 to 1994 and find large transitory responses (of AGI) surrounding the tax acts of the 1990s, but conclude that longer-term responses are likely much smaller. They do not, though, estimate taxable income elasticities.

${ }^{79}$ Note, however, these interacted estimates are only reported for gross (and not taxable) income.
} 
Moffitt and Wilhelm (2000) investigate behavioral responses to TRA 86, using panel data from the 1983 and 1989 Survey of Consumer Finances (SCF) instead of income tax return data. ${ }^{80}$ Due to data limitations, they study an income concept close to AGI rather than taxable income. When using Feldstein's (1995) approach, they report tax elasticities for AGI from 1.76 to 1.99, similar to Feldstein's taxable income elasticity estimates. Moffitt and Wilhelm then turn to a two-stage least-squares regression approach, employing several alternative instruments for the change in the net-of-tax rate, ${ }^{81}$ including education and measures of illiquid assets, and conclude that those instruments that are successful in discriminating between the high-income group and the balance of the population yield tax elasticity estimates that range from 0.35 to 0.97. As Auten and Carroll (1999), such estimates based on comparing only 2 years are sensitive to mean reversion. Indeed, when including 1983 AGI as a control for mean reversion, their elasticities increase by between 0.3 and 0.5 ; recall that TRA86 compressed MTRs, so mean reversion biases downward estimated ETIs. Because SCF data include labor supply measures (hours of work), they also estimate labor supply response and conclude that the surge in the taxable income of high-income individuals between 1983 and 1989 was not accompanied by an increase in reported hours of work.

Gruber and Saez (2002) use the public-use version of the CWHS panel for the years 1979 to 1990 to examine taxable income responses to both ERTA and TRA $86{ }^{82}$ They study the response of two different measures of income. The first is called "broad income," which equals AGI plus "adjustments" such as IRA contributions, but it does not include capital gains. The other is a concept close to taxable income that accounts for itemized deductions and adjustments that are reported for all years from 1979 to 1990, but also does not include capital gains. They measure behavioral changes (between paired observations) over three-year intervals, which provides them with variation in tax rates across time for all income levels. Furthermore, because they incorporate state as well as federal income tax changes, they also have cross-sectional variations in tax rate changes within income groups. ${ }^{83}$

Gruber and Saez devote much attention to the issues of mean reversion and secular income trends, and separately estimate income and substitution effects of the tax change. They

\footnotetext{
${ }^{80}$ They limit their data set to male heads of household, ages 25 to 53 in 1983, who worked over 200 hours, and who also appear in the 1989 sample. For their analysis, they also restrict the sample to observations with positive AGI, and a marginal tax rate above 0.2 . Their resulting sample size is 406 .

${ }^{81}$ Because it has much richer demographic information than the tax-return data, the SCF data set provides a much wider range of potential instruments for the net-of-tax rate.

${ }^{82}$ They exclude filers below $\$ 10,000$ in the first year of the difference to control for mean reversion. Filers are not necessarily the same for all nine years. Thus, they can include only filers for which they can construct at least one three-year difference. In total, the nine sets of differences provide approximately 100,000 observations. They make no exclusions for changes in Subchapter S income across years.

${ }^{83}$ Auten and Carroll (1995 and 1999) also used state tax rates, but it mattered little because they were still only using two years of data.
} 
instrument for the change in the net-of-tax rate using an instrument very similar to that used by Auten and Carroll (1999): the change in the net-of-tax rate assuming each filer's income grows at the rate of the overall nominal income growth between the base and subsequent year. They also construct an analogous instrument for capturing the income effect. They include the change in the log of after-tax income as an explanatory variable, but instrument for it using the log change in after-tax income again assuming that base year income grows at the same rate as total income. The second stage regresses the log of (taxable or broad) income growth against the change in the log of the after-tax rate, year fixed effects, and dummies for marital status. As they use multiple years simultaneously, they can include a rich set of controls for base income.

Looking at other income definitions, and analyzing subsets of their overall results gives further insight into the behavioral response to tax changes. Gruber and Saez's elasticity estimate for broad income, 0.12 , is much smaller than their corresponding estimate for taxable income, suggesting that much of the taxable income response comes through deductions, exemptions, and exclusions. Additionally, they find that most of the response can be attributed to itemizers (for taxable income, the elasticity is 0.647 , whereas for non-itemizers, it is negative and insignificant). Although estimates by income group are not statistically distinguishable from each other, they do vary greatly and are generally higher for higher-income taxpayers $(0.57$ for people with incomes over $\$ 100,000,0.11$ for those from $\$ 50,000-\$ 100,000$ and 0.18 for those with income from $\$ 10,000$ to $\$ 50,000)$.

Kopczuk (2005) analyzes the 1979 to 1990 public-use version of the CWHS panel to investigate the hypothesis that the ETI is not a structural parameter, but rather a function of the tax base (which he defines as taxable income divided by total income). Available deductions lower the cost of shifting income outside the tax base; as the tax base becomes smaller, responsiveness to changes in tax rates increases. After first-differencing (he uses three-year intervals, following the methodology of Gruber and Saez (2002)), he uses a two-stage least-squares approach with instruments for both the change in the log net-of-tax rate and for the interaction of that variable with the share of income that is deductible. For instruments, he uses the log of the predicted changes of these variables, absent any behavioral response. Including both the instrumented changes in marginal tax rates and an interaction term between the change in tax rate and change in tax base, generates estimates for the elasticity of broad income of 0.003 and 0.727 , respectively. For taxable income, the respective income-weighted elasticities are 0.123 and $1.063 .^{84}$ Kopczuk (2005) concludes that "these results imply that an individual

\footnotetext{
${ }^{84}$ All of these elasticities are with respect to married filers only. Kopczuk excludes single filers, noting that the results for singles are highly unstable, with the estimates of the direct elasticity and the interaction term varying widely in subsamples and always insignificant.
} 
who has no access to any deductions would not respond to changes in the tax rates. The more deductions are available, the stronger the response."

Kopczuk (2005) also examines the robustness of previous estimates to changes in the estimation method. He finds for a given specification that imposing different sample income floors (based on those used in other published papers) generates a wide range of reasonable values; excluding taxpayers with incomes below $\$ 10,000$ (Gruber and Saez's restriction) results in an elasticity of 0.36 ; excluding those with tax rates below $22 \%$ ( $\$ 21,020$ for joint filers) yields an elasticity of 0.82. Making no sample restrictions gives an elasticity of 2.3 and increasing the restriction to $\$ 30,000$ gives estimates of essentially zero. As we discussed in Section 3.4.2, this lack of robustness to bottom trimming is probably due to the log-income specification combined with the fact that many low-income earners experience very large percentage changes in income over time.

Giertz (2007) applies the methods of Gruber and Saez (2002) to larger panel data sets of tax returns from 1979 to 2001 available only within government agencies (see appendix B.1). Using first the data from the Continuous Work History Survey (CWHS) which does not oversample higher income earners, he shows that Gruber and Saez's approach yields an estimated elasticity of taxable income (ETI) for the 1990s of 0.20 - or about half the size of the corresponding estimate for the 1980s. However, when he uses broad income, instead of taxable income, the estimated elasticity is 0.15 , as opposed to 0.12 for the $1980 \mathrm{~s}$. This significant difference between the taxable income estimates and small difference between the broad income estimates is consistent with the results from Kopczuk (2005), suggesting that the availability of deductions and exemptions matter in determining the ETI. Indeed, the fraction of taxpayers choosing to itemize was approximately $25 \%$ lower at the time of OBRA 93 compared to TRA 86. Calculating the ETI for 1979 to 2001, Giertz obtains an estimate of 0.30 .

Following Kopczuk (2005), Giertz includes separate and nonlinear controls for mean reversion and divergence within the income distribution. This explains about one-third of the difference between the 1980s and 1990s estimates, lowering the SOI-based 1980s estimate from 0.43 to 0.40 and raising the 1990s estimate to 0.26. Additionally, Kopczuk's work implies that changes to the tax base since 1986 could account for 14 to $29 \%$ of the remaining difference.

When Giertz (2007, 2008a) uses the full SOI data set, which oversamples high-income earners, (see appendix B.1) to calculate the estimate for the 1990s tax changes, he finds (when employing the same specification) estimates of 0.30 and 0.20 when he examines the years 1989 to 1995 and 1988 to 2001, respectively. The corresponding estimates for broad income are 0.20 and 0.13 (the first is strongly significant, whereas the second is not statistically different 
from zero). Giertz hypothesizes that the year choice affects estimates by altering the baseline income trend. For example, if the income growth for upper-income filers (relative to lowerincome filers) moderated during those years, then the spline coefficients might be affected. That could result in a flatter baseline income trend, which would result in lower estimated responses. As we discussed in Section 3.4.2, having a set of controls for base-year income eliminates bias in the estimation only if changes in mean reversion or income inequality are stable over the time period studied.

Both Heim (2009) and Auten, Carroll and Gee (2008) examine the elasticity of taxable income for the U.S. Economic Growth and Tax Relief Reconciliation Act of 2001 (EGTRRA) and the Jobs and Growth Tax Relief Reconciliation Act of 2003 (JGTRRA). Unfortunately for identification purposes, the variation in the marginal tax rates for these two acts was much lower than the tax acts in the 1980s and 1990s. The authors acknowledge this, and use state as well as federal income tax variation to provide an additional source of identification. The primary estimation method for both papers is based on the approach used in Gruber and Saez (2002). ${ }^{85}$ In contrast to Gruber and Saez, Auten, Carroll and Gee include only a base-year income control for mean reversion rather than a spline. ${ }^{86}$ Heim builds on Gruber and Saez by adding controls for adjacent year income shifting. Auten, Carroll and Gee include control variables very similar to Auten and Carroll (1999). Under their initial specification, they estimate a statistically significant ETI of 0.39 . In contrast to this, when employing a $\$ 50,000$ cutoff (applying to the earlier year of each paired observation), Heim reports a statistically insignificant ETI estimate of 0.22 ; however, this estimate is based on a model that includes a 10 -piece spline. When including those with incomes less than $\$ 50,000$, Heim's estimated ETI increases to 0.32 and is now statistically significant. Heim's results are fairly robust to the inclusion of controls for adjacent year income shifting - i.e., income shifting that would affect income in either year for each paired (or differenced) observation. When Auten, Carroll and Gee compare income changes between end years 2000 and 2005, their ETI estimate rises to 0.67 . Their results are quite robust to the income cutoff, in contrast to what much of the literature finds. For example, changing the income cutoff from $\$ 50,000$ to $\$ 15,000$ decreases the estimated ETI to 0.16, but it remains positive and statistically significant, unlike similar analyses in Kopczuk (2005). Heim also presents ETI estimates for various income groups by

\footnotetext{
${ }^{85}$ Both studies exclude capital gains from income measures and use SOI panel data sets for years 1999 to 2005 (see appendix B.1). The studies exclude some observations based on pre-reform income, age and other demographic information. In general, Auten, Carroll and Gee are more restrictive in constructing their sample than is Heim.

${ }^{86}$ As discussed earlier, specifications that include a 10-piece spline are likely to destroy identification, since the percent change in MTRs was very similar for different points in the income distribution, nor was there much time variation within the income distribution.
} 
interacting the tax rate variable with income group dummies. Heim reports substantial ETI estimates for both tails of the income distribution and estimates that are close to zero in between. For example, his estimated ETI for those with incomes under $\$ 10,000$ is 0.32 . For those with incomes above $\$ 500,000$ his estimated ETIs exceed 1.2.

Goolsbee (2000) also examines high-income responses to OBRA 93, but with a much different data set - panel data on executive compensation for the five highest-paid employees for each firm in the Standard \& Poor's 500, Standard and Poor's Mid Cap 400, and the Standard and Poor's Small Cap 600 from 1991 through 1995. ${ }^{87}$ In general, Goolsbee calculates large responses to the current net-of-tax rate - estimated ETI's are often well above one. Notably, though, much of that response is a temporary shifting of income into the relatively low-tax period. Longer-term elasticities are much smaller, often close to zero, but as high as 0.40 .88 Among income sources, he finds that stock option exercises are the most responsive to tax rates; when stock options are excluded, the short-run and long-run elasticities are almost the same, and much lower (approximately 0.14). Hall and Liebman (2000) replicate the results of Goolsbee (2000) with a similar data set that spans the 1980s, but only includes CEOs; they do not find the same contrast between temporary and permanent responses to the tax cuts of the 1980s. Their short-term elasticities are much smaller than Goolsbee's — often modestly negative, but not statistically different from zero - while their longer-term estimates are also generally modest, ranging from 0.30 to 0.55 for TRA 86 and modestly negative for ERTA. ${ }^{89}$

As the discussion above suggests, the calculated ETI estimates for the 1990s, estimated largely off of the 1990 and 1993 tax changes, are lower than those for the 1980s, estimated largely off of the 1981 and 1986 changes. There are two broad, and not mutually exclusive, categories of explanations. The first suggests there is no reason to expect a universal parameter in the first place. Leading proponents of this hypothesis are Slemrod and Kopczuk (2002), who argue that the ETI is not a structural parameter and is a function of not only preferences, but also the breadth of the tax base and tax enforcement parameters. Recall that Kopczuk (2005) found empirical support for this hypothesis and that Giertz (2007) found that the elasticity with respect to taxable income varies much more by decade than the elasticity with respect to broad income, supporting the argument that changing rules for deductions affects the taxable income elasticity.

The second category of explanations points to estimation issues as the driving reason

\footnotetext{
${ }^{87}$ The sample includes 21,299 observations for executives with at least four years of observations. If attrition is non-random, and is more likely for those whose income falls, the estimates will be biased downwards because tax rates are rising.

${ }^{88}$ The long-term elasticity is calculated as the sum of the current and future net-of-tax rate elasticities.

${ }^{89}$ The compositional analysis in Section 3.6, Figure 2 suggested indeed that the response of wage income to TRA 86 had a temporary component, and also quite possibly a permanent component as well.
} 
behind the differences between decades. One such argument proposed by Carroll (1998) and Giertz (2007), among others, suggests that (for at least some periods) the model is unable to adequately control for exogenous income trends. As a result, the rising, and non-tax-related, income inequality trend could bias ETI estimates upward when top tax rates fall and downward when they rise. Gruber and Saez (2002), by showing that their 1980s estimates are robust to including a linear time trend for each decile and year dummies, claim that exogenous income trends do not affect the size of their estimates. However, these controls may not be complete. The results of Kopczuk (2005) and Giertz (2007) suggest the sensitivity of ETI estimates to how one controls for income trends, and show that this choice has different effects depending on the decade, so that the same specification may not be able to control for exogenous income trends in both periods. Another potential source of bias that varies across periods could arise if the models fail to capture some potentially important types of income shifting, such as the shifting between the corporate and individual income tax base. Incentives for this type of shifting were greater in the 1980s than in the 1990s.

\subsection{Unlegislated variation in U.S. tax rates}

Saez (2003) examines responses to tax increases resulting from bracket creep between 1979 and 1981 using the public-use version of the CWHS panel. ${ }^{90}$ During those years, inflation was around $10 \%$ a year, but the tax brackets were fixed in nominal terms (that is, not indexed). "Bracket creep" was a major issue in the late 1970s and early 1980s, so it is likely that individuals were largely aware of its effects. Saez compares taxpayers with similar incomes and thus the same tax rate in period one, but whose predicted incomes (that year's income grown at the inflation rate) put them into different brackets in a subsequent year.

He regresses the one-year change in the log of income against the instrumented log change in the net-of-tax rate, along with base-year income controls and dummies for filing and itemization status (for the specifications that group all taxpayers together). ${ }^{91}$ The discontinuities created by "bracket creep" provide Saez with a unique opportunity to effectively control for mean reversion and exogenous trends in income, because he can include taxable income in period one as a control in the first stage (as well as the second), while maintaining a well-identified system.

Saez finds a statistically insignificant overall ETI estimate of 0.31, which he decomposes into values of 0.42 for itemizers and approximately 0 for non-itemizers. For AGI, the estimated

\footnotetext{
${ }^{90} \mathrm{He}$ includes all single and married taxpayers in this study. He also excludes those whose marital status changed. He includes all individuals that were in two simultaneous years (that is, he does not require individuals to be in all three years of the study).

${ }^{91}$ He uses the instrument for tax rates first used by Auten and Carroll (1999).
} 
overall ETI is 0.18 and insignificant, but when itemizers are considered separately, the estimate rises to 0.34 and is significant. This suggests that itemizers are more responsive, both in their itemization decisions, and in the amount of income they report. Estimated elasticities for wage income are much smaller, and never significantly different from zero.

In principle this study addresses both mean reversion and exogenous income trends issues as control and treatment groups are evenly distributed along the tax schedule. Reassuringly, the results are actually fairly close to tax-change-based results: the elasticity of wage income is about zero, the broad income elasticity is positive but small in most specification, while the taxable income elasticity is around 0.4 and statistically significant. This study, however, captures only short-term (or transitory) responses to the tax rate changes. As a result, the elasticity estimated is a Frisch elasticity which is theoretically larger than the elasticity to a permanent tax change which is of most interest to policy makers. Furthermore, responding to bracket creep requires that tax filers know the locations of tax brackets and are able to finetune their incomes and deductions accordingly. As a result, the positive elasticities obtained using bracket creep are inconsistent with the complete lack of bunching around the kink points of the regular federal income tax schedule documented in Saez (2009).

Looney and Singhal (2006) examine changes in marginal tax rates resulting from the loss of a dependent tax deduction or exemption to estimate elasticities for middle-income families. ${ }^{92}$ Looney and Singhal's primary data source is the Survey of Income and Program Participation $(\mathrm{SIPP})^{93}$ (for years 1990 to 1996), but they also use the public-use version of the CWHS panel ${ }^{94}$ (for years 1987 to 1990) to see whether the results they found are robust to another, more commonly used, data set. Their identification strategy is based on comparing the behavior of those experiencing a change in rates (due to a change in their number of dependents) to similarly situated families who also experience a change in their number of dependents, but do not experience a change in tax rates. ${ }^{95}$ Looney and Singhal report a statistically significant estimated elasticity of 0.75 with the SIPP data, and a wage income elasticity of 0.71 with the tax data, although this estimate is not statistically significant. As discussed earlier, such large elasticities are inconsistent with the absence of bunching around the kink points of the federal income tax. Note also that Looney and Singhal estimate a response to a temporary tax change (as the marginal tax rate difference between control and treatment groups applies

\footnotetext{
${ }^{92}$ Initial-period income ranges from $\$ 35,000$ to $\$ 85,000$.

${ }^{93}$ They only use married taxpayers with dependents. To be included, dependents must reside with the taxpayer for at least one year that is covered by this panel. Also, those with changes to marital status are excluded.

${ }^{94}$ The exclusions are the same as for the SIPP, with several minor additional exclusions.

${ }^{95}$ For the time period under examination, losing a dependent exemption could shift a family from the $15 \%$ to the $28 \%$ tax bracket.
} 
only to the following year). As a result, their elasticity estimate is a Frisch elasticity which is theoretically larger than the elasticity to a permanent tax change.

Finally, Saez (2009) develops a method to estimate the compensated elasticity of reported income with respect to the net-of-tax rate using bunching evidence around the kink points of the federal U.S. income tax schedule. In the standard model, the amount of bunching should be proportional to the elasticity and the net-of-tax rate (log) change at the kink. Saez (2009) finds clear evidence of bunching around the first kink point of the Earned Income Tax Credit ${ }^{96}$ with an implied estimated intensive earnings elasticity of around 0.25 , but this elasticity is driven entirely by the self-employed with no elasticity for wage earners, and hence could be due entirely to tax manipulation rather than actual labor supply responses. Saez (2009) also finds evidence of bunching at the threshold of the first tax bracket where tax liability starts, especially in the 1960s when the tax schedule was stable and simple. However, there is no evidence of bunching at all for other kink points of the tax schedule, even when the tax brackets are stable over many years and where jumps in marginal tax rates are substantial. This suggests that simplicity and saliency are critical to observe bunching at kink points as the standard model predicts, and that tax filers are unlikely to respond at all to small and non-salient changes in incentives.

\subsection{Empirical Analysis of Legislated Tax Changes in Other Countries}

While the bulk of the research on the ETI has been based on U.S. tax return data, some studies have addressed Canada and certain European countries. In the years following TRA 86 in the United States, many of these countries underwent similar major tax reforms that involved a broadening of the tax base along with substantial cuts in marginal tax rates. Note, though, that because the ETI will depend on many aspects of a country's tax system, including the tax base definition, avoidance opportunities, and the enforcement regime, there is no reason to expect the ETI will be the same across countries, even if preferences-including the substitutability between leisure and goods-were the same everywhere.

\subsubsection{United Kingdom}

The United Kingdom experienced a dramatic drop in the marginal income tax rate at the top during the Thatcher administration. Indeed, the top MTR on earnings fell from $83 \%$ to $60 \%$ in 1979, and then dropped further to $40 \%$ in 1988.

Dilnot and Kell (1988) first analyzed the 1979 top rate cut. They note that the share of tax receipts from the top $1 \%$ of taxpayers stayed constant from 1978 to 1985 in spite of

\footnotetext{
${ }^{96}$ The EITC is based on earnings with a phase-in, plateau, and phase-out ranges, which create large kinks in the budget sets of low income families with children.
} 
the tax rate cut, which implies that top incomes must have increased following the tax cut. Dilnot and Kell do not estimate elasticities but quantify the expected changes in tax receipts assuming no behavioral responses and controlling for macro-economic conditions (as in Lindsey 1987). More recently, Blow and Preston (2002) have used micro tax data for 1985 and 1995 to analyze responses to tax rates, but they focus exclusively on the self-employed, and do not look specifically at top incomes.

Brewer et al. (2008) carry out a top income share time series analysis from 1962 to 2003. They show that the top 1\% income share was falling in the United Kingdom until 1978, and started increasing precisely in 1979. The top $1 \%$ share doubled from $6 \%$ in 1978 to $12.6 \%$ in 2003, while over the same period the net-of-tax rate also doubled from $21 \%$ to $47 \%$, implying an elasticity of 0.9 . Time-series-based regressions of the $\log$ top $1 \%$ income share on the $\log$ net-of-tax rate produces significant elasticities around 0.5, even when controlling for changes in inequality using the share of income accruing to the next $4 \%$ (which did not experience significant changes in marginal tax rates over the period). They also show that the fraction of foreigners at the top of the U.K. distribution has increased much more quickly than the fraction of foreigners in middle or upper groups. Differential tax rates across European countries might generate migration, which is a potential source of behavioral response contributing to the ETI in particular countries. The migration effects of taxes are potentially important but have been understudied, primarily because of lack of citizenship or country of birth information in administrative individual tax data.

\subsubsection{Denmark}

Kleven and Schultz (2009) use panel tax return data since 1980 to analyze behavioral responses to various income tax reforms over the period 1984 to 2005 in Denmark using a method similar to Gruber and Saez (2002). Their study has three key advantages relative to U.S.-based studies. First, they can use the full universe of Danish tax filers over a long period, generating a very large longitudinal dataset which also contains detailed socio-economic information. Second, the Danish income distribution has been very stable over this period compared to the U.S. distribution, making tax effects much easier to identify. Third, the Danish tax reforms of the period 1984-2005 generated substantial tax variation that is not systematically correlated with income, as different reforms affected different brackets and consisted of both rate increases and decreases for a given bracket. Furthermore, many changes apply only to specific income components as the Danish tax system imposes different rates on different components. As a result, they can control for a rich set of base-year incomes. They find that (1) population-wide elasticities are modest compared to most existing studies, (2) elasticities for capital income are 
larger than for labor income, (3) elasticities for negative income (deductions, negative capital income) are larger than for positive income, (4) elasticities for the self-employed are larger than for employees, (5) elasticities are monotonically increasing in income level and are 2 to 3 times larger in the top quintile of the distribution than in the bottom quintile of the distribution, and (6) income effects are very small.

Chetty et al. (2009) also use population tax files from Denmark and estimate the ETI using bunching evidence around kink points, building upon the method developed in Saez (2009) in the U.S. case. They develop a new method of estimating the long-run elasticity in an environment where adjustment costs attenuate short-run behavioral responses by comparing the short-run effects of small vs. large tax changes. Consistent with the existence of large adjustment costs, the amount of bunching they obtain is a highly convex function of the size of the change in the net-of-tax rate at the kink. Interestingly, they find that much of the bunching at kink points is driven by collective bargaining agreements by unions, who facilitate coordination and effectively reduce adjustment costs. The degree of bunching varies across demographic groups and occupations in a manner that appears to be correlated with the flexibility of labor supply and is much more pronounced for secondary earners and especially the self-employed. Their results suggest that adjustment frictions create heterogeneity in the size of the elasticity response in the short-run and that such effects need to be taken into account to obtain the long-run elasticity that is often of interest for policy making.

\subsubsection{Canada}

The 1988 Canadian tax reform raised statutory marginal tax rates for the two lowest-income groups, and lowered them for those falling into the top nine brackets. It also broadened the tax base by either eliminating many deductions and exemptions or converting them to nonrefundable tax credits, and raised the fraction of capital gains (or losses) included in taxable income from one-half to two-thirds. Canadian provincial income tax rates are generally a proportion of federal rates, thus magnifying the federal changes.

In examining behavioral responses to the Canadian reform, Sillamaa and Veall (2001) use a panel of taxpayers who filed in both 1986 and 1989. ${ }^{97}$ Marginal tax rate calculations include both federal and provincial income taxes. Sillamaa and Veall employ a method similar to Auten and Carroll (1999), differencing variables for the two years and instrumenting for the

\footnotetext{
${ }^{97}$ Their data are from the Longitudinal and Administrative Data Base (LAD), which includes information that respondents provide on their Canadian tax returns. They exclude taxpayers with low incomes (roughly under $\$ 9000$ for singles, $\$ 13,000$ for married individuals), those who moved from one province to another, and Quebec residents. Their measure of taxable income includes actual dividend income (rather than adjusted dividend income) and excludes capital gains. Further, they split the sample, analyzing ages 25 to 61 , and over 64, separately. Other age groups are excluded.
} 
net-of-tax rate. As control variables they use log of 1986 income, the log of 1986 capital income (i.e., interest plus dividends), age and age squared in 1986, dummies for self-employment and marital status, and number of children.

They estimate an ETI of 0.14 for those ages 25 to 61 and 0.27 for those over age $64 .{ }^{98}$ Their corresponding estimates for $\mathrm{AGI}^{99}$ are 0.25 and 0.29 , respectively. Interestingly, their gross income elasticity estimates are higher than their taxable income elasticity estimates, in contrast to the usual finding based on U.S. data, possibly related to the fact that deductions in Canada are much more limited than in the United States. Similar to many of the U.S. studies, they report much larger elasticities for upper income groups. Strikingly, the estimated elasticity for self-employment income is 1.32 , but is just 0.08 for regular employment (i.e., non-selfemployment) income. Given that 1989 was the first year that the new tax rate system was in place, one concern is that their elasticity estimates might capture the short-term response while overstating the long-run response to the tax change. As discussed earlier, using only two years of data makes it impossible to control adequately for mean reversion or income inequality changes.

Saez and Veall (2005) use aggregated-time-series income-share methods to analyze the effect of taxation on top income shares in Canada. ${ }^{100}$ They first show that the trends in income shares were quite similar for the United States and Canada, and that in the long run the Canadian trends track U.S. trends more closely than they track Canadian tax rate changes, although there were clear short-run responses to changes in the marginal tax rates. Additionally, like the U.S., a significant portion of the increase was due to wages and salary growth.

They go on to argue that, for Canada, one must consider the possibility of a "brain drain" where high-income individuals move to the U.S. if after-tax compensation was more attractive there. They regress the log income share against the log net-of-tax rate for both the top $1 \%$ and top $0.1 \%$ of taxpayers, yielding elasticity estimates of 0.83 and 0.96 , respectively. ${ }^{101}$ When they also include a control for the income share of the top $1 \%$ (or 0.1 )\% of taxpayers in the U.S., the elasticities drop to 0.48 and 0.30 .

Examining wage income shares, the elasticity falls from 2.55 to being not statistically

\footnotetext{
${ }^{98}$ These are with respect to their measure of taxable income, which is constant-law with respect to 1989.

${ }^{99}$ This measure is reported income, adjusted in the following ways: actual dividend income is substituted for adjusted dividend income, refundable tax credits and nontaxable transfers are included, and capital gains are excluded.

${ }^{100}$ Their estimates are from personal income tax return statistics compiled annually by the Canadian federal taxation authorities since 1920. They exclude capital gains, and only examine the top decile of the income distribution.

${ }^{101}$ The net-of-tax rate is the average (income-weighted) marginal tax rate applicable to the top $1 \%$ group in Canada.
} 
different from zero when the U.S. income control is included. This lends additional credence to their brain-drain hypothesis by suggesting that the rise in Canadian wages can be attributed to a rise of incomes in the U.S., and not to changes in Canadian marginal tax rates. It also implies that some rise in real incomes (not just tax avoidance measures) took place in the U.S.; otherwise, there would have been no incentive for Canadians to move to the U.S. in seek of higher compensation. Arguably, though, the U.S. share variable is proxying for a trend toward inequality in all developed countries.

\subsubsection{Germany}

Germany's 1990 tax reform (passed in mid-1988) reduced marginal tax rates throughout the income distribution, with by far the largest decreases for those in the middle of the distribution, while at the same time changing the tax base, with some allowances eliminated and others expanded.

Gottfried and Schellhorn (2004) estimate taxable income responses to the German tax reform using data from a tax return panel ${ }^{102}$ for the years 1988 to 1991 , although they focus on 1988 and 1990. They base their taxable income measure on the 1990 definition and impute 1990 marginal tax rates by inflating 1988 income to 1990 and running this measure through a tax calculator (as done by Auten and Carroll (1999)).

Gottfried and Schellhorn follow the approach used by Gruber and Saez (2002), but use only one pair of years, 1988 and 1990. Unlike Gruber and Saez, their regressions are not income-weighted and they consider as an alternative a median regression framework that puts less weight on outliers. For the full model, they report a compensated ETI estimate of 0.58 and an income elasticity of zero. ${ }^{103}$ The compensated ETI estimate is most directly comparable to Gruber and Saez's estimate for the U.S. of 0.61. However, as discussed earlier, using only two years makes it impossible to control adequately for mean reversion or income inequality changes without compromising identification.

\subsubsection{Sweden}

The Swedish tax reform of 1991 cut the federal income tax rate structure from one with five tax brackets, with marginal rates reaching $42 \%$ in 1989, to one with just one bracket of $20 \%$. Additionally, the tax rates on capital income were set at a flat rate of $30 \%$, whereas before

\footnotetext{
${ }^{102}$ The data is from Institute für Angewandte Wirtschaftsforschung, IAW. They excluded individuals that chose to retire, changed marital status, received unemployment or sick benefits, or had a taxable income of less than 10,000 DM.

${ }^{103}$ It is noteworthy that, without the $\log$ of 1988 income in the model to control for mean reversion, the estimated ETI is approximately zero.
} 
they were taxed under the same graduated rate structure as earned income. In addition, Sweden substantially cut back on deductions and exclusions and reformed its transfer policies. ${ }^{104}$ Estimating behavioral responses to the Swedish reform is complicated by the fact that the timing of the reform coincided with a sharp recession and modified drastically the tax base making it difficult to construct the same income concepts before and after the reform.

Selén (2002) and Hansson (2007) both estimate taxable income responses to Sweden's 1991 tax reform, relying on different data sets and employing somewhat different methodologies. Selén studies a stratified sample (Statistic Sweden's household income survey, HINK) that includes demographic information and is linked to administrative tax and social insurance records. Hansson uses data (Longitudinell individdatabas, LINDA) on a random sample of Swedes that includes income, wealth, and tax information, as well as other census and demographic variables.Both studies, though, focus on prime-age individuals appearing in the data in both 1989 and 1992. ${ }^{105}$ While using different sets of control variables, both studies employ difference-in-differences methodologies based on those used by Feldstein (1995), and Moffitt and Wilhelm (2000). Additionally, Selén produces estimates employing a number of variations of the approach used by Gruber and Saez (2002), while Hansson also utilizes a similar approach, but relies on just one pair of years. As discussed earlier, using only two years makes it impossible to control adequately for mean reversion or income inequality changes, casting doubt on the robustness of those results.

When Selén allows for an income effect and includes the log of base year income among his control variables, he reports estimated ETIs that are generally between 0.2 and 0.4. Among components of taxable income, wage and salary income generally has the smallest estimated elasticity (often less than 0.2) and factor income has the largest (generally above 0.3). When focusing on those in the top two tax brackets (who also work 200 or more hours per year), Selén reports an estimated ETI of 0.53. When allowing for an income effect, he finds an estimated (compensated) ETI of 0.41 and an income effect of 0.27 . The significance of the income effect and the effect of its inclusion on the ETI estimate runs contrary to Gruber and Saez's results for the U.S. during the 1980s.

Hansson reports several ETI estimates for Sweden that range from 0.37 to 0.43. She then conducts a range of sensitivity analyses. One approach attempts to control for mean reversion by including as control variables, such as dummies for students and welfare recipients. This results in slightly smaller estimated ETIs, ranging from 0.36 to 0.39 .

\footnotetext{
${ }^{104}$ See Ljunge and Ragan (2005) for details. Swedes also pay municipal taxes with marginal rates that averaged $30 \%$; these rates did not change much in 1991.

${ }^{105}$ Selén focuses only on males, while Hansson examines the behavior of both males and females. Sweden, like many countries, has individual-based income tax filing and, pre-reform, very few women were in the upper tax brackets.
} 
Holmlund and Soderstrom (2008) use panel data from 1991-2002 to study two recent income tax reforms in Sweden: the top rate increased by 5 percentage points in 1995 and the top bracket was split into two brackets with a bottom rate lower by 5 percentage points. They adopt the stacked panel approach. As mentioned above, an important innovation they propose is to distinguish between short-term and long-term responses by including a lagged change in marginal tax rate in their panel specification. They obtain significant long-term elasticities between 0.1 and 0.3 for men and insignificant and very close to zero elasticities for women.

Blomquist and Selin (2009) use earlier Swedish tax reforms in the 1980s and combine tax return data with survey data in order to estimate the elasticity of the hourly wage rate with respect to the net-of-tax rate. They use longitudinal data for 1981 and 1991. The standard labor supply literature assumes that the pre-tax hourly wage rate is exogenous but, as the ETI literature points out, tax rates could also affect, among other things, occupational choices and hence the pre-tax wage rate. They find a statistically significant response both for married men and married women. The hourly wage rate elasticity with respect to the net-of-tax rate is estimated to be $0.14-0.16$ for males and $0.41-0.57$ for females. Notably, they also estimate significant income effects. The main drawbacks of the analysis are the small sample size - the sample with survey data that includes hours of work is small - and the use of only two years of data. Marginal tax rate changes are instrumented with predicted changes in net-of-tax rates based on income from a middle year 1986. This method is related in spirit to Carroll (1998) who used as instruments the predicted changes in net-of-tax rates based on average pre- and post-reform income (see Section 3.4.2).

\subsubsection{Norway}

Prior to 1992, top marginal tax rates in Norway neared $58 \%$ for employees and $63 \%$ for the self-employed, while the top rate on capital income exceeded 40\%. A major reform in 1992 lowered rates, especially for high-income groups, and broadened the tax base, dropping the marginal income tax rates for labor, capital, dividend and corporate income to $28 \%$. Labor income, however, was also made subject to taxes for social insurance and to a surtax on incomes above a threshold. For high earners subject to the surtax, the difference in tax rates on capital and labor income widened substantially. A potential obstacle to identification of taxable income elasticities is that Norway underwent an economic recovery shortly after the tax

reform (although likely not resulting from the reform), which may have had a heterogeneous impact across income groups.

Aarbu and Thoreson (2001) use a panel of more than 2000 individuals for years 1991 and 
1994 to estimate taxable income ${ }^{106}$ responses to the Norwegian reform. Their data includes detailed information on income and taxes, plus some demographic and social security information. ${ }^{107}$ They pursue both a regression-based tabulated differences approach developed by Moffitt and Wilhelm (2000), and one based on Auten and Carroll (1999). In addition to the instrumented log of the net-of-tax rate, ${ }^{108}$ they include macroeconomic variables in their models to account for business cycle effects. Like Hansson (2007), they also construct a variable measuring the gap between capital and labor tax rates in order to control for income shifting. They include dummy variables for life cycle (a dummy variable for unmarried persons under the age of 28), marital status, education, area, and children's age, as well as a variable for age. Using the Auten and Carroll-based approach, the full model produces an estimated ETI of -0.03 (and not statistically different from 0), decidedly lower than similar estimates in the U.S.

\subsubsection{New Zealand}

Atkinson and Leigh (2008) analyze the top 1\% income share in New Zealand from 1921 to 2005. ${ }^{109}$ Similar to studies examining Canada (Saez and Veall, 2005), U.S. (Saez, 2004), and Australia (Atkinson and Leigh, 2007), they find large growth in the top 1\% of income shares over the 1980s and 1990s. Like Saez and Veall's (2005) analysis of Canada, they consider two main stories for the changes in top income shares: changes in top marginal income tax rates in New Zealand, and changes in the "threat of emigration" as captured by changes in top income shares in Australia and the U.K. ${ }^{110}$ To estimate the behavioral response to tax rates, they regress the top $1 \%$ income share on a quadratic time trend and one year lags of the netof-tax rate for top-bracket individuals, the Australian and U.K. top 1\% income share, and the growth rate in real GDP. When including all these controls simultaneously, they estimate the coefficient on the net-of-tax rate to be 0.06 and statistically significant; this corresponds to an elasticity of 0.41 when calculated at 2005 tax year values. The coefficients on the top income shares of Australia and the United Kingdom are 0.32 and 0.28 , respectively, ${ }^{111}$ which they interpret as suggesting that the threat of emigration has had a larger effect on high-income

\footnotetext{
${ }^{106}$ Their taxable income measure includes both labor and capital income and is constant-law 1994.

${ }^{107}$ For their sample, they include only those ages 22 to 65 in 1994 with positive incomes, whose marital status and number of children remain the same. Their sample size is 2,246 .

${ }^{108}$ The instrument is calculated using the same methodology as Auten and Carroll (1999), except they use the growth in nominal wage income to inflate 1991 income.

${ }^{109}$ They use tax return and national accounts data to construct the top income shares. After 1953, they include all individuals over age 15 (before 1953, they exclude married women, since the taxpaying unit at that time was a household, rather than an individual).

${ }^{110}$ The authors note that emigration to Australia and the U.K. account for almost $75 \%$ of total emigration from New Zealand.

${ }^{111}$ The former is statistically significant at the $5 \%$ level, the latter is not.
} 
shares than the change in New Zealand's marginal tax rates.

\subsubsection{Other Countries}

France: Piketty (1999) uses repeated cross sections of French tax data to show that small changes in French top tax rates generated small short-term responses for top incomes, but that those responses do not seem to persist over time.

Finland: Pirtilla and Selin (2006) analyze the Finnish tax reform of 1993 which sharply reduced the marginal tax rates on capital income for some, but not all, taxpayers, but did not change simultaneously the taxation of labor income. They use panel tax data for two years, 1992 and 1995. They find that the reform led to a small positive impact on overall taxable income, but that part of the positive response was probably offset by income shifting from labor to capital income among the self-employed in order to take advantage of the lower rates. Janti et al. (2009) construct top income shares in Finland and argue that the 1993 tax reform had an impact on the level and composition of top incomes. They document a surge in dividends and self-employment income just after the 1993 reform as those income sources received preferential tax treatment following the institution of a dual income tax.

Poland: Kopczuk (2009) analyzes the impact of the 2004 tax reform in Poland which introduced an optional broad-based low-rate tax for business income. The analysis relies on a large panel of tax return data and uses a difference-in-difference strategy relying on the differential benefits from the reform among otherwise similar individuals due to the level of earnings of the spouse and pre-existing deductions. The identification strategy is innovative as this low rate optional flat-rate applies only to business income and is favorable only upon certain conditions. As a result, it generates compelling instruments and shows that such business income is quite responsive to taxation.

Russia: Gorodnichenko, Martinez-Vazquez, and Sabirianova (2009) examine the effects of Russia's 2001 flat rate income tax reform on consumption, income, and tax evasion using the gap between household expenditures and reported earnings as a proxy for tax evasion. They use household panel data for 1998-2004 and a difference-in-difference strategy as different income groups were affected differently. They find a significant effect of the tax rate reduction on reported income but not on consumption, suggesting that most of the response was the consequence of tax evasion. Building on Chetty's (2008) framework, they show that the efficiency gains from the reform are substantially smaller than the gains estimated from the conventional approach using solely the ETI. This analysis is based on a relatively small sample

and does not capture well changes at the top of the distribution where changes were most dramatic. Therefore, it would certainly be valuable to evaluate more systematically the flat- 
tax reforms that many of the former communist countries have adopted over the last 10-15 years using tax return based evidence.

\section{Conclusions and Future Work}

\subsection{What we've learned}

As Feldstein (1995) first asserted, under certain assumptions all behavioral responses to income tax rate changes are symptoms of inefficiency, and all such responses are captured by the elasticity of taxable income. Because of the centrality of this parameter to the marginal efficiency cost of raising revenue though tax rate increases and therefore to the evaluation of tax structure, and because of the growing availability of longitudinal tax return data, a large empirical literature followed. The early literature, focusing on the U.S. tax cuts of 1981 and particularly 1986, produced elasticity estimates large enough to suggest that, not only was the marginal efficiency cost of tax rates high, but that the U.S. might be on the wrong side of the Laffer curve.

Subsequent research generated considerably lower estimates, in part because of better data and improved methodology, but also because the variety of tax rate changes after 1986 facilitated separating out the impact of tax rate changes from non-tax-related changes in the inequality of pre-tax income. The most reliable longer-run estimates range from 0.12 to 0.4 , suggesting that the U.S. marginal top rate is far from the top of the Laffer curve, but greater than one would calculate if the sole behavioral response was labor supply. Estimates for other countries are, for the most part, in this same range.

There is much evidence to suggest that the ETI is higher for high-income individuals who have more access to avoidance opportunities, including deductible expenses. This finding highlights the importance of the fact that the ETI is not an immutable parameter, but can be influenced by government policies regarding, for example, the broadness and extent of enforcement of the tax base. For this reason it is likely to vary across countries and within countries over time when non-rate aspects of tax systems change.

One attraction of the ETI concept-that it is a sufficient statistic for welfare analysis and therefore one need not inquire into the anatomy of behavioral response - has proven to be overstated. The welfare relevance of the elasticity depends on the extent of fiscal externalities - whether taxable income is shifted to or from another tax base, or to and from the same tax base at a different time. Moreover, if classical externalities apply to often-deductible items such as charitable contributions, the ETI must be adjusted for welfare purposes. Examining which components of taxable income respond to tax rates (the "anatomy" of response) can help clarify the extent of these externalities. This brings us back to the pre-ETI attention to 
each of the many margins of behavioral response to tax rate changes.

Nevertheless, the essential insight underlying the ETI remains valid: that income tax rates cause taxpayers to respond on a wide range of margins and, under some conditions, all of these responses reflect inefficiency, because they would not have been undertaken absent the tax rates. This is especially true of high-income, financially savvy taxpayers who in most countries have access to sophisticated tax avoidance techniques. There is clear evidence of responses that would fall in the first two tiers of the Slemrod (1995) hierarchy-timing, shifting, avoidance - based on U.S. evidence since 1980, but only at the top end of the income distribution. Given this finding, it is especially critical to understand the mechanisms and efficiency consequences of any given tax change - legal structure, taxpayer information, and so on.

The empirical methods are most convincing in estimating the short-term response to tax rate changes, and in that case one must be careful to distinguish the response to anticipated versus unanticipated changes. Estimates of the long-run elasticity of taxable income are plagued by extremely difficult issues of identification, so difficult that we believe that there are no convincing estimates of the long-run elasticity of reported taxable income to changes in the marginal tax rate. Analysis of panel data does not seem likely to resolve the identification issues raised by trends in income inequality and mean reversion at the top and bottom ends of the income distribution. Repeated cross-section analysis based on longer time series is very useful to analyze changes in the share of income accruing to various income groups and assess whether those changes are systematically related to changes in marginal tax rates. However, evidence from a single country is in general not enough to conclusively estimate behavioral elasticities as many factors besides tax rate shape the income distribution. Time-series share analysis, coupled with compositional analysis, is extremely useful to detect large short-term changes due to behavioral responses.

\subsection{What we need to learn}

First, future research that attempts to quantify the welfare cost of higher tax rates should attempt to measure the components of behavioral responses as well as their sum. It needs to be more attentive to the extent to which the behavioral response reflects shifting to other bases.

Second, empirical analyzes should look more systematically at non-U.S. experience in order to potentially validate the conclusions based on U.S. experience and to sharpen our understanding of how the environment, writ large, affects the ETI. As discussed above, this line of research is already underway and indeed the most promising and innovative recent studies on 
the ETI have been based on non-US data. Part of the reason is that several OECD countries, especially in Scandinavia, are now substantially in advance of the United States in terms of tax data availability for research. This trend is likely to continue unless the United States broadens access to population tax return data.

Third, researchers should be seeking better sources of identification; for example, parallel income tax systems that differentially affect taxpayers over a long period of time. Conceivably, field experiments could be designed where individuals are randomly assigned to different tax schedules in the spirit of the older Negative Income Tax experiments in the United States (Munnell, 1987).

Finally, research needs to be sensitive to the possibility that non-standard aspects of tax systems and the behavioral response to them such as salience, information, popular support, asymmetric response to increases versus decreases, might affect the size of behavioral response. The recent approach of Chetty (2009) is particularly promising. His meta-analysis, which includes most ETI studies, shows that the discrepancies across estimates could be explained by imperfect optimization and frictions such as adjustment costs. In that context, large and salient changes in tax rates provide much more informative estimates of the long-run ETI than small or non-salient changes.

\subsection{The tax base elasticity}

Although the literature reviewed in this article addresses the behavioral response to income taxation, many of the issues apply to any tax base. Certainly the idea that, under some assumptions, all responses are symptoms of inefficiency applies generally. For example, from the perspective of states imposing cigarette excise taxes, under some assumptions the central empirical parameter is the elasticity of the tax base, which includes not only the response of smoking to tax rate changes but also the impact on the tax base of smuggling and tax-free Internet purchases. This generalization is, of course, subject to the same caveats this article has focused on, such as shifting across bases. 


\section{A Recent legislated tax changes in the United States}

In this appendix section, we briefly outline the major changes in the U.S. individual income tax since the mid 1950s. Table A1 reports the top statutory marginal federal income tax rates on (1) ordinary individual income, (2) earned income, (3) long-term realized capital gains, as well as the corporate tax rate since 1952. The table also describes briefly the most important additional provisions affecting high-income tax rates.

Although Congress regularly amends the tax code, only occasionally does it make major reforms. The 1954 Internal Revenue Code represented an important and fundamental reform to the U.S. tax system. The 1954 Code created 24 tax brackets with marginal tax rates increasing with income from 20 to $91 \%$, but with a maximum tax rate of $25 \%$ applied to capital gains; the top corporate tax rate was $52 \%$. (While the 1954 act represented a fundamental change to the U.S. tax system, it did not alter MTRs on top incomes.) The 1954 Code was amended many times, but remained in place until 1986. The 1960s saw a couple of important tax changes. One was the Revenue Act of 1964, inspired by President John Kennedy, but enacted under President Lyndon Johnson. This act reduced individual and corporate tax rates, notably lowering the top marginal income tax rate from $91 \%$ to $70 \%$. The Tax Reform Act of 1969 introduced a new rate schedule. While the top individual income tax rate remained at $70 \%$, the top rate on earned income was lowered (over the next few years) to $50 \% .{ }^{112}$ The 1970 s saw federal tax revenues (and effective marginal tax rates) increase as a result of "bracket creep" brought on by the combination of unusually high inflation and tax brackets not indexed for inflation. In response to this, a series of tax acts were passed, most of which lowered tax revenues by increasing allowable tax deductions and credits.

Congress has changed federal marginal tax rates several times since 1980. The Economic Recovery Tax Act of 1981 (ERTA) reduced the top rate from $70 \%$ to 50\%, and lowered all other tax rates in three annual steps by a total of about $23 \%$ (not 23 percentage points). TRA 86 represented the most comprehensive tax reform since 1954. It dropped the top marginal tax rate to $28 \%$ in two steps from 1986 to 1988, and made smaller cuts across the income distribution. TRA 86 also eliminated the exclusion of $60 \%$ of long-term capital gains, lowered the corporate tax rate from $46 \%$ to $34 \%$, and contained scores of other provisions several of which reduced deductions.

The tax changes of the Omnibus Budget Reconciliation Acts of 1990 and 1993 (OBRA 90 and OBRA 93) were smaller and more focused on high-income filers than those of the 1980s. OBRA 90 increased the top tax rate from 28 to $31 \%$. OBRA 93 further increased the top rate

\footnotetext{
${ }^{112}$ The 1969 Act also extended a 5\% income tax surcharge. Additionally, it established both the individual and corporate Alternative Minimum Tax.
} 
from 31 to $36 \%$ and applied this rate to individuals with lower incomes. It also created a new top marginal tax rate of $39.6 \%$ by legislating a 10\% surtax. (Top tax rates on earned income increased by roughly another 2.9 percentage points because the cap on income subject to the Medicare portion of the payroll tax was lifted.) Unlike TRA 86, OBRA 90 incorporated only a few changes to the tax code and there were no additional changes made when OBRA 93 was passed. OBRA 93 is the first U.S. legislated tax act clearly qualifies as an anticipated change - Clinton announced his intention of passing this act in 1992. ${ }^{113}$ Also in the 1990s, the Taxpayer Relief Act of 1997 substantially lowered capital gains tax rates, among other things. This Act did not change tax rates on earned income other than capital gains.

Tax rates have also changed since 2000. In 2001, the Economic Growth Tax Relief and Reconciliation Act (EGTRRA) lowered marginal tax rates, reduced the number of tax brackets and expanded allowable credits and deductions. Different aspects of EGTRRA were scheduled to phase in over a number of years, with the act expiring completely in 2011. In 2003, the Jobs Growth Tax Relief and Reconciliation Act (JGTRRA) accelerated all of the marginal rate cuts from EGTRRA that were not set to fully phase-in until 2006. Additionally, JGTRRA substantially lowered tax rates on capital gains and dividends down to 15\%. Like EGTRRA, these changes will expire in 2011, absent action by Congress.

Before proceeding, note that, as a practical matter, a number of studies in the empirical literature (as well the empirical exercise in Section 3) examine adjusted gross income (AGI) in place of taxable income. Taxable income equals AGI minus the value of personal exemptions and either the standard or itemized deductions. Many data sets do not include enough information to calculate taxable income in a consistent way over many years. This is especially true for data sets spanning many decades, over which the definition of taxable income changes substantially. Creating a constant-law income measure (see the previous section) often requires information that is not reported, and therefore not available to researchers, in many years. Many taxable income responses are also captured in AGI; however, changes in itemized deductions are not observed. Also, recall from Section 2 that the potential for positive externalities associated with some itemized deductions could argue for examining responses to AGI - even when good measures of taxable income are available.

\section{B Tax Return Data}

As discussed in the paper, the estimation of behavioral responses of reported income to tax changes relies critically on the availability of high quality individual income tax data. In this

\footnotetext{
${ }^{113}$ Romer and Romer (2008) examine the motivation for tax changes since WWII, which is important to assess the endogeneity of tax changes and their implications for identification.
} 
appendix section, we discuss briefly data availability in the United States and we describe in more detail the data we used in Section 3.4.

\section{B.1 U.S. Tax Return Data}

The Statistics of Income (SOI) division at the Internal Revenue Service has created large annual micro-datasets of individual tax returns since 1960. The SOI data are stratified random samples of about 250,000 tax returns and include most of the information reported on the filers' tax returns, plus some additional demographic information. Sampling rates vary by income (and other tax return characteristics). The SOI heavily over samples high-income filers with $100 \%$ sampling rates at the top of the distribution, a key advantage as top incomes play a critical role in determining overall responses to changes in tax rates.

Sampling into the SOI data is based on (a random transformation of) Social Security numbers of tax filers. These assigned numbers do not change from year to year, and beginning with year 1979, enable researchers to link SOI annual cross-sections into a panel dataset. (For more detail on the SOI data and the SOI's sampling strategy, see the discussion below on the data used in section 3.) In particular, a core set of five last 4 digits of the Social Security numbers are always sampled and hence are a pure longitudinal sample of $0.05 \%$ of US tax returns. This core longitudinal sample within the SOI data is called the Continuous Work History Sample (CWHS).

In several cases, SOI has supplemented the core SOI cross sections by creating additional panel data drawing from the full population of individual tax returns. One such example is the Treasury's Family Panel, which is a stratified random sample of tax filers followed from 1987 to 1996. The Family Panel begins with 88,000 tax returns in 1987, follows filers and their dependents through 1996 and includes "refreshments" in order to remain representative of the overall filing population. Treasury's 1999 Edited Panel, which begins in 1999, is designed similarly to the Family Panel. It currently runs through 2005. Another example is the Sales of Capital Assets Panel (SOCA), which follows a sample of tax filers reporting sales of capital assets (on Schedule D of IRS Form 1040).

SOI has released to the public the so-called "Public Use File" (PUF) version of the SOI annual cross-sections. In order to protect the identity of taxpayers, those public use files have a lower sampling rate at the very top (1/3 instead of 1$)$ and they also blur some variables for very high incomes by combining several tax returns together. The PUF contain about 100,000 tax returns per year. However, the PUF do not contain longitudinal identifiers and hence cannot be linked into panel data. Another important limitation of the PUF is that they do not report separately income items of each spouse in the case of married joint filers, limiting 
our ability to measure the important secondary earner response to tax changes. ${ }^{114}$

A public-use version of the CWHS was also made public for years 1979 to 1990. The public version of the panel also included some "blurring" of information in order to protect the identity of taxpayers. The public-use version of the CWHS goes by various names, including the "University of Michigan Tax Panel" or "NBER Tax Panel." The absence of publicly available U.S. panel data since 1990 has severely limited the ability of academic researchers to study more recent tax changes. As a result, most of the recent studies have been carried out by researchers within government agencies (in a few cases in collaboration with outside academics).

Due to improvements in information technology, it has now become feasible for SOI to use the complete population files of tax returns, i.e., about 140 million tax returns each year. Those samples can of course be linked longitudinally. The extremely large size of the population files could be used to broaden the scope of tax changes that can be analyzed. Indeed, the United States offers very rich variation at the state levels. Most existing data samples are too small to analyze convincingly local changes. The availability of population files for research use could spur new work on responses to tax changes. However, data for the full population of filers still require substanital "data cleaning" before these files will include the same breadth of information that is included in the samples.

\section{B.2 Tax Return Data used in Section 3}

The panel of individual tax returns used in Section 3 are from the Statistics of Income (SOI) and spans years 1991 to 1997. Marginal tax rates are imputed using CBO's federal tax model. Income, denoted $z_{i t}$, is a constant-law measure of AGI (adjusted gross income for individual $i$ at time $t$ ), excluding capital gains and including all Social Security benefits, such that $z_{i t}$ $=$ reportedAGI - realizedCG + nontaxableSSbenefits + deductedmovingexpenses. Dollar values are adjusted by the IRS's inflation adjustment factors, using 1991 as the base. Marginal tax rates are imputed for only the federal income tax using the Congressional Budget Office's internal tax calculators. The rate imputations exclude changes to the payroll tax (which only applies to earned income) and to changes in state tax rates. While this leaves an incomplete measure of the marginal tax rate, it has the virtue of simplicity.

Note that selection into the SOI is conditional on several factors, including income. More specifically, each individual is assigned a number at random, which does not change from year to year. For each year, tax returns are separated into strata based on AGI and the forms and schedules used by the filers. Sampling probabilities vary by strata and reach 100 percent

\footnotetext{
${ }^{114}$ The SOI files can be merged within SOI to individual wage income information in order to obtain the breakdown of income by spouse.
} 
for very high-income filers. The returns in each stratum are sorted by the randomly assigned values and the strata sampling probability is used to determine the cut point for inclusion into the SOI. Because the individual maintains the same random value over time and because the stratum sampling probability simply determines the cut point for inclusion in the sample, once included in the SOI, an individual is automatically included in future years if his income remains the same or if his income increases because this would either put him in the same stratum or in a stratum with a higher sampling probability — thus maintaining or lowering the cut point for inclusion. Therefore, an individual observed in the base year is much more likely to be observed in the future year if his income rises than if it falls. In fact, the probability that one is observed in two different years is simply the minimum of the strata sampling probabilities for the two years. This raises the potential for spurious correlation between the dependent variable $\left(\ln \left(\frac{\text { incomet }_{t}}{\text { income }_{t+1}}\right)\right)$ and the independent variables, including the tax variable. To avoid this possibility, (paired) observations from the full SOI are weighted by the reciprocal of their probability of appearing in the sample. This same strategy is employed by a number of researchers using these data. 


\section{References}

Aarbu, Karl and Thor Thoreson. 2001. "Income Responses to Tax Changes-Evidence from the Norwegian Tax Reform," National Tax Journal, 54(2): 319-334.

Alvaredo, Facundo and Emmanuel Saez. 2008. "Income and Wealth Concentration in Spain in a Historical and Fiscal Perspective", forthcoming Journal of the European Economic Association.

Aktinson, Anthony and Andrew Leigh. 2004 "Understanding the Distribution of Top Incomes in Anglo-Saxon Countries over the Twentieth Century," Working Paper.

Aktinson, Anthony and Andrew Leigh. 2007. "The Distribution of Top Incomes in Australia." Economic Record, 83(262): 247-261.

Aktinson, Anthony and Andrew Leigh. 2008. "Top Incomes in New Zealand 1921-2005: Understanding the Effects of Marginal Tax Rates, Migration Threat, and the Macroeconomy", Review of Income and Wealth, 54(2).

Atkinson, Anthony and Thomas Piketty. 2007. Top Incomes over the Twentieth Century. Oxford: Oxford University Press: 585 pp.

Atkinson, Anthony and Thomas Piketty. 2010. Top Incomes: A Global Perspective. Oxford: Oxford University Press.

Auerbach, Alan. 1988. "Capital Gains Taxation in the United States." Brookings Papers on Economic Activity, 2: 595-631.

Auerbach, Alan and Joel Slemrod. 1997. "The Economic Effects of the Tax Reform Act of 1986." Journal of Economic Literature, 35(2): 589-632.

Auten, Gerald and Robert Carroll. 1995. "Behavior of the Affluent and the 1986 Tax Reform Act." in Proceedings of the 87th Annual Conference on Taxation of the National Tax Association, Columbus, Ohio, 70-76.

Auten, Gerald and Robert Carroll. 1999 "The Effect of Income Taxes on Household Behavior." Review of Economics and Statistics, 81(4): 681-693.

Auten, Gerald, Robert Carroll and Geoffrey Gee. 2008. "The 2001 and 2003 tax rate reductions: An overview and estimate of the taxable income response." National Tax Journal, 61(3): 345-364.

Auten, Gerald, Holger Sieg and Charles Clotfelter. 2002. "Charitable Giving, Income, and Taxes: An Analysis of Panel Data." American Economic Review, 92(1): 371-82.

Bebchuk, Lucian and Jesse Fried. 2004. Pay without Performance: The Unfulfilled Promise of Executive Compensation Harvard University Press: Cambridge.

Blomquist, Soren and Hakan Selin (2009) "Hourly Wage Rate and Taxable Labor Income Responsiveness to Changes in Marginal Tax Rates", Uppsala University Working paper 2009-1. Blow, Laura and Ian Preston. 2002. "Deadweight Loss and Taxation of Earned Income: Evidence from Tax Records of the UK Self-Employed." Institute for Fiscal Studies Working Paper.

Blundell, Richard and Thomas MaCurdy. 1999. "Labor Supply: A Review of Alternative Approaches." In O. Ashenfelter, D. Card, ed., Handbook of Labor Economics, Amsterdam: North-Holland, v3. 
Brewer, Michael, Emmanuel Saez and Andrew Shephard. 2008 "Means Testing and Tax Rates on Earnings," IFS Working Paper, April 2008, forthcoming in The Mirrlees Review: Reforming the Tax System for the 21st Century, Oxford University Press.

Burman, Leonard, Kimberly Clausing and John O'Hare. 1994. "Tax Reform and Realizations of Capital Gains in 1986." National Tax Journal, 47(1): 1-18.

Burman, Leonard, and William Randolph. 1994. "Measuring Permanent Responses to Capital-Gains Tax Changes in Panel Data." American Economic Review 84: 794-809.

Carroll, Robert. 1998. "Tax Rates, Taxpayer Behavior, and the 1993 Tax Act." Office of Tax Analysis working paper, U.S. Department of the Treasury.

Carroll, Robert and David Joulfaian. 1997. "Taxes and Corporate Choice of Organizational Form," Office of Tax Analysis Working Paper No. 73, U.S. Department of the Treasury. Chetty, Raj. 2008. "Is the Taxable Income Elasticity Sufficient to Calculate Deadweight Loss? The Implications of Evasion and Avoidance," NBER Working Paper No. 13844, forthcoming American Economic Journal: Economic Policy.

Chetty, Raj. 2008b. "Sufficient Statistics for Welfare Analysis: A Bridge Between Structural and Reduced-Form Methods", NBER Working Paper No. 14399, forthcoming Annual Review. Chetty, Raj. 2009. "Bounds on Elasticities with Optimization Frictions: An Application to Taxation and Labor Supply" UC Berkeley Working Paper, April 2009.

Chetty, Raj, Anders Frederiksen, John N. Friedman, Tore Olsen, and Luigi Pistaferri. 2009. "Adjustment Costs and Earnings Responses to Income Taxation: Evidence from Denmark", UC Berkeley mimeo (in preparation).

Chetty, Raj and Emmanuel Saez. 2005. "Dividend Taxes and Corporate Behavior: Evidence from the 2003 Dividend Tax Cut," Quarterly Journal of Economics, 120(3): 791833.

Chetty, Raj and Emmanuel Saez. 2007. "An Agency Theory of Dividend Taxation," NBER Working Paper No. 13538.

Chetty, Raj and Emmanuel Saez. 2009. "Teaching the Tax Code: Earnings Responses to an Experiment with EITC Claimants,' NBER Working Paper.

Clotfelter, Charles and Richard Schmalbeck. 1996. "The Impact of Fundamental Tax Reform on Nonprofit Organizations." in Economic Effects of Fundamental Tax Reform, Henry Aaron and William Gale, eds. Washington, D.C.: Brookings Institution Press, 211-46.

Congressional Budget Office. 2009. "Shares of Federal Tax Liabilities for All Households, by Comprehensive Household Income Quintile, 1979-2006", available online at http://www.cbo.gov/publications/collections/tax/2009/tax_liability_shares.pdf

Diamond, Peter and James Mirrlees. 1971. "Optimal Taxation and Public Production I: Production Efficiency and II: Tax Rules," American Economic Review, 61: 8-27 and 261-278. Dilnot, Andrew and Michael Kell. 1988. "Top-Rate Tax Cuts and Incentives: Some Empirical Evidence," Fiscal Studies, 9: 70-92.

Eissa, Nada and Seth Giertz. 2006. "Trends in High-Income and Behavioral Responses to Taxation: Evidence from Executive Compensation and Statistics of Income Data." Congressional Budget Office, Washington D.C., Working Paper 2006-14, www.cbo.gov/ftpdocs/77xx/doc7711/200614.pdf. 
Feenberg, Daniel and Elisabeth Coutts. 1993. "An Introduction to the TAXSIM Model." Journal of Policy Analysis and Management, 12(1): 189-194.

Feenberg, Daniel and James Poterba. 1993. "Income Inequality and the Incomes of Very High Income Taxpayers: Evidence from Tax Returns," In Tax Policy and the Economy, James Poterba, ed., (MIT Press: Cambridge), 7: 145-177.

Feldstein, Martin. 1995. "The Effect of Marginal Tax Rates on Taxable Income: A Panel Study of the 1986 Tax Reform Act." Journal of Political Economy, 103(3): 551-572.

Feldstein, Martin. 1999. "Tax Avoidance and the Deadweight Loss of the Income Tax." Review of Economics and Statistics, 81(4): 674-680.

Feldstein, Martin and Daniel Feenberg. 1996. "The Effect of Increased Tax Rates on Taxable Income and Economic Efficiency: A Preliminary Analysis of the 1993 Tax Rate Increases", In Tax Policy and the Economy, James Poterba, ed., (MIT Press: Cambridge), 10: 89-117.

Fullerton, Don. 1996. "Comment on 'High-Income Families and the Tax Changes of the 1980s: The Anatomy of Behavioral Response'." in Martin Feldstein and James Poterba, eds., Empirical Foundations of Household Taxation, Chicago: University of Chicago Press.

Giertz, Seth. 2004. "Recent Literature on Taxable-Income Elasticities, "Technical Paper 2004-16, Congressional Budget Office, Washington D.C., www.cbo.gov/ftpdocs/60xx/doc6028/200416.pdf.

Giertz, Seth. 2007. "The Elasticity of Taxable Income over the 1980s and 1990s," National Tax Journal, 60(4): 743-768..

Giertz, Seth. 2008a. "Taxable Income Responses to 1990s Tax Acts: Further Explorations, "Working Paper 2008-08, Congressional Budget Office, Washington D.C., www.cbo.gov/doc.cfm?index=9715. Giertz, Seth. 2008b "Taxable Income Responses to 1990s Tax Acts: Further Explorations," Working Paper 2008-08, Congressional Budget Office, Washington D.C..

Giertz, Seth. 2008c. "Panel Data Techniques and the Elasticity of Taxable Income," CBO Working Paper No. 2008-11, Congressional Budget Office, Washington D.C.

Giertz, Seth. 2009. "The Elasticity of Taxable Income: Influences on Economic Efficiency and Tax Revenues, and Implications for Tax Policy, "in Tax Policy Lessons from the 2000s, ed. Alan Viard, AEI Press, Washington, D.C.: 101-136.

Glaeser, Edward and Jesse Shapiro. 2003. "The benefits of the home mortgage interest deduction." in James Poterba, ed., Tax Policy and the Economy, 17: 37-82.

Goolsbee, Austan. 1999. "Evidence on the High-Income Laffer Curve from Six Decades of Tax Reform." Brookings Papers on Economic Activity, 2: 1-47.

Goolsbee, Austan. 2000a. "What Happens When You Tax the Rich? Evidence from Executive Compensation." Journal of Political Economy, 108(2): 352-378.

Goolsbee, Austan. 2000b. "It's Not about the Money: Why Natural Experiments Don't Work on the Rich." In Joel Slemrod, ed., Does Atlas Shrug? The Economic Consequences of Taxing the Rich, Cambridge University Press.

Gordon, Roger and Joel Slemrod. 2000. "Are 'Real' Responses to Taxes Simply Income Shifting Between Corporate and Personal Tax Bases?" In Joel Slemrod, ed., Does Atlas Shrug? The Economic Consequences of Taxing the Rich, Cambridge University Press. 
Gorodnichenko, Yuriy, Jorge Martinez-Vazquez, and Klara Sabirianova. 2009. "Myth and Reality of Flat Tax Reform: Micro Estimates of Tax Evasion Response and Welfare Effects in Russia", forthcoming Journal of Political Economy.

Gottfried, Peter and Hannes Schellhorn. 2004. "Empirical Evidence on the Effects of Marginal Tax Rates on Income - The German Case." Discussion Paper.

Gruber, Jonathon and Joshua Rauh. 2007. "How Elastic is the Corporate Income Tax Base?" Taxing Corporate Income in the 21st Century, Alan Auerbach, James Hines and Joel Slemrod, ed., Cambridge: Cambridge University Press: 140-163.

Gruber, Jonathan and Emmanuel Saez. 2002. "The Elasticity of Taxable Income: Evidence and Implications." Journal of Public Economics, 84: 1-32.

Hall, Brian and Jeffrey Liebman. 2000. "The Taxation of Executive Compensation." in Tax Policy and the Economy, James Poterba, ed., Cambridge: MIT Press: .

Hansson, Åsa. 2007. "Taxpayers' responsiveness to tax rate changes and implications for the cost of taxation in Sweden." International Tax and Public Finance, 14(5): 563-582.

Harberger, Arnold. 1964. "Taxation, Resource Allocation, and Welfare." in John Due, ed., The Role of Direct and Indirect Taxes in the Federal Revenue System, Princeton, NJ: Princeton University Press: 25-75.

Heim, Bradley. 2007. "The Elasticity of Taxable Income: Evidence from a New Panel of Tax Returns." working paper.

Heim, Bradley. 2009. "The Effect of Recent Tax Changes on Taxable Income: Evidence from a New Panel of Tax Returns." Journal of Policy Analysis and Management, 9(1), 147163.

Holmlund, Bertil and Martin Soderstrom. 2008. "Estimating Dynamic Income Responses to Tax Reforms: Swedish Evidence" Working Paper 2008:28, Institute for Labour Market Policy Evalution (IFAU).

Jantti, M, M Riihela, R Sullstrom, and M Tuomala. 2009. "Trends in top income shares in Finland" Chapter 8 in A. B. Atkinson and T. Piketty, eds. Top Incomes: A Global Perspective, Oxford: Oxford University Press.

Karlan, Dean and John List. 2007. "Does Price Matter in Charitable Giving? Evidence from a Large-Scale Natural Field Experiment." American Economic Review, 97(5): 1774-1793. Katz, Lawrence and David Autor. 1999. "Changes in the Wage Structure and Earnings Inequality." in Handbook of Labor Economics, eds. O. Ashenfelter and D. Card, Amsterdam: North-Holland, v3A.

Kleven, Henrik and Esben Anton Schultz. 2009. "Identifying the Elasticity of Reported Income Using a Large Panel of Danish Tax Payers", work in progress.

Kopczuk, Wojciech. 2005. "Tax Bases, Tax Rates and the Elasticity of Reported Income." Journal of Public Economics, 89(11-12): 2093-2119.

Kopczuk, Wojciech. 2009. "The Effect of the Polish Flat Tax on Taxable Income of Entrepreneurs", mimeo in preparation, Columbia University.

Kubik, Jeffrey. 2004. "The Incidence of the Personal Income Taxation: Evidence from the Tax Reform Act of 1986." Journal of Public Economics, 88(7-8): 1567-1588. 
Lindsey, Lawrence. 1987. "Individual Taxpayer Response to Tax Cuts: 1982-1984, with Implications for the Revenue Maximizing Tax Rate." Journal of Public Economics, 33: 173206.

Ljunge, Martin and Kelly Ragan. 2005. "Labor Supply and the Tax Reform of the Century." working paper, University of Chicago, Chicago, IL.

Looney, Adam and Monica Singhal. 2006. "The Effect of Anticipated Tax Changes on Intertemporal Labor Supply and the Realization of Taxable Income." NBER Working Papers 12417.

MaCurdy, Thomas. 1981. "An Empirical Model of Labor Supply in a Life-Cycle Setting", Journal of Political Economy 89(6): 1059-1085.

Maki, Dean. 1996. "Portfolio Shuffling and Tax Reform." National Tax Journal, 49(3): 317-29.

Meyer, Bruce and Daniel Rosenbaum. 2001. "Welfare, the Earned Income Tax Credit, and the Labor Supply of Single Mothers." Quarterly Journal of Economics, 116(3): 1063-1114. Minarik, Joseph. "The Tax Shares Boomlet." Tax Notes, June 11, 1984.

Mirrlees, James. 1971. "An Exploration in the Theory of Optimal Income Taxation." Review of Economic Studies, 38: 175-208.

Moffitt, Robert and Mark Wilhelm. "Taxation and the Labor Supply Decisions of the Affluent." Does Atlas Shrug? The Economic Consequences of Taxing the Rich, Joel Slemrod, ed., New York: Harvard University Press and Russell Sage Foundation, 2000.

Moriguchi, Chiaki and Emmanuel Saez. 2008. "The Evolution of Income Concentration in Japan, 1885-2005: Evidence from Income Tax Statistics", Review of Economics and Statistics, 90(4): .

Munnell, Alicia, ed. (1987) Lessons from the Income Maintenance Experiments, Federal Reserve Bank of Boston Conference Series 30.

Murphy, Kevin J. 1999. "Executive Compensation." in Handbook of Labor Economics, eds. Orley Ashenfelter and David Card, Amsterdam: North-Holland, v3B.

Navratil, John. "The Economic Recovery Act of 1981." In Essays on the Impact of Marginal Tax Rate Reductions on the Reporting of Taxable Income on Individual Tax Returns, Doctoral Dissertation (Chapter 1), Harvard University, 1995.

Navratil, John. "The Tax Reform Act of 1986: New Evidence on Individual Taxpayer Behavior from Panel Tax Return Data." In Essays on the Impact of Marginal Tax Rate Reductions on the Reporting of Taxable Income on Individual Tax Returns, Doctoral Dissertation (Chapter 3), Harvard University, 1995.

Ohanian, Lee, Andrea Raffo and Richard Rogerson. 2008. "Long-Term Changes in Labor Supply and Taxes: Evidence from OECD Countries, 1956-2004," NBER Working Paper 12786, 2006, Journal of Monetary Economics.

Okun, Arthur. 1975. Equality and Efficiency. The Brookings Institution: Washington, D.C. Parcell, Ann. "Income Shifting in Responses to Higher Tax Rates: The Effects of OBRA 93." Office of Tax Analysis, U.S. Department of the Treasury, Washington, D.C.

Piketty, Thomas. 1999. "Les Hauts Revenus face aux Modifications des Taux Marginaux Supérieurs de l'Impôt sur le Revenu en France, 1970-1996." Economie et Prévision, 138-139: 
25-60.

Piketty, Thomas and Emmanuel Saez. 2003. "Income Inequality in the United States, 1913-1998." Quarterly Journal of Economics, 118(1): 1-39.

Pirttila, Jukka and Håkan Selin. 2006. "How Successful is the Dual Income Tax? Evidence from the Finnish Tax Reform of 1993." CESIfo Working Paper No. 1875.

Randolph, William. 1995. "Dynamic Income, Progressive Taxes, and the Timing of Charitable Contributions." Journal of Political Economy, 103(4): 709-38. .

Roine, Jesper, Jonas Vlachos, Daniel Waldenstrom. 2008. "The long-run determinants of inequality: What can we learn from top income data?", Working Paper, Stockholm University.

Romer, Christina and David Romer. 2008. "A Narrative Analysis of Post-War Tax Changes." working paper, University of California, Berkeley, CA.

Saez, Emmanuel. 2001. "Using Elasticities to Derive Optimal Income Tax Rates." Review of Economic Studies, 68: 205-229.

Saez, Emmanuel. 2003. "The Effect of Marginal Tax Rates on Income: A Panel Study of 'Bracket Creep'." Journal of Public Economics, 87: 1231-1258.

Saez, Emmanuel. 2004. "Reported Incomes and Marginal Tax Rates, 1960-2000: Evidence and Policy Implications." in James Poterba, ed., Tax Policy and the Economy, 18: 117-174.

Saez, Emmanuel. 2004b. "The Optimal Treatment of Tax Expenditures", Journal of Public Economics, 88(12): 2657-2684.

Saez, Emmanuel. 2009. "Do Tax Filers Bunch at Kink Points? Evidence, Elasticity Estimation, and Salience Effects," Working Paper University of California at Berkeley, Berkeley, CA, April 2009.

Saez, Emmanuel, and Michael Veall. 2005. "The Evolution of High Incomes in Northern America: Lessons from Canadian Evidence." American Economic Review, 95(3): 831-849

Sammartino, Frank and David Weiner. 1997. "Recent evidence on taxpayers' response to the rate increases in the 1990s." National Tax Journal, 50(3): 683-705.

Selén, Jan. 2002. "Taxable income response to tax changes: Evidence from the 1990/91 Swedish Tax Reform," FIEF Working Paper No. 177.

Sillamaa, Mary Anne and Michael Veall. 2001. "The Effect of Marginal Tax Rates on Taxable Income: a Panel Study of the 1988 Tax Flattening in Canada." Journal of Public Economics, 80(3): 341-356.

Simonson, Kenneth. 1984a. "Supply Side Tax Changes: Do They Soak the Rich or Sock it to the Poor?" Tax Notes, (June 11, 1984): 684.

Simonson, Kenneth. 1984b. "A Closer Look at the 1981-1982 Tax Changes." Tax Notes, (September 24, 1984): 1293.

Singleton, Perry. 2007. "The effect of taxes on taxable earnings: Evidence from the 20012004 U.S. federal tax acts." working paper, Syracuse University, Syracuse, NY.

Slemrod, Joel. 1994. "On the High Income Laffer Curve." In Joel Slemrod, ed., Tax Progressivity and Income Inequality, Cambridge University Press: Cambridge: 177-210.

Slemrod, Joel. 1995. "Income Creation or Income Shifting? Behavioral Responses to the Tax Reform Act of 1986." American Economic Review, 85(2): 175-180. 
Slemrod, Joel. 1996. "High Income Families and the Tax Changes of the 1980s: The Anatomy of Behavioral Response." In Empirical Foundations of Household Taxation, eds. Martin Feldstein and James Poterba, University of Chicago.

Slemrod, Joel. 1998. "Methodological Issues in Measuring and Interpreting Taxable Income Elasticities." National Tax Journal, 51(4): 773-788.

Slemrod, Joel and Jon Bakija. 2001. "Growing Inequality and Decreased Tax Progressivity." in Kevin Hassett, ed., Inequality and Tax Policy, Washington D.C: American Enterprise Institute Press.

Slemrod, Joel and Wojciech Kopczuk. 2002. "The Optimal Elasticity of Taxable Income." Journal of Public Economics, 84(1): 91-112.

Slemrod, Joel and Shlomo Yitzhaki. 2002. "Tax Avoidance, Evasion and Administration." in Alan Auerbach and Martin Feldstein, ed., Handbook of Public Economics, v3, North-Holland: 1423-1470.

U.S. Treasury Department, Internal Revenue Service. Annual since 1916. Statistics of Income: Individual Income Tax Returns, Washington, D.C. 
A. Top $1 \%$ Income Share and Marginal Tax Rate

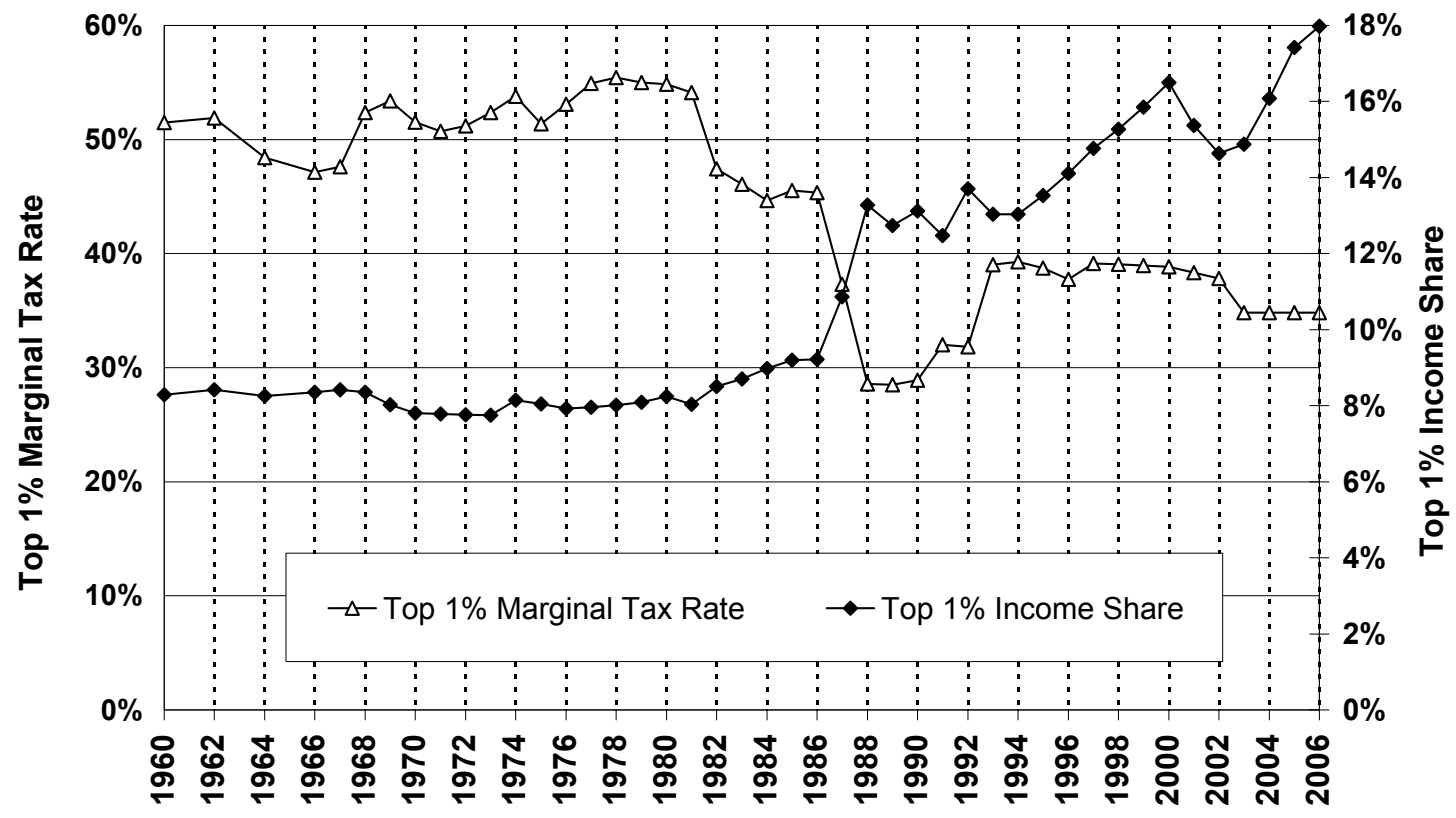

B. Next $9 \%$ Income Share and Marginal Tax Rate

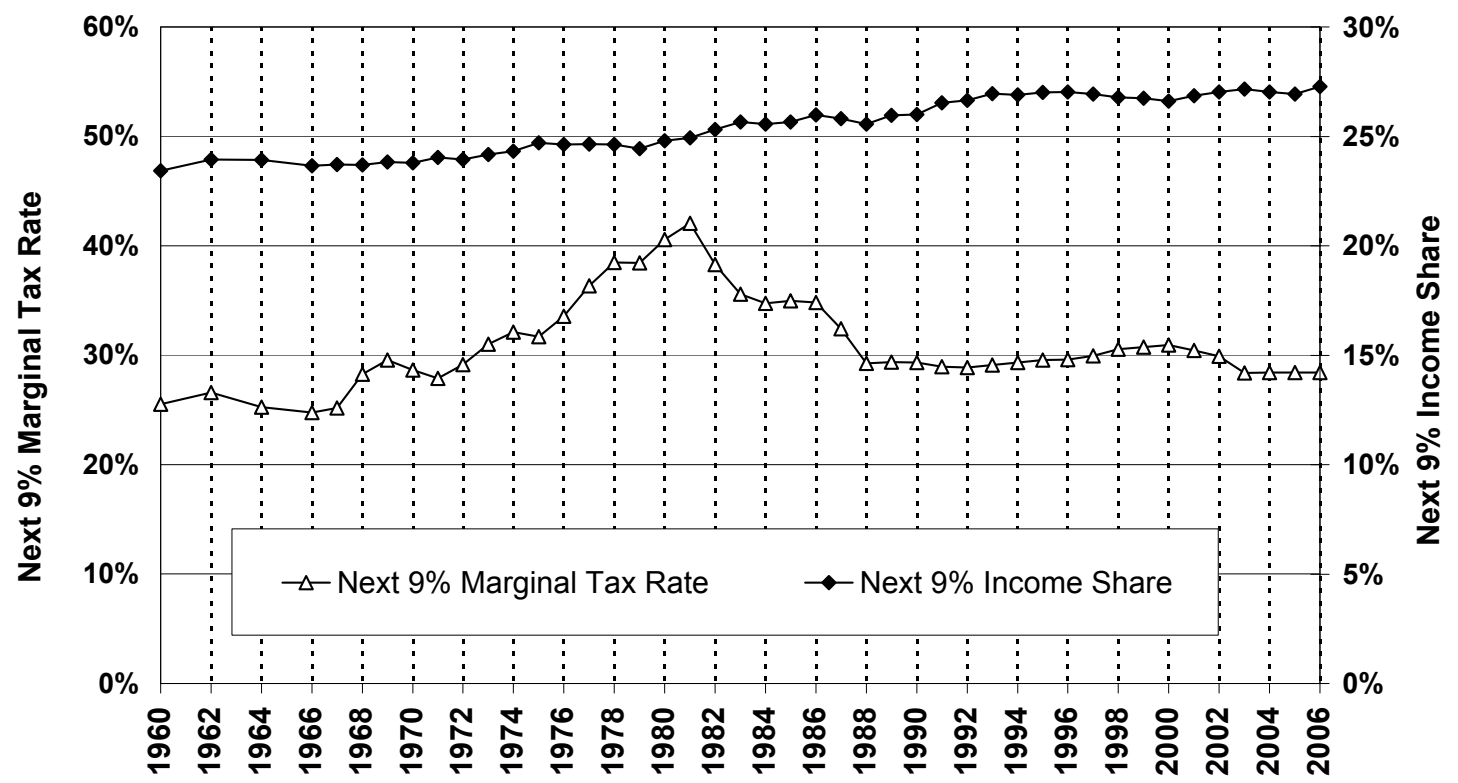

FIGURE 1

Top Income Shares and Marginal Tax Rates, 1960-2006

Source: Updated version of Figure 8 in Saez (2004). Computations based on income tax return data. Income excludes realized capital gains, as well as Social Security and unemployment insurance benefits. The figure displays the income share (right y-axis) and the average marginal tax rate (left $y$-axis) (weigthed by income) for the top 1\% (Panel A) and for the next $9 \%$ (Panel B) income earners. 


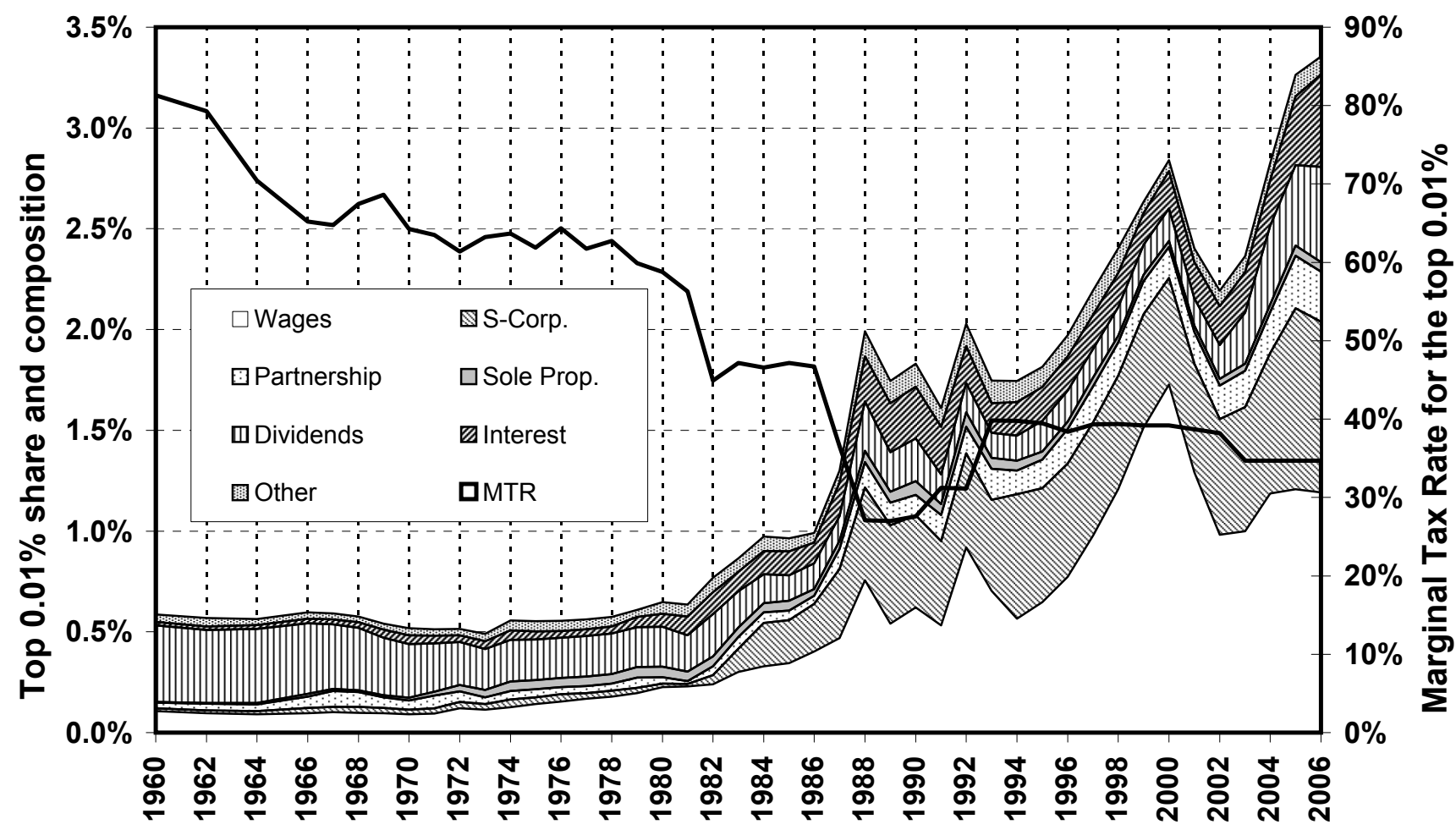

FIGURE 2.

The Top $0.01 \%$ US Income Share, Composition, and Marginal Tax Rate, 1960-2006

Source: Updated version of Figure 8 in Saez (2004). Computations based on income tax return data.

The figure displays the income share of the top .01\% tax units, and how the top $.01 \%$ incomes are divided into seven income components: wages and salaries (including exercised stock options), S-corporation profits, partnership profits, sole proprietorship profits, dividends, interest income, and other income. The figure also displays the average marginal tax rate (weigthed by income) for the top $0.01 \%$ in a bold line on the right $y$-axis. 
Table 1.

Elasticity estimates using top income share time series

\begin{tabular}{ccc}
\hline \hline & Top 1\% & Next 9\% \\
\cline { 2 - 3 } & $(1)$ & $(2)$ \\
\hline
\end{tabular}

\section{A. Tax Reform Episodes}

1981 vs. 1984 (ERTA 1981)

$0.60 \quad 0.21$

1986 vs. 1988 (TRA 1986)

$1.36-0.20$

1992 vs. 1993 (OBRA 1993)

0.45

1991 vs. 1994 (OBRA 1993)

$-0.39$

\section{B. Full Time Series 1960-2006}

No time trends

$\begin{array}{lc}1.71 & 0.01 \\ (0.31) & (0.13)\end{array}$

Linear time trend

$\begin{array}{cc}0.82 & -0.02 \\ (0.20) & (0.02)\end{array}$

Linear and square time trends

$\begin{array}{cc}0.74 & -0.05 \\ (0.06) & (0.03)\end{array}$

Linear, square, and cube time trends

$\begin{array}{ll}0.58 & -0.02 \\ (0.11) & (0.02)\end{array}$

Notes: Estimates in panel A are obtained using series from Figure 1 and using the formula $e=[\log ($ income share after reform)-log(income share before reform) $] /[\log (1-$ MTR after reform)- $\log (1-$ MTR before reform)]

Estimates in Panel B are obtained by time-series regression of log(top 1\% income share) on a constant, log (1 - average marginal tax rate), and polynomials time controls from 1960 to 2006 (44 observations). OLS regression. Standard Errors from Newey-West with 8 lags. 
Table 2.

Elasticity estimates using the 1993 top rate increase among top $1 \%$ incomes

\begin{tabular}{lcc}
\hline \hline Control group & next $9 \%$ & next $49 \%$ \\
\cline { 2 - 3 } & $(1)$ & $(2)$ \\
\hline
\end{tabular}

A. Repeated Cross Sections Analysis

A1. Comparing two years only

1991 and 1994

$0.998 \quad 0.958$

$(0.109) \quad(0.107)$

1991 and 1994

$-0.481 \quad-0.576$

A2. Using all years 1991 to 1997

$(0.115) \quad(0.111)$

1991 to 1997 (no time trends controls) $\quad-0.404 \quad-0.570$

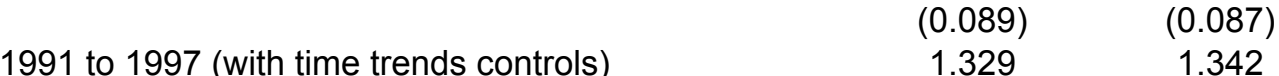

1.342
$0.104)$

B. Panel Analysis

B1. Comparing two years only

1992 to 1993 changes (no controls) $\quad 1.395 \quad 1.878$

1091 (0.107) $\quad(0.184)$

1991 to 1994 changes (no controls) $\quad 2.420 \quad 3.352$

(0.221) (0.446)

1992 to 1993 changes (log base year income control) $\quad-0.721 \quad 0.814$

$(0.213) \quad(0.149)$

1992 to 1993 changes (+splines income controls) $\quad-1.669 \quad-1.866$

(1.052) (0.711)

B2. Using all 1991-1992,..,1996-1997 changes

$\begin{array}{lll}\text { No income controls } & 1.395 & 1.878\end{array}$

Base year log income control $\quad 0.537 \quad 0.955$

Base year log income control $\quad(0.264) \quad(0.247)$

Base year log income + splines controls $\quad 0.564 \quad 0.723$

Base year log income + splines controls $\quad 0.143 \quad(0.260)$

(using predicted MTR change instrument) (0.200)

Notes: Estimates based on a panel of tax returns (see appendix and Giertz, 2008).

Panel A estimates are obtained from 2SLS regression: $\log \left(z_{i t}\right)=e^{*} \log \left(1-\tau_{i t}\right)+\alpha * 1$ (top $\left.1 \%\right)+\beta * 1$ (post reform) $+\varepsilon_{\text {it }}$ using 1 (top $1 \%)^{*} 1$ (post reform year) as instrument. Time controls in the last row of Panel A2 are group specific: $\gamma_{1}{ }^{*} t^{\star} 1$ (top $\left.1 \%\right)+\gamma_{2}{ }^{*} t^{*} 1$ (not top $\left.1 \%\right)$

Panel B1 estimates are obtained from 2SLS panel regression: $\Delta \log \left(z_{i t}\right)=e^{*} \Delta \log \left(1-\tau_{i t}\right)+\varepsilon_{i t}$ using 1 (top $1 \%$ in base year) as instrument. Base year income controls $\log \left(z_{i t}\right)$ and 10 splines in $z_{i t}$ are added in last two rows. In Panel B2, comparisons 1991 to $1992, \ldots, 1996$ to 1997 are stacked and year dummies are included in the 2 SLS regression. The instrument is 1 (top $1 \%$ in base year) ${ }^{*} 1(t=1992)$. Instrument MTR predicted change $\log \left[\left(1-\tau^{\mathrm{p}}{ }_{\mathrm{it}}\right) /\left(1-\tau_{\mathrm{it}}\right)\right]$ is used in the 4 th row of estimates where $\tau^{\mathrm{p}}{ }_{\mathrm{it}}$ is the marginal tax rate in year $\mathrm{t}+1$ using (inflation adjusted) year $t$ income.

In column (1), the estimates are run using the top 10\% tax filers (so that the treatment group is the top $1 \%$ and the control group is the top $10 \%$ excluding the top $1 \%$, "The next $9 \% "$ "). In column (2), the estimates are run using the top $50 \%$ tax filers (so that the control group is the top $50 \%$ excluding the top $1 \%$, "The next $49 \% ")$. 
Table A1.

Top Federal Marginal Tax Rates

\begin{tabular}{ccccc}
\hline \hline & Ordinary Income & Earned Income & Capital Gains & Corporate Income \\
\cline { 2 - 5 } Year & $(1)$ & $(2)$ & $(3)$ & $(4)$ \\
\hline $1952-1963$ & 91.0 & 91.0 & 25.0 & 52 \\
1964 & 77.0 & 77.0 & 25.0 & 50 \\
$1965-1967$ & 70.0 & 70.0 & 25.0 & 48 \\
1968 & 75.3 & 75.3 & 26.9 & 53 \\
1969 & 77.0 & 77.0 & 27.9 & 53 \\
1970 & 71.8 & 71.8 & 32.3 & 49 \\
1971 & 70.0 & 60.0 & 34.3 & 48 \\
$1972-1975$ & 70.0 & 50.0 & 36.5 & 48 \\
$1976-1978$ & 70.0 & 50.0 & 39.9 & 48 \\
$1979-1980$ & 70.0 & 50.0 & 28.0 & 46 \\
1981 & 68.8 & 50.0 & 23.7 & 46 \\
$1982-1986$ & 50.0 & 50.0 & 20.0 & 46 \\
1987 & 38.5 & 38.5 & 28.0 & 34 \\
$1988-1990$ & 28.0 & 28.0 & 28.0 & 34 \\
$1991-1992$ & 31.0 & 31.0 & 28.0 & 35 \\
1993 & 39.6 & 39.6 & 28.0 & 35 \\
$1994-1996$ & 39.6 & 42.5 & 28.0 & 35 \\
$1997-2000$ & 39.6 & 42.5 & 20.0 & 35 \\
2001 & 39.1 & 42.0 & 20.0 & 35 \\
2002 & 38.6 & 41.5 & 20.0 & 35 \\
$2003-2009$ & 35.0 & 37.9 & 15.0 & \\
& & & &
\end{tabular}

Notes: MTRs apply to top incomes. In some instances, lower income taxpayers may face higher MTRs because of income caps on payroll taxes or the so-called 33 percent "bubble" bracket following TRA 86. From 1952 to 1962, a 87\% maximum average tax rate provision made the top marginal tax rate $87 \%$ instead of $91 \%$ for many very top income earners. From 1968 to 1970, rates include surtaxes. For earned income, MTRs include the Health Insurance portion of the payroll tax beginning with year 1994. Rates exclude the effect of phaseouts, which effectively raise top MTRs for many high-income filers. MTRs on realized "long-term" capital gains are adjusted to reflect that, for some years, a fraction of realized gains were excluded from taxation. Since 2003 , dividends are also tax favored with a maximum tax rate of $15 \%$. 